\title{
Einführung
}

O. Assadian, A. Bialasiewicz, K. Falke, R. F. Guthoff, A. Kramer, S. Peschel,

U. Pleyer, B. Seitz, P. Steven, N. Szentmáry, A. Zhivov

\subsection{Hintergrund/Diagnostische Grundkonzepte - 4}

1.1.1 Allgemeine Prinzipien und "Philosophie“ zur Behandlung okularer Entzündungen (engl. general principles, diagnostic concepts, history on ocular inflammation) - 4

1.1.2 Grundzüge: Immunologie/Entzündung (engl. basics of clinical immunology, inflammation pathways) - 6

1.1.3 Korrelation: (Leit)befund-Morphologie bei Konjunktivitis/ Keratitis (engl. key features, conjunctivitis, keratitis) - 8

1.1.4 Stellenwert der mikrobiologischen Labordiagnostik bei Konjunktivitis und Keratitis (engl. microbiology conjunctivitis, keratitis) - 9

1.1.5 Bildgebende Diagnostik bei entzündlichen Augenerkrankungen (engl. Confocal microscopy, diagnostic procedure, imaging techniques) - 14

1.2 Therapie: Grundkonzepte/Prinzipien - 23

1.2.1 Antiinfektive Therapie bei Konjunktivitis und Keratitis (engl. conjunctivitis, keratitis, therapy) - 23

1.2.2 Antientzündliche und Immunmodulatorische Therapie bei Konjunktivitis und Keratitis (engl. Anti-inflammatory agents, immune modulation, immunmodulatory, keratitis, conjunctivitis) - 33

1.3 Chirurgische Maßnahmen bei entzündlichen Erkrankungen des vorderen Augenabschnitts (VAA) - 36

1.3.1 Photodynamische Therapie (PDT) bei infektiöser Keratitis (engl. surgery, inflammatory disease, anterior eye segment) - 36

Literatur - 38 


\subsection{Hintergrund/Diagnostische Grundkonzepte}

\subsubsection{Allgemeine Prinzipien und „Philosophie“ zur Behandlung okularer Entzündungen (engl. general principles, diagnostic concepts, history on ocular inflammation)}

U. Pleyer

\section{Ein Rückblick}

Ein kurzer Blick in die Geschichte zeigt, dass bereits im alten Ägypten dem Problem entzündlicher Augenveränderungen und auch deren Behandlung besondere Beachtung gezollt wurde. Erste Berichte zur Behandlung von Wundverletzungen können bis ca. 2600 v. Chr. zurückdatiert werden. Später im sog. „Papyros Ebers“ (ca. 1500 v. Chr.) wurden bereits Behandlungen mit antientzündlich wirksamen Heilpflanzen, aber auch Wirkstoffen wie Zink, Kupfer und Antimon berichtet. Sowohl eine antientzündlich ausgerichtete Behandlung des Trachoms als auch die Bedeutung der Pupillenerweiterung bei intraokularer Entzündung waren bereits als Prinzipien erkannt worden.

Die antike griechische Medizin unter Galen und Sokrates führte diese Tradition fort und fügte einige (eher wenige) Behandlungsansätze, z. B. bei Trübungen der Hornhaut, hinzu. Es sollte dann bis in das 19. Jahrhundert hinein dauern, bis Erkenntnisse aus Mikrobiologie und Immunologie einen raschen Wissensgewinn für die Genese und Behandlung entzündlicher Augenerkrankungen brachte. Die Arbeiten von Pasteur und die Entdeckung von zirkulierenden Antikörpern durch Behring und Kitasato (1890-1892) hatten nachhaltigen Einfluss auf das Verständnis infektiöser und nicht infektiöser Augenerkrankungen (• Abb. 1.1). In der Folge wurde das Auge eines der bevorzugten Organe zur Untersuchung entzündlicher und immunmediierter Mechanismen.

\section{Grundlegende Erkenntnisse}

Bereits 1906 propagierte der Ophthalmologe Anton Elschnig eine Autoimmunpathogenese der sympathischen Ophthalmie. Zusammen mit dem Immunologen Weil postulierte er, dass ein Antigen des verletzten Auges zu einer „Überempfindlichkeit“ des nicht betroffenen zweiten Auges führte. Schließlich gelang es ihnen, in tierexperimentellen Untersuchungen Uveapigment als auslösendes Antigen herauszustellen. Wenige Jahre später gelang es Karl Wessely, den nach ihm benannten immunpathologischen Hornhautprozess („Wessely-Ring“, • Abb. 1.2), durch Injektion von Antigen in die Hornhaut eines sensibilisierten Kaninchens zu provozieren.

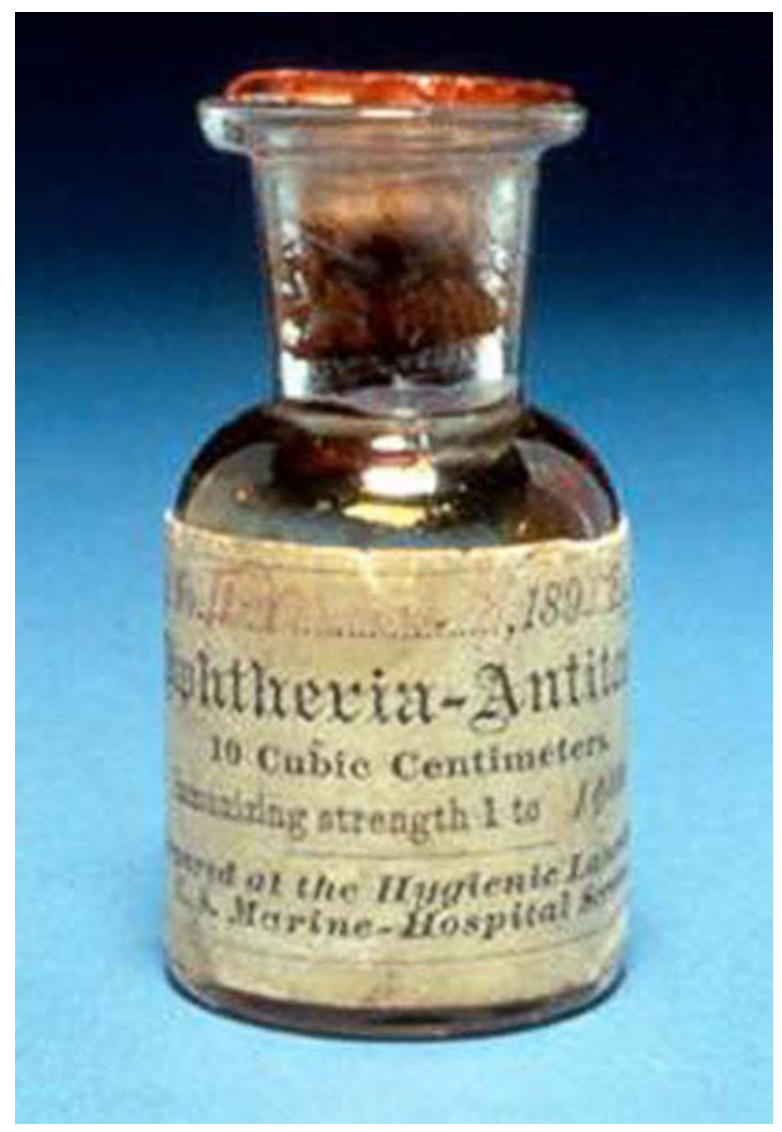

- Abb. 1.1 Emil von Behring und Shibasaburo Kitasato zeigten 1890, dass Diphtherie-Antitoxin-Serum gegen eine letale Dosis von Diphterie-Toxin schützte. Ein erster Einsatz eines Anti-DiphterieSerums erfolgte Weihnachten 1891

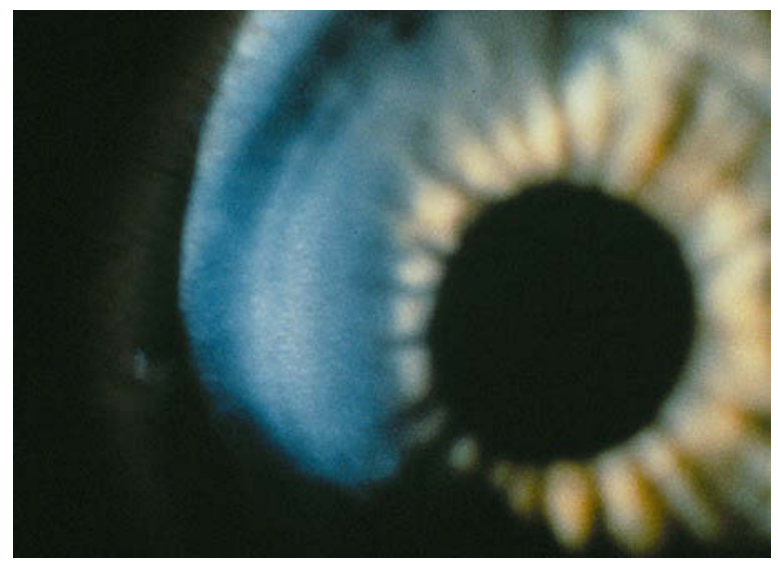

- Abb. 1.2 „Wessely-Ring“ in der Hornhaut eines 7-jährigen Kindes

Die Hornhaut und der vordere Augenabschnitt blieben für Immunologen und wissenschaftlich interessierte Ophthalmologen, insbesondere aufgrund des ,immunologischen Privilegs“, eine bevorzugte Region für Experimente, die zu grundlegenden Erkenntnissen führten. Peter Brian 
Medawar erkannte die Bedeutung des immunologischen Privilegs für die Allograftreaktion nach Hornhauttransplantation und den afferenten und efferenten Wege der Immunreaktion. Nur wenig später konnten Hans Goldmann und Rudolf Witmer eindrücklich zeigen, dass intraokular spezifische Antikörper gebildet werden und für die Diagnose infektiöser Augenerkrankungen genutzt werden können ( $\triangleright$ Kap. 5).

Stets sind die grundlegenden Arbeiten zur Immunologie entzündlicher und infektiöser Augenerkrankungen von praktischer, diagnostischer und therapeutischer Bedeutung gewesen. Darüber hinaus haben sie deutlich auf die Entwicklung der Augenheilkunde Einfluss genommen. Historische Ereignisse waren das große Problem sich epidemisch ausbreitender Erblindungen durch venerische Erkrankungen und das Trachom nach Napoleons Ägypten Feldzügen. Dies führte schließlich zur Gründung erster Krankenanstalten für Augenerkrankungen in Frankreich.

Auch heute sind entzündliche Augenerkrankungen von tiefgreifender individueller und sozioökonomischer Bedeutung. So sind z. B. die finanziellen Aufwendungen zur Therapie intraokularer Entzündungen im jungen Erwachsenenalter höher, als zur Behandlung der diabetischen Retinopathie. Diese Herausforderung wurde lange wenig beachtet. Die Diagnostik bei diesen Patienten war wenig zielführend. „Fokussuche“ und Tuberkulose standen bei den diagnostischen Maßnahmen bis in die 1950er Jahre im Mittelpunkt. Das Engagement für eine zielgerichtete Therapie der Uveitis war begrenzt. Die Einführung von Kortikosteroiden war zwar ein wichtiger Meilenstein in der Behandlung intraokularer Entzündungen, die damit verbundenen, vielfältigen Nebenwirkungen wurden jedoch auch bald erkannt und begrenzten den initialen Erfolg.

\section{Die Herausforderung}

Der sprunghafte Wissenszuwachs zu Beginn des 20. Jahrhunderts und das große Interesse an immunmediierten Mechanismen am Auge lebte in den 1970er- und 80er Jahren wieder auf. Neue Erkenntnisse zur Genese von Autoimmunerkrankungen, die genetischen Grundlagen und die HLA-Disposition für bestimmte Erkrankungen, aber auch die Wechselwirkungen zwischen Infektionserregern und Immunsystem standen im Fokus des Interesses. Für die praktische Betreuung des Patienten ergaben sich sowohl in der Diagnostik als auch in der Therapie neue Ansätze. Eine konsequente, „maßgeschneiderte Diagnostik“ begann sich z. B. für intraokulare Entzündungen zunehmend durchzusetzen. Die Orientierung an Leitbefunden und eine zielgerichtete Labordiagnostik zum Ausschluss infektiöser Erkrankungen unter Einbeziehung von genetischen Prädispositionen (HLA-B27, HLA-A29) wurden Routine ( $\triangleright$ Kap. 5). Mit zunehmend spezifischeren Wirkstoffen, wie Ciclosporin A, wurden konsequent neue Er- kenntnisse für die Behandlung der Patienten umgesetzt. Die Bedeutung interdisziplinärer Zusammenarbeit wurde zunehmend erkannt und führte zur Etablierung von „Uveitis“- und „Entzündungszentren“1. Dies hat sich in den letzten Jahren auch für die Anwendung neuer Wirkstoffe niedergeschlagen. Die rasanten Fortschritte in der Behandlung von Autoimmunerkrankungen aus Rheumatologie, Dermatologie und Neurologie sind mit zeitlicher Verzögerung auch für die Ophthalmologie bedeutsam geworden. Das Interesse am „Immunorgan Auge“ ist erkennbar, wenngleich bedauert werden muss, dass dies oft deutlich zeitlich verzögert ist, und das ursprüngliche „Modellorgan“ Auge für immunologische Erkenntnis eher in den Hintergrund rückte.

\section{Die Perspektive}

Die herausgehobene Bedeutung des Sinnesorgans Auge und die große Bedeutung entzündlicher und infektiöser Erkrankungen des Sinnesorgans erfordern weitere Anstrengungen. Fortschritte in molekularbiologischer Diagnostik erlauben uns heute, rasch den Nachweis von spezifischen Erregern zu erbringen. Gleichzeitig muss jedoch erkannt werden, dass die Herausforderung, z. B. mit einem minimalen Probenvolumen umzugehen und die Anforderungen im routinemäßigem Diagnostikverfahren, nicht immer adäquat berücksichtigt werden. Mikrobiologische Labore, die lange Zeit Bestandteil von Augenkliniken waren, sind heute weitgehend verschwunden. Dies liegt z. T. auch an verbesserten therapeutischen Möglichkeiten. Hocheffektive, breit wirksame Lokalantibiotika und Antiinfektiva haben dazu beigetragen, dass die Primärtherapie, z. B. bei Keratitis, häufig ohne vorherige, adäquate mikrobiologische Diagnostik erfolgt ( $\triangleright$ Kap. 5). Neue diagnostisch verwendbare Techniken, wie die konfokale Mikroskopie, sind zusätzlich hervorzuheben und ermöglichen einen unmittelbar morphologischen Befund, z. B. bei parasitären Hornhautinfektionen.

Die Behandlung von autoimmunologischen Erkrankungen des Auges wird vermutlich von der zunehmenden Armada hochspezifischer Wirkstoffe, insbesondere der Biologika, die bisher ausschließlich aus anderen Fachbereichen stammen, profitieren. Dies kann allerdings nicht darüber hinwegtäuschen, dass nicht alle dieser Therapeutika in den unterschiedlichen Organsystemen ähnlich effektiv sind. „Überraschungen“ in klinischen Studien zeigen, dass nicht unbedenklich Ergebnisse aus experimentellen und klinischen Studien an anderen Organsystemen 1:1 übertragbar sind.

1 Entzündungszentren: dgrh.de/entzuendungszentren.html, http:// inflammation-at-interfaces.de/ - Homepage Exzellenzzentrum Entzündung. 
Ebenfalls zu erwarten ist, dass die Bedeutung individueller patientenspezifischer Faktoren wichtig wird. Dies kann sowohl für genetische Prädispositionen, z. B. für Infektionen, als auch für immunologische Fehlsteuerungen relevant werden. Für beide Situationen könnten sich Konsequenzen für Diagnostik, Behandlung und Prognose unserer Patienten ergeben.

\section{Offene Fragen}

Viele "einfache" Fragen, die oft von Patienten gestellt werden, können nicht beantwortet werden. Welche Rolle kommt z. B. „Umwelteinflüssen“ zu? Spielen äußere Faktoren wie „Stress“ für Manifestation und Verlauf, z. B. bei intraokularer Entzündung, eine Rolle? Die Wechselwirkungen des Neuroendokrinen- und Immunsystems sind im Bereich der Augenheilkunde trotz vieler Hypothesen weitgehend unbekannt. Es ist keine Frage, dass viele Wissenslücken existieren.

Eine weitere wichtige Herausforderung ist das Interesse und die klinisch-wissenschaftliche Auseinandersetzung mit entzündlichen Augenerkrankungen bei jungen Kollegen zu wecken. Die raschen und spektakulären Erfolge refraktivchirurgischer Maßnahmen können zwar nicht geboten werden. Die intellektuellen Leistungen von Ophthalmologen und Kollegen aus anderen Fachbereichen zeigen allerdings, dass das Sinnesorgan Auge einen eigenen „Mikrokosmos" für wissenschaftliche Fragestellungen darstellt. Dies hat früher oder später zur besseren Behandlung unserer Patienten beigetragen.

\subsubsection{Grundzüge: Immunologie/ Entzündung (engl. basics of clinical immunology, inflammation pathways)}

P. Steven

Das vordere Augensegment ist einem täglichen Ansturm von potentiellen Pathogenen, Allergenen und toxischen Substanzen ausgesetzt. Um Schädigungen des Auges zu verhindern, existiert eine hochwirksame Schleimhautbarriere der Augenoberfläche, die aus komplexen mechanischen und funktionellen Abwehrmechanismen zusammengesetzt ist. Diese Abwehrmechanismen sind jedoch nicht ausschließlich protektiv wirksam, sondern können im Rahmen von teils autoreaktiven Entzündungsreaktionen auch selbst Schädigungen der Schleimhaut und der darunter liegenden Gewebe des Auges verursachen. Aus diesem Grund existieren differenzierte Regulationsmechanismen, die eine adäquate Abwehr steuern und überschießende Entzündungsreaktionen unterbinden sollen. Diese Immunbalance ist nicht nur von herausragender Bedeu- tung für einen Schutz der Augenoberfläche sondern aller okulären Gewebe und eine unbedingte Voraussetzung zum dauerhaften Erhalt der Sehfunktion.

\section{Schleimhautabwehr}

Die Augenoberfläche des vorderen Augensegments enthält verschiedene Abwehrmechanismen, die in angeborene und erworbene Mechanismen eingeteilt werden können. Da zunehmend verstanden wird, dass beide Abwehrsysteme durch zahlreiche funktionelle Schnittstellen vernetzt sind, ist es sinnvoll, die Abwehrmechanismen gemäß ihrem Lokalisationsort und dem Weg potentieller Pathogene in das vordere Augensegment darzustellen. Im Folgenden werden daher die Abwehrmechanismen von Tränenfilm, Epithel und Bindehaut bzw. Hornhautstroma nacheinander beschrieben.

\section{Tränenfilm}

Der Tränenfilm enthält nach heutigem Kenntnisstand ungefähr 400 verschiedene Substanzen. Eine Abwehrfunktion besitzen vor allem antimikrobielle Peptide sowie Muzine und Immunglobuline (v. a. IgA). Antimikrobielle Peptide, wie Lysozym, Laktoferrin, Beta-Defensine, MMP7 u. v. m., werden zum angeborenen Immunsystem gezählt und erzeugen z. B. die Bildung von letal wirkenden Poren in der Zellwand von Mikroorganismen. Interessanterweise sind aufgrund dieses Wirkmechanismus Resistenzen, wie z. B. gegenüber Antibiotika, praktisch unbekannt. Antimikrobielle Peptide wirken außerdem chemotaktisch auf Zellen des erworbenen Immunsystems (APCs und T-Zellen), was die angesprochene enge funktionelle Vernetzung zwischen angeborenem und erworbenem Immunsystem, demonstriert.

Muzine Muzine sind Peptide, die viele unterschiedliche $\mathrm{Zu}$ ckerseitenketten enthalten und somit zahlreiche Bindungsstellen sowohl für Interaktionen mit Körperzellen der $\mathrm{Au}$ genoberfläche als auch Pathogenen aufweisen. Aktuell sind 19 verschiedene Muzine bekannt, die in Gel-bildende und Membran-gebundene Muzinen eingeteilt und von allen Epithelzellen der Augenoberfläche, inklusive Becherzellen, sezerniert werden und/oder in der Zellmembran verankert sind. Muzine wirken dabei sowohl als benetzender, da hydrophiler Bestandteil des Tränenfilms, aber interagieren auch mit den auf der Augenoberfläche lokalisierten Mikroorganismen, die über ihre Bindungsstellen an die Epitope der Muzine koppeln. Muzine umhüllen Bakterien mit einem Film, verhindern damit eine Bindung an das Epithel und fördern anschließend die Clearance der „inaktivierten“ Erreger von der Augenoberfläche über die ableitenden Tränenwege. Eine Sonderstellung nehmen sog. Trefoil-FactorPeptide (TFF-Peptide) ein, die eine Verbindung zwischen unterschiedlichen Muzinmolekülen herstellen und damit die Viskosität des Gelfilms deutlich beeinflussen können. TFF-Peptide werden bei verschiedenen Entzündungen der 


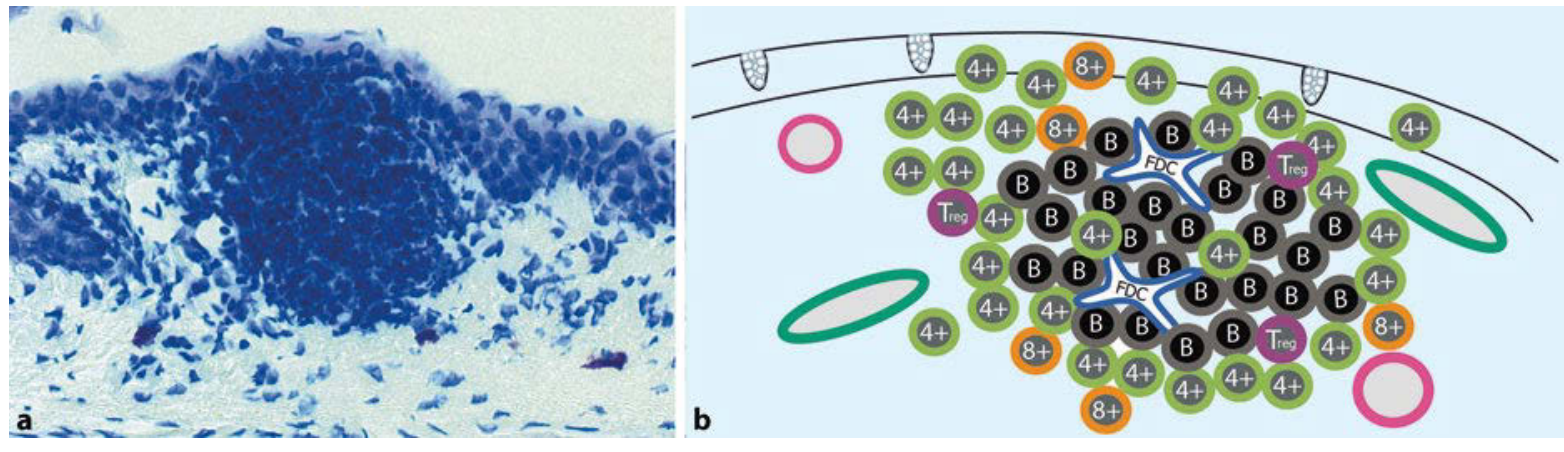

- Abb. 1.3a,b Konjunktiva-assoziiertes lymphatisches Gewebe (CALT). a Histologischer Schnitt, b Schematische Darstellung mit B- und Z-Zone, Follikulär Dendritischen Zellen (FDC), regulatorischen T-Zellen (Tregs), Lymphgefäßen (grün) und Blutgefäßen (rot). Beachte die intraepithelialen CD4 ${ }^{+}$und $C D 8^{+}$T-Zellen

Augenoberfläche exprimiert und fördern außerdem die epitheliale Wundheilung, was im Falle von Entzündungen den Strukturerhalt der Abwehrbarriere unterstützt.

Surfactant Proteine A-D Sie gehören zur Gruppe der Collectine und sind erst kürzlich im Tränenfilm nachgewiesen worden. Außer der Beeinflussung der Tränenfilm-Rheologie binden Surfactant Proteine an die Oberfläche von Mikroorganismen und sollen so zu einer Inaktivierung oder Eliminierung der Erreger durch Phagozytose oder durch eine Komplementaktivierung führen. Im Tränenfilm sind außerdem Immunglobuline (physiologisch in absteigender Menge: $\operatorname{sg} A>\operatorname{IgE}>\operatorname{IgG}>\operatorname{IgM}$ ) enthalten. sIgA bindet hierbei an Mikroorganismen und verhindert dadurch eine Kolonisierung auf der Augenoberfläche. Entzündungen führen zu einem deutlichen Anstieg der Immunglobulinkonzentrationen in der Tränenflüssigkeit.

\section{Bindehaut-, Hornhaut- und Tränenwegsepithel}

Zusätzlich zum Tränenfilm bildet das Epithel von Bindehaut, Hornhaut und ableitenden Tränenwegen eine dünne, jedoch sehr widerstandsfähige Barriere gegenüber potentiellen Pathogenen. Sowohl die Epithelzellen als auch intraepitheliale Immunzellen tragen dabei zur Abwehr bei. Ausgehend von einem mikrobiellen Reiz exprimieren und sezernieren Epithelzellen dabei Teile der oben beschriebenen Muzine und antimikrobielle Peptide, die damit eine direkte Abwehrfunktion erfüllen. Weiterhin werden sog. Toll-like Rezeptoren exprimiert, die im Falle eines Kontakts mit zumeist mikrobiellen Erregern intrazelluläre Signalkaskaden mit einer nachfolgenden Entzündungsreaktion auslösen.

Epithelzellen können außerdem unter bestimmten Umständen MHCII Moleküle herstellen, wodurch sie eine aktive Rolle bei der Antigenpräsentation im Rahmen von Entzündungsreaktionen erfüllen. Vor allem im Bindehautepithel sind zahlreiche Immunzellen (vor allem $\mathrm{CD}^{+}$und $\mathrm{CD}^{+} \mathrm{T}-$ Zellen, aber auch Langerhanszellen und andere APCs) lokalisiert. Intra- und subepitheliale Plasmazellen sezernieren Immunglobuline, die anschließend im Tränenfilm nachweisbar sind. T-Zellen patrouillieren innerhalb der Basalzellschicht die Epithelbarriere und kontaktieren dabei einzelne Epithelzellen. Pathogene, die den Tränenfilm und die oberste Epithelzellschicht überwunden haben, werden so noch vor Durchdringung der Basalmembran erkannt und ggf. abgetötet und/oder phagozytiert. Im Rahmen einer spezifischen Immunantwort erfolgt dann die Präsentation gegenüber anderen Immunzellen. Diese klassische Reaktion des erworbenen Immunsystems findet sowohl im Konjunktiva-assoziierten lymphatischen Gewebe als auch in den regionalen Lymphknoten statt.

\section{Bindehaut und Hornhautstroma}

In der Bindehaut findet man sog. diffuses und organisiertes lymphatisches Gewebe. Dieses besteht aus räumlich unterschiedlich, jedoch funktionell speziell angeordneten T-Zellen, B-Zellen und Antigen-präsentierenden Zellen (Eine detaillierte Charakterisierung der einzelnen Immunzelltypen befindet sich im $>$ Abschn. 5.1.2). Das diffuse Konjunktiva-assoziierte lymphatische Gewebe verteilt sich mit locker angeordneten Lymphozyten und Makrophagen entlang der Schleimhaut der gesamten Augenoberfläche. Lokalisiert kommen jedoch auch physiologisch Lymphfollikel vor, die das organisierte Konjunktiva-assoziierte lymphatische Gewebe (syn. CALT) bilden. CALT besteht aus einem Lymphfollikel mit einer zentralen B-Zell-Zone, die von zahlreichen $\mathrm{CD}^{+}$und $\mathrm{CD} 8^{+} \mathrm{T}$-Zellen umgeben ist. In tierexperimentellen Studien sind außerdem viele regulatorische T-Zellen (Tregs) in enger räumlicher Nähe zu CALT beschrieben worden. Der Follikel enthält weiterhin dendritische Zellen, und ist direkt unter dem Epithel der Bindehaut lokalisiert (- Abb. 1.3). Das Epithel weist zahlreiche intraepitheliale Taschen auf, die $\mathrm{CD} 4^{+}$und $\mathrm{CD} 8^{+}$ T-Zellen enthalten und von sog. M-Zellen gebildet werden sollen. Die Existenz dieser M-Zellen wird zwar kontrovers diskutiert, konnte jedoch kürzlich durch funktionelle invivo Aufnahmen belegt werden. 
CALT stellt nach bisherigem Verständnis eine immunologische Schnittstelle dar, die eine sog. immunosensorische und regulatorische Aufgabe erfüllt. Im Rahmen der immunosensorischen Funktion werden Antigene über M-Zellen kontrolliert aufgenommen und durch immunkompetente Zellen verarbeitet und präsentiert. Innerhalb des Follikels und weiterhin im regionalen Lymphknoten kommt es dann zu einer Aktivierung und Expansion von T- und B-Zellen sowie einer Emigration der aktivierten Zellen in den Körperkreislauf. Nach weiterer Reifung der Zellen und Rezirkulation migrieren die Effektor- und Plasmazellen dann über lokale Adhäsionsmolekül-exprimierende Blutgefäße wieder in die Zielregion der Augenoberfläche und greifen in Abwehrprozesse ein. Damit diese immunologischen Abwehrprozesse nicht im Rahmen von überschießenden Reaktionen Gewebeschädigungen verursachen, existieren weiterhin sog. regulatorische T-Zellen (und bislang am Auge noch nicht nachgewiesene regulatorische B-Zellen), die eine Immunreaktion auf verschiedene Arten vermindern können. Sie tragen so zur wichtigen immunologischen Homöostase bei. Da regulatorische T-Zellen in Mukosaassoziierten lymphatischen Geweben gebildet werden, ist naheliegend, dass CALT somit als Schnittstelle zwischen Immunaktivierung und -regulation fungiert.

\section{Immunprivileg am vorderen Augensegment}

Das bestehende Immunprivileg am vorderen Augensegment (Anterior-chamber associated Immune Deviation, ACAID), das sich auch auf die Hornhaut bezieht, wird in - Abschn. 5.1.2 gesondert betrachtet und detailliert erläutert. In diesem Zusammenhang wurde in den vergangenen Jahren das angiogene Privileg der Hornhaut als weiterer, klinisch höchst bedeutsamer Faktor für das immunologische Gleichgewicht erkannt.

\section{Entzündung}

Jede Schädigung der Augenoberfläche führt zu einer Entzündungsreaktion, die entsprechend dem Auslöser einen immunologischen und/oder nicht-immunologischen Charakter haben kann. Als Entzündungsauslöser können mechanische, toxische, physikalische und chemische Reize sowie infektiöse, allergische und autoimmune Auslöser vorkommen (• Tab. 1.1).

Ultrastrukturelle, molekularbiologische, genetische u. a. Untersuchungen von Bindehaut- und Hornhautgeweben sowie der Tränenflüssigkeit bei unterschiedlichen Entzündungen zeigen teilweise typische Veränderungen, die ein äußerst komplexes Bild vermitteln ( Abschn. 5.1.2). Grundsätzlich sind am vorderen Augenabschnitt folgende (insbesondere therapeutischen Maßnahmen zugängliche) pro- und anti-inflammatorische Mechanismen bekannt:

1. Aktivierung von Matrixmetalloproteinasen (MMPs),

2. Induktion autoreaktiver T-Zellen,
Tab. 1.1 Reizarten und Entzündungsauslöser

\begin{tabular}{l|l}
\hline Reizart & Auslöser \\
\hline Mechanisch & Reibung, Druck \\
\hline Toxisch & Konservierungsmittel, Medikamente \\
\hline Chemisch & Säuren, Laugen \\
\hline Physikalisch & UV-Licht \\
\hline Infektiös & Bakterien, Viren, Pilze, Parasiten \\
\hline Allergisch & Allergene, Medikamente \\
\hline Autoimmun & „Unbekannt“, Viren?, Genetik?, Autoantigene
\end{tabular}

3. Ausschüttung pro-entzündlicher Faktoren (Interleukine, Chemokine, etc.),

4. Lymph- und Hämangiogenese,

5. Anflutung und Aktivierung von Antigen-präsentierenden Zellen,

6. Bildung immunregulatorischer T-Zellen,

7. Expression von Chemokin- und Homingrezeptoren (• Abb. 1.4).

Die meisten dieser Mechanismen werden im klinischen Alltag nicht routinemäßig untersucht, jedoch gibt es aktuelle Entwicklungen, die eine Charakterisierung und Graduierung von Entzündungen des vorderen Augenabschnitts in Aussicht stellen. Dies sind zum einen Immunoassey-Schnelltests, die eine unmittelbare Messung von z. B. MMP-9 im Tränenfilm beim Trockenen Auge zulassen als auch nicht-invasive Bildgebungsverfahren ( $\triangleright \mathrm{Ab}$ schn. 1.1.5).

\subsubsection{Korrelation: (Leit)befund- Morphologie bei Konjunktivitis/ Keratitis (engl. key features, conjunctivitis, keratitis)}

\section{A. Bialasiewicz}

Am äußeren Auge können sich praktisch alle Infektionserreger manifestieren. Der Augenarzt kann mit der hochauflösenden Vergrößerung an der Spaltlampe, d. h. der Biomikroskopie, die Lokalisation, den Typ und den Zugang von Entzündungen definieren.

Unter Berücksichtigung von Krankheitsverlauf und demographischen Parametern lässt sich eine weitgehende differentialdiagnostische Einengung infektiös bedingter Erkrankungen erreichen, und es können Leitbefunde festgelegt werden, aufgrund derer eine spezifische Diagnostik und kalkulierte empirische Soforttherapie möglich ist. Die betroffenen Gewebe sind zudem einer visuellen klinischen 


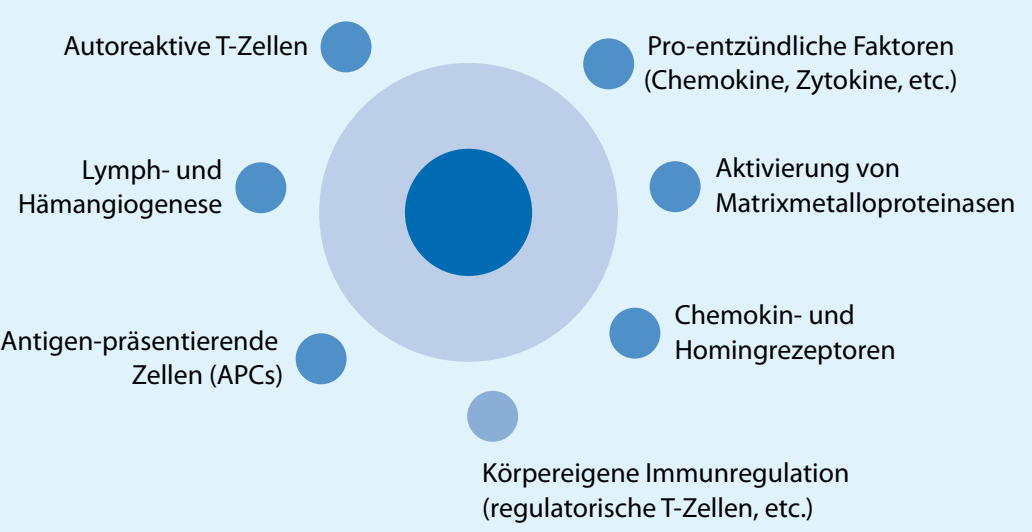

Pro-inflammatorische Mechanismen Anti-inflammatorische/regulatorische Mechanismen

- Abb. 1.4 Körpereigene pro- und anti-inflammatorische Mechanismen. (Mod. nach Steven, Cursiefen 2012)

Diagnostik mit Photodokumentation und anderen bildgebenden Verfahren, wie Confoscan und OCT, zugänglich.

Nur durch diese genaue biomikroskopische Befundaufnahme, Dokumentation und morphologische Klassifizierung in

- exogene direkte,

- endogene fortgeleitete,

- lokale fortgeleitete und

- infektionsassoziierte

Infektionen und Entzündungen, können häufig unnötige und kostenintensive diagnostische und therapeutische Maßnahmen vermieden werden.

\subsubsection{Stellenwert der mikrobiologischen Labordiagnostik bei Konjunktivitis und Keratitis (engl. microbiology conjunctivitis, keratitis)}

\section{O. Assadian, A. Kramer}

\section{Mikrobiologie des vorderen Augenabschnittes}

Das gesunde Auge weist trotz starker Exposition gegenüber exogenen Mikroorganismen eine erstaunlich geringe natürliche mikrobielle Flora auf. Kornea, Konjunktiva sowie Lidränder sind beim gesunden Menschen mit nur geringen Zahlen an typischen Vertretern der Hautflora besiedelt. I. d. R. prädominieren Corynebacterium spp., Propionibacterium spp., Koagulase-negative Staphylokokken sowie in wechselndem Anteil Vertreter der physiologischen Oro- pharyngealflora wie apathogene Neisseria spp. und vergrünende Streptokokken, die z. B. endogen mehrmals am Tag über die Finger als Vehikel zum Auge getragen werden. Auf der Außenseite der Lider ist die normale physiologische Flora der Haut zu finden.

Die Ursache für die geringe mikrobielle Besiedelung des Auges liegt in der speziellen Zusammensetzung des Tränenfilms sowie zu einem Teil im permanent stattfindenden Spüleffekt. Dabei ermöglicht die im Tränenfilm enthaltene Kombination aus Lactoferrin, sekretorischem Immunglobulin A, Komplementsystem, Lysozym und dem Lactoperoxidase-Thiocyanat-Wasserstoffperoxid-System eine antimikrobielle Wirkung, ohne dabei durch chronische Entzündungsprozesse den natürlichen Visus zu behindern. Üblicherweise beträgt der Lactoferrinanteil $25 \%$ $(w / w)$ des gesamten Proteingehaltes mit einer Konzentration von $2,2 \mathrm{mg} / \mathrm{mL}$ Tränenflüssigkeit. Je nach zusätzlich bestehender Grundkrankheit kann die Lactoferrinkonzentration starken Schwankungen von 0,63 bis $2,9 \mathrm{mg} / \mathrm{mL}$ Tränenflüssigkeit unterworfen sein. Mit zunehmend hohem Alter, aber auch bei Vorliegen systemischer Erkrankungen wie Sjögren Syndrom, Diabetes mellitus, myotonisch muskulärer Dystrophie, allergischer Konjunktivitis, Trachom, Herpes-simplex-Virus-Keratitis, HIV-Erkrankung, chronischer Hepatitis C, lepröser Typ 2 Reaktion oder okularem Pemphigiod ist der Lactoferrinanteil deutlich erniedrigt.

Entzündungen im vorderen Augenabschnitt können durch infektiöse oder nicht-infektiöse Ursachen bedingt sein. $\mathrm{Zu}$ den häufig befundeten bakteriellen Erreger einer Konjunktivitis mit und ohne Blepharitis zählen Staphylococcus aureus, beta-hämolysierende Streptokokken, Streptococcus pneumoniae, Haemophilus influenzae, Chlamydia trachoma- 
Tab. 1.2 Überblick der wesentlichsten Mikroorganismen als Ursache für Infektionen des vorderen Augenabschnittes

\begin{tabular}{|c|c|c|}
\hline Mikroorganismen & Keratitis & Konjunktivitis \\
\hline \multicolumn{3}{|l|}{ Bakteriell } \\
\hline Häufig & $\begin{array}{l}\text { Staphyloccocus aureus, Streptococcus pneumoniae, } \\
\text { Pseudomonas aeruginosa }\end{array}$ & $\begin{array}{l}\text { Staphylococcus aureus, beta-hämolysierende Strep- } \\
\text { tokokken, Streptococcus pneumoniae, Haemophilus } \\
\text { influenzae, Chlamydia trachomatis, Pseudomonaden, } \\
\text { Enterobakterien }\end{array}$ \\
\hline Selten & $\begin{array}{l}\text { Mycobacteium leprae, Neisseria gonorrhoeae, Neisse- } \\
\text { ria meningitides }\end{array}$ & $\begin{array}{l}\text { Haemophilus influenzae sub. aegyptius, Moraxella } \\
\text { lacunata, Corynebacterium diphtheriae, Listeria mo- } \\
\text { nocytogenes, aerobe und anaerobe Aktinomyzeten, } \\
\text { Francisella tularensis, Mycobacterium tuberculosis, } \\
\text { Treponema pallidum }\end{array}$ \\
\hline \multicolumn{3}{|l|}{ Viral } \\
\hline Häufig & $\begin{array}{l}\text { Adenovirus (Typ 8, Typ 19), Varizella-Zoster-Virus, } \\
\text { Herpes-simplex-Virus I, Enteroviren }\end{array}$ & $\begin{array}{l}\text { Adenovirus (Typ 8, Typ 19), Herpes-simplex-Virus, } \\
\text { Varizella-Zoster-Virus, Enterovirus, Begleitkonjunkti- } \\
\text { vitis durch Masernvirus, Rötelvirus, Varizella-Zoster- } \\
\text { Virus, Molluscum contagiosum Virus }\end{array}$ \\
\hline Selten & $\begin{array}{l}\text { Bunyaviridae, H9N2 Influenzavirus, H7N3 Influenzavi- } \\
\text { rus, H1N1 dpm09 Influenzavirus, Humanes Metapneu- } \\
\text { movirus, Sandfly fever Turkey Virus, Zika Virus, Aichi } \\
\text { Virus, Parvovirus B19 }\end{array}$ & $\begin{array}{l}\text { Influenzaviren, Epstein-Barr-Virus, Respiratory } \\
\text { syncytial-Virus }\end{array}$ \\
\hline \multicolumn{3}{|l|}{ Mykotisch } \\
\hline Häufig & Candida spp., Aspergillus spp. & $\begin{array}{l}\text { Nocardia, Fusarium, Aspergillus, Phaeohyphomyce- } \\
\text { ten, Scedosporium apiospermum, Curvularia }\end{array}$ \\
\hline Selten & $\begin{array}{l}\text { Hier sind einige Erreger aus der Literatur der letzten } \\
10 \text { Jahre wiedergegeben, es kommen fast monatlich } \\
\text { neue hinzu. } \\
\text { Chaetomium atrobrunneum, Arthrographis kalrae, } \\
\text { Exserohilum rostratum, Colletotrichum graminicola, } \\
\text { Absidia corymbifera, Cephaliophora irregularis, Sco- } \\
\text { pulariopsis brevicaulis, Beauveria bassiana, Exophiala } \\
\text { jeanselmei, Aureobasidium pullulans, Pichia anomala }\end{array}$ & $\begin{array}{l}\text { Candida spp. (bei Immunsuppression), Aspergillus } \\
\text { spp., Blastomyces dermatitidis, Sporothrix schenckii, } \\
\text { Rhinosporidium seeberi, Coccidioides immitis }\end{array}$ \\
\hline \multicolumn{3}{|l|}{ Parasitär } \\
\hline & Acanthamoeba spp., Onchocerca volvulus & Onchocerca volvulus, Loa Loa \\
\hline
\end{tabular}

tis sowie Pseudomonaden und Enterobakterien. Abhängig von geographischer Lage und speziellen Populationen können auch Haemophilus influenzae sub. aegyptius, Moraxella lacunata, Neisseria gonorrhoeae, N. meningitidis, Corynebacterium diphtheriae, Listeria monocytogenes, aerobe und anaerobe Aktinomyzeten, Francisella tularensis, Mycobacterium tuberculosis oder Treponema pallidum eine infektiöse Konjunktivitis verursachen. Infektionen durch atypische Mykobakterien sind zwar noch selten, durch LASIK-Eingriffe in den vergangenen Jahren jedoch häufiger zu beobachten.

Eine isolierte Keratitis kann durch Mycobacterium leprae, Acanthamoeba spp., Onchocerca volvulus sowie Candida spp. und Aspergillus spp. verursacht sein. Virale Erreger wie Adeno-, Herpes- oder Enteroviren zählen vermutlich zu den häufigsten infektiösen Ursachen und führen meist zu einer kombinierten Kerato-Konjunktivitis. Eine indirekt durch
Infektionen verursachte Entzündung des vorderen Augenabschnittes kann zudem nach Darminfektionen mit Shigella spp. oder Yersinia spp. sowie im Zusammenhang mit einer reaktiven Arthritis infolge abgelaufener Infektion mit Chlamydia trachomatis, Campylobacter spp. oder Salmonella spp. als Reiter Syndrom auftreten. • Tabelle 1.2 gibt einen Überblick über die wesentlichsten Mikroorganismen als Ursache von Infektionen des vorderen Augenabschnittes.

Im Vergleich zur infektiösen Konjunktivitis sind die Konsequenzen der Keratitis deutlich bedrohlicher. Aufgrund der akuten Gefahr eines Visus-Verlustes ist es wichtig, infektiöse Konjunktivitiden von Keratitiden zu unterscheiden. Dabei spielen zunächst die Möglichkeit einer mikrobiologischen Diagnostik weniger eine Rolle als die anamnestischen Angaben und die Klinik. Eine Übersicht der wesentlichen klinischen Unterschiede zwischen einer 
Tab. 1.3 Hilfreiche Symptome und Befunde zur klinischen Abgrenzung einer Konjunktivitis von einer Keratitis

\begin{tabular}{|l|l|l|}
\hline & Konjunktivitis & Keratitis \\
\hline Juckreiz & + & - \\
\hline Fremdkörpergefühl & + & $(+)$ \\
\hline Krusten an Wimpern & + & - \\
\hline Verklebte Augenlider & + & - \\
\hline Konjunktivale Hyperämie & + & - \\
\hline Eitriger Ausfluss & + & - \\
\hline $\begin{array}{l}\text { Schwellung der Augen- } \\
\text { lider }\end{array}$ & $(+)$ & - \\
\hline Trübung“ & & \\
\hline Zirkumkorneale Injektion & $(-)$ & + \\
\hline Photophobie & - & + \\
\hline Schmerz & - & + \\
\hline Visuseinschränkung & $(-)$ & + \\
\hline $\begin{array}{l}\text { a insbesondere bei S. aureus oder P. aeruginosa Keratitis auf- } \\
\text { grund Immunreaktion, }{ }^{\mathrm{b}} \text { insbesondere bei Adenoviren }\end{array}$ & \\
\hline
\end{tabular}

infektiösen Keratitis und Konjunktivitis sind in • Tab. 1.3 gegenüber gestellt. Daneben können morphologische Aspekte auch ansatzweise bakterielle Konjunktivitis-Erreger abschätzbar machen (• Tab. 1.4).

\section{Mikrobiologische Labordiagnostik bei Verdacht auf infektiöse Konjunktivitis}

Die mikrobiologische Diagnostik (• Tab. 1.5) bei Infektionen des Auges wurde rezent in der entsprechenden S2-Leitlinie Deutscher Fachgesellschaften bewertet und dargelegt. Die Leitlinie hat bis 2016 Gültigkeit und empfiehlt bei Verdacht auf bakterielle Konjunktivitis, die klinische Diagnose durch eine mikrobiologische Untersuchung zu ergänzen.

(2) Bei der Probenentnahme ist darauf zu achten, dass keine falsch negativen Ergebnisse durch zuvor applizierte (konservierungsmittelhaltige) Lokalanästhetika, Antibiotika oder Antiseptika entstehen.

Häufige Fehlerquellen bei Abnahme und Transport sind in - Tab. 1.6 dargestellt.

Mit einem Abstrichtupfer (z. B. Dacron- oder Alginattupfer) ist nach Abziehen des Unterlides unter Verwendung frisch angelegter Einmaluntersuchungshandschuhe die gesamte Länge des unteren Fornix abzustreichen, wobei der Abstrichtupfer für einige Sekunden bis zur vollständigen Durchtränkung im Fornix belassen werden soll. Um die Austrocknung empfindlicher Mikroorganismen zu
- Tab. 1.4 Typische klinische Befunde einer bakteriellen Keratitis

\begin{tabular}{|l|l|}
$\begin{array}{l}\text { Erreger } \\
\begin{array}{l}\text { Staphylococ- } \\
\text { cus aureus }\end{array}\end{array}$ & $\begin{array}{l}\text { Keutlinischer Befund } \\
\text { benes Stromainfiltrat }\end{array}$ \\
$\begin{array}{l}\text { Streptococcus } \\
\text { pneumoniae }\end{array}$ & $\begin{array}{l}\text { Ulkus serpens; überwiegend oberflächliche } \\
\text { Ausbreitung mit kriechendem Rand; Eiter } \\
\text { mit Spiegelbildung }\end{array}$ \\
\hline $\begin{array}{l}\text { Pseudomonas } \\
\text { aeruginosa }\end{array}$ & $\begin{array}{l}\text { Schnell ausbreitendes purulentes Infiltrat, } \\
\text { Gefahr frühzeitiger Korneaperforation, } \\
\text { stark mukopurulentes Sekret; Eiter mit } \\
\text { Spiegelbildung }\end{array}$ \\
\hline Bacillus cereus & $\begin{array}{l}\text { Anamnestisch stärkere Staubexposition, } \\
\text { Trauma-Anamnese, Konjunktivitis mit Opa- } \\
\text { kifizierung der Kornea, wenig bis kein Eiter }\end{array}$
\end{tabular}

verhindern oder Schädigungen durch Oxidation zu minimieren, sollte allerdings auch bei nur kurzen Transportwegen ein Abstrichtupfer mit Transportmedium eingesetzt werden. Im Sinne der verbesserten Interpretierbarkeit des Befundes wird sinnvollerweise empfohlen, bei einseitiger Konjunktivitis mit einem zweiten Abstrichtupfer auch einen Abstrich des zweiten Auges abzunehmen.

\section{$>$ Getrennte Abstriche von den Lidkanten werden nicht mehr empfohlen.}

Die Fachgesellschaften empfehlen bei chronischen Konjunktivitiden und granulomatösen Prozessen zur Diagnosestellung die Materialgewinnung mittels Biopsie, wobei Probengewinnung mittels Kimura-Spatel oder Hockeymesser zur mikroskopischen und zytologischen Untersuchung oft rasch eine Differenzierung zwischen infektiösen und malignen Prozessen ermöglichen kann.

Als Labormethoden steht bei eitriger Konjunktivitis die Fertigung eines Grampräparates zur Verfügung, was oft einen schnellen Hinweis auf einen möglichen bakteriellen Erreger liefern kann. Bei Verdacht auf Infektion mit N. gonorrhoeae ist besonders auf kurze Transportzeiten oder die Verwendung spezieller Transportmedien mit Amies-Kohle Medium zu achten. Bei granulomatöser Konjunktivitis mit oder ohne begleitende Lymphadenopathie muss insbesondere an Infektionen durch Pasteurella spp. und Bartonella spp., entsprechend der Anamnese zusätzlich auch an eine Infektion durch Francisella tularensis (Jäger, Kontakt mit Nagetieren) gedacht werden.

Bei Verdacht auf Vorliegen eines Trachoms (auch: ägyptische Körnerkrankheit oder trachomatöse Einschlusskonjunktivitis) durch Infektion mit Chlamydia trachomatis Serotyp A bis C stehen, wie auch z. T. bei den anderen genannten Erregern, kulturelle Verfahren mittels Anzüchten des Erregers in Zellkulturen, die sich auch zum 
Tab. 1.5 Indikationen für mikrobiologische Untersuchungen bei Konjunktivitis

Akute mukopurulente Konjunktivitis bei Kindern und Erwachsenen

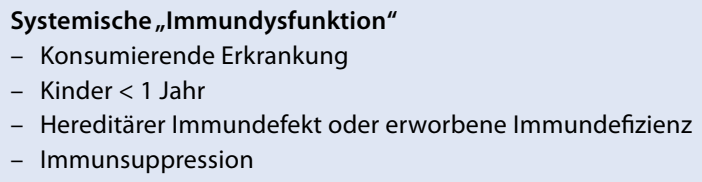

\section{Lokale „Immundysfunktion“}

- Kürzlich erfolgter ophthalmochirurgischer Eingriff

- Filterkissen oder Glaukomdrainageimplantat

- Langfristige topische Kortikosteroidtherapie

- Langfristige Antibiotikatherapie

- Kontaktlinsen

- Augenprothese

\section{Transmission unter besonderen Voraussetzungen}

- Nosokomiale Übertragung

Kontakt mit durch Neisseria meningitidis, Neisseria gonorrhoeae oder Haemophilus influenzae Infizierten

Wiederkehrende akute mukopurulente Konjunktivitis

Akute mukopurulente Konjunktivitis, die innerhalb 7-10 Tagen auf empirische Therapie nicht anspricht

\section{Neonatale Konjunktivitis}

Langfristige Antibiotikatherapie
Hereditärer Immundefekt
Mutter mit Neisseria gonorrhoeae oder Haemophilus influenzae Infektion

Mutter besiedelt mit Gruppe B Streptokokken

Akute mukopurulente Konjunktivitis, die innerhatb $7-10$ Tagen au

- Tab. 1.6 Gründe für fehlerhafte mikrobiologische Diagnostik

\begin{tabular}{|l|l|}
\hline Probenentnahme & - Falsche Methode für gewünschte Fragestellung \\
& - Kontamination mit apathogenen Mikroorganismen infolge ungeübter Abnahmetechnik \\
& - Applikation von Anästhetika, Antiseptika oder topischen Antibiotika unmittelbar vor Probenab- \\
& nahme \\
\hline Transport & - Nicht optimal gewählte Abnahmematerialien \\
\hline Probenverarbeitung & - Zu hohe oder zu niedrige Temperatur \\
& - Lange Lagerungszeit bei wechselnder Temperatur \\
& - Inadäquates Transportmedium \\
\hline Antibiogramm & - Lange Transportzeit \\
\hline Ergebnisinterpretation & - Mangelnde oder falsche Einsendeangaben \\
\hline & - Kalsche Probenbeschriftung \\
\hline & - Fehlerhafte Verdünnung \\
\hline & - Inadäquates Medium \\
\hline & - Inadäquate Kulturtechnik (Inokulumgröße, Bebrütungstemperatur, Bebrütungsdauer) \\
\hline
\end{tabular}

direkten Nachweis von viralen Erregern wie HSV eignen, mikroskopische Verfahren mittels Giemsa-Färbung, direkte Immunfluoreszenztests, Immunoassays oder molekularbiologische Methoden zur Verfügung.

Das klinische Bild einer Infektion mit Chlamydia trachomatis Serotyp $D-K$, der sog. okularen C. trachomatisInfektion (OCI) oder auch Schwimmbadkonjunktivitis, ist nicht so ausgeprägt wie beim Trachom. Da zudem andere Therapieoptionen erforderlich sein können, sollte eine mi- krobiologische Labordiagnostik zur Bestätigung des klinischen Verdachtes erfolgen. Da die Erreger interzellulär vorliegen, sollten möglichst große Mengen an Bindehautzellen gewonnen werden. Dazu wird am ektropionierten Oberlid (• Abb. 1.5) das Epithel mit einem Bürstchentupfer angeraut und das gewonnene Material mit einem Watteträger auf einen Spezialobjektträger gebracht. Da die Erreger auch im Nasen-Rachen-Raum sitzen, kann ein zusätzlicher Nasenabstrich die Trefferquote weiter erhöhen. 


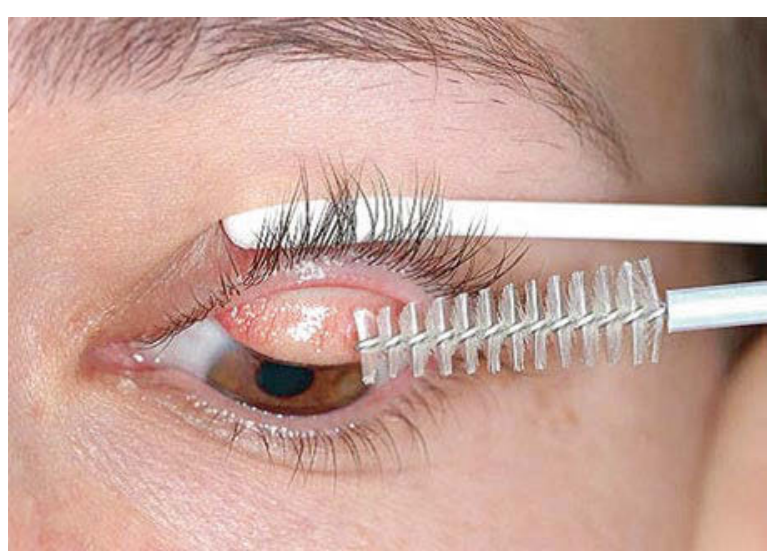

- Abb. 1.5 Probenabnahme bei Verdacht auf C. trachomatis Serotyp D-K Konjunktivitis. (Aus Behrens-Baumann 2007)

Das gewonnene Material kann im Labor mittels verschiedener Untersuchungsmethoden verarbeitet werden. Das Anlegen des Probenmaterials in einer McCoy-Zellkultur zum Nachweis von charakteristischen Einschlusskörpern gilt als Referenzmethode. Chlamydien-Einschlusskörper werden nach 2-3 Tagen, manchmal bis zu einer Woche, mittels Färbungen (Immunfluoreszenz, Iod- oder Giemsafärbung) sichtbar gemacht.

Eine schnellere und weniger aufwendige Methode ist die Durchführung einer spezifischen Polymerase-KettenReaktion (PCR). Hierbei ist bei der Befundinterpretation zu beachten, dass nicht nur vitale, sondern auch devitale Erreger nachgewiesen werden. Daher kann eine Chlamydien-positive PCR auch bei klinisch gesunden Personen vorliegen.

Billiger und noch schneller ist die direkte Immunfluoreszenz-Antikörper-Technik (DFA, DIF), die eine ausreichend hohe Sensitivität und Spezifität aufweist. Letztlich stehen noch Immunperoxidasetests (IPO) oder Enzyimmunoassay (EIA) zur Verfügung.

\section{Mikrobiologische Labordiagnostik bei Verdacht auf infektiöse Keratitis}

Zur mikrobiologischen Bestätigung des Verdachts einer infektiösen Keratitis soll ein mehrstufiges Materialgewinnungsverfahren eingesetzt werden. Dabei soll zunächst ein Konjunktivalabstrich mit je einem Abstrichtupfer von beiden Augen abgenommen werden. Anschließend wird mit einem weiteren Abstrichtupfer, Kimura-Spatel oder Hockeymesser Material vom Ulkus und vom Ulkusrand gewonnen. Insbesondere bei Verdacht auf eine mykotische Keratitis (• Tab. 1.7) sollte bei Materialgewinnung mittels Kimura-Spatel oder Hockeymesser darauf geachtet werden, auch ausreichend subepitheliales Material vom Ulkusrand zu gewinnen, um vitale Pilzelemente mit zu erfassen ( $\triangleright$ Abschn. 1.1.5). Für zusätzliche Untersuchungen auf
Tab. 1.7 Klinische Symptome einer mykotischen Keratitis
Pilztypisch
Pilzcharakteristisch
- Landkartenartige Konfi- guration
- Zähes Hypopyon
Satellitenphänomene
- Erhabenes Infiltrat
- Keiner oder nur geringer Epitheldefekt bei
- Pyramidenförmig
- Zapfen von oben, unten oder nach hinten oder
- Abtropfen von oben

Akanthamöben sind weitere getrennte Proben erforderlich, wobei zusätzlich eine Keratektomie oder exzisionale kurative Keratoplastik mit histopathologischer Aufarbeitung zur Diagnosesicherung notwendig werden kann. Falls möglich, sollte gleich am Ort der Abnahme ein mikroskopisches Präparat angefertigt werden und das gewonnene Kornea-Abrasiomaterial in ein flüssiges oder auf ein festes Transportmedium gegeben werden. Bei generellem Verdacht auf bakterielle Erreger soll neben der direkten Mikroskopie das eingesendete Material auf (Columbia-) Blut- und Kochblutagarplatten 3 bis 4 Tage bei $36^{\circ} \mathrm{C}$ in 5-10\% $\mathrm{CO}_{2}$ und täglicher Ablesung sowie in angereicherter Hirn-Herz-Bouillon bebrütet werden.

Bei klinischem Verdacht auf Vorliegen einer viralen Keratitis reicht ein einstufiges Vorgehen. Hierbei kann wieder ein Abstrich durchgeführt werden oder direkt Tränenflüssigkeit kontaminationsfrei entnommen und der Virusdiagnostik zugeführt werden. Das Abtragen von Korneamaterial soll bei Vorliegen des Verdachts einer viralen Keratitis unterbunden werden, da durch diese Maßnahme eine Kornea-Stromainfektion durch z. B. Herpesviren begünstig werden kann. Bei Keratouveitis kann ein intraokularer Erregernachweis v. a. durch lokale Antikörperbildung ggf. PCR hilfreich sein.

\section{Praxistipp}

Praktisches Vorgehen bei intraokularer Infektionsdiagnostik (nach Pleyer und Behrens-Baumann 2007):

1. Für Anzucht (Bakterien und Pilz): unverdünnte Probe mit mindestens $10 \mu \mathrm{l}$ einsenden oder direkt beimpfen

2. Für Antikörpernachweis/PCR unverdünnte Probe mit einer (Tuberkulin-)Spritze einsenden (je 100$200 \mu$ l) für Bakterien, Pilze und Viren

3. Bei Kontaktlinsenträgern: Kontaktlinsen-Behälter und Flüssigkeit einsenden 


\section{Beurteilung mikrobiologischer Untersuchungsverfahren}

Alle genannten Untersuchungsmethoden weisen hinsichtlich Sensitivität und Spezifität Vor- und Nachteile auf, setzen mehr oder weniger viel Erfahrung in der Durchführung voraus und können teilweise je nach Ergebnis noch weiterführende Bestätigungsuntersuchungen erforderlich machen.

Grundsätzlich sollte von sog. „Routineeinsendungen“ abgesehen werden. Ohne weiterführende Informationen kann die mikrobiologische Diagnostik auch im Falle des Nachweises einer oder mehrerer Mikroorganismen in ihrer Aussage hinsichtlich der klinischen Relevanz limitiert sein. Ohne klare Fragestellung gibt der mikrobiologische Standardbefund i. d. R. lediglich Angaben über Genus (Gattung) und ggf. die Spezies (Art) der Mikroorganismen einschließlich ihrer Empfindlichkeit gegen ausgewählte Antibiotika an. Angaben über das Vorliegen oder Fehlen von speziellen Pathogenitätsfaktoren fehlen, falls nicht gesondert erwünscht. Daher kann z. B. von einem mikrobiologischen Nachweis eines Corynebacterium diphtheriae Isolates allein noch keine Aussage über seinen Krankheitswert und die Notwendigkeit weiterführender, evtl. invasiver Maßnahmen abgeleitet werden. Neben der individuellen Klinik des Patienten kann es u. U. auch entscheidend sein, ob der isolierte Stamm in der Lage ist, Diphtherie-Toxin zu bilden. Die vier relevanten Subspezies C. diphtheriae mitis, C. diphtheriae intermedius, C. diphtheriae gravis und C. diphtheriae belfant $i$ unterscheiden sich nur geringfügig in ihrer Morphologie und ihren biochemischen Eigenschaften, alle vier können jedoch stammabhängig entweder Toxinbildner sein oder die Fähigkeit, das Diphtherie-Toxin zu bilden, nicht besitzen.

\section{$(2$ Die Qualität der mikrobiologischen Diagnostik wird umso besser, je konkreter die Fragestellung und klinische Verdachtsdiagnose sind.}

Die mikrobiologische Diagnostik kann dabei einen Verdacht mehr oder minder rasch, je nach eingesetzter Methode, bestätigen oder ausschließen. Welche Methode der Probengewinnung und -verarbeitung am geeignetsten ist, hängt damit wesentlich von der Verdachtsdiagnose und der klinischen Fragestellung ab. Daher ist eine gute und enge Kommunikation mit dem eigenen mikrobiologischen Labor von entscheidendem Vorteil. Erst durch Kenntnis der machbaren diagnostischen Leistungen des eigenen Labors einerseits und durch Wissen der klinischen Relevanz für die weiterführende Behandlung des Patienten anderer- seits, kann eine optimale und punktgerichtete Materialgewinnung und -verarbeitung realisiert werden.

\subsubsection{Bildgebende Diagnostik bei entzündlichen Augenerkrankungen (engl. Confocal microscopy, diagnostic procedure, imaging techniques)}

\section{A. Zhivov, S. Peschel, K. Falke, R. F. Guthoff}

\section{Stellenwert der konfokalen Mikroskopie}

Die moderne in vivo konfokale Mikroskopie ermöglicht eine differenzierte Diagnostik bei entzündlichen Augenkrankheiten im vorderen Augenabschnitt. Die Technologie erlaubt eine nicht-invasive Untersuchung in der Patientenbetreuung sowie im Tierexperiment. Diese Untersuchung ist nicht mehr nur eine „Labormikroskopie“, sondern eine etablierte klinische Untersuchungsmethode. Bestimmung der Zellzahl, Darstellung des subbasalen Nervenplexus, Differentialdiagnose von verschiedenen Zellpopulationen, zwei- und drei-dimensionale Rekonstruktion sowie on-line 2D-Mapping sind die vielversprechenden Möglichkeiten der modernen konfokalen Mikroskopie.

\section{In vivo konfokale Mikroskopie der normalen Bulbusoberfläche}

Eine Beurteilung der Hornhaut und Bindehaut ist ein fester Bestandteil der augenärztlichen Diagnostik. Die traditionelle mikromorphologische Untersuchung erfolgt mittels invasiver Gewebeentnahme (Scraping, Impressionszytologie, etc.) mit einer anschließenden aufwendigen immunhistochemischen bzw. mikrobiologischenAufbereitung. Die in vivo konfokale Mikroskopie erlaubt eine detaillierte und zeitsparende Darstellung der Hornhaut sowie der Bindehaut.

Der zelluläre Aufbau der Hornhaut kann mit der konfokalen Mikroskopie in vivo dargestellt werden: Hornhautepithelium mit Superfizial-, Intermediär- und Basalzellen, Bowman-Membran, Subbasaler Nervenplexus (SNP), Stroma, Descemetmembran und Endothelium (• Abb. 1.6a-j, ๑ Tab. 1.8).

Alle normalen Hornhäute zeigten ein vergleichbares Muster des Subbasalen Nervenplexus (SNP): hoch reflektive Nervenfasern, die zwischen der Bowman-Membran und der Basalzellschicht des Hornhautepithels liegen.

- Abb. 1.6a-k In vivo konfokale Mikroskopie der Hornhaut bei Normalprobanden. Die Strukturen des Epithels (Superfizialzellen (a), obere (b) und untere (c) Intermediärzellen und Basalzellen (d), Subbasaler Nervenplexus - SNP (e), Bowman-Membran (f), vorderes (g) und mittleres (h) Stroma und Endothel (i). Zur Veranschaulichung der Schichtstruktur zeigt (k) einen Schrägschnitt durch das Epithel, die Bowman-Membran und das anteriore Stroma. Bei Aufnahmen dieser Art liegt die konfokale Ebene nicht oberflächenparallel zum Epithel, sondern gekippt. j präsentiert die 3D Rekonstruktion der Hornhaut. (Modifiziert nach Guthoff 2009) 


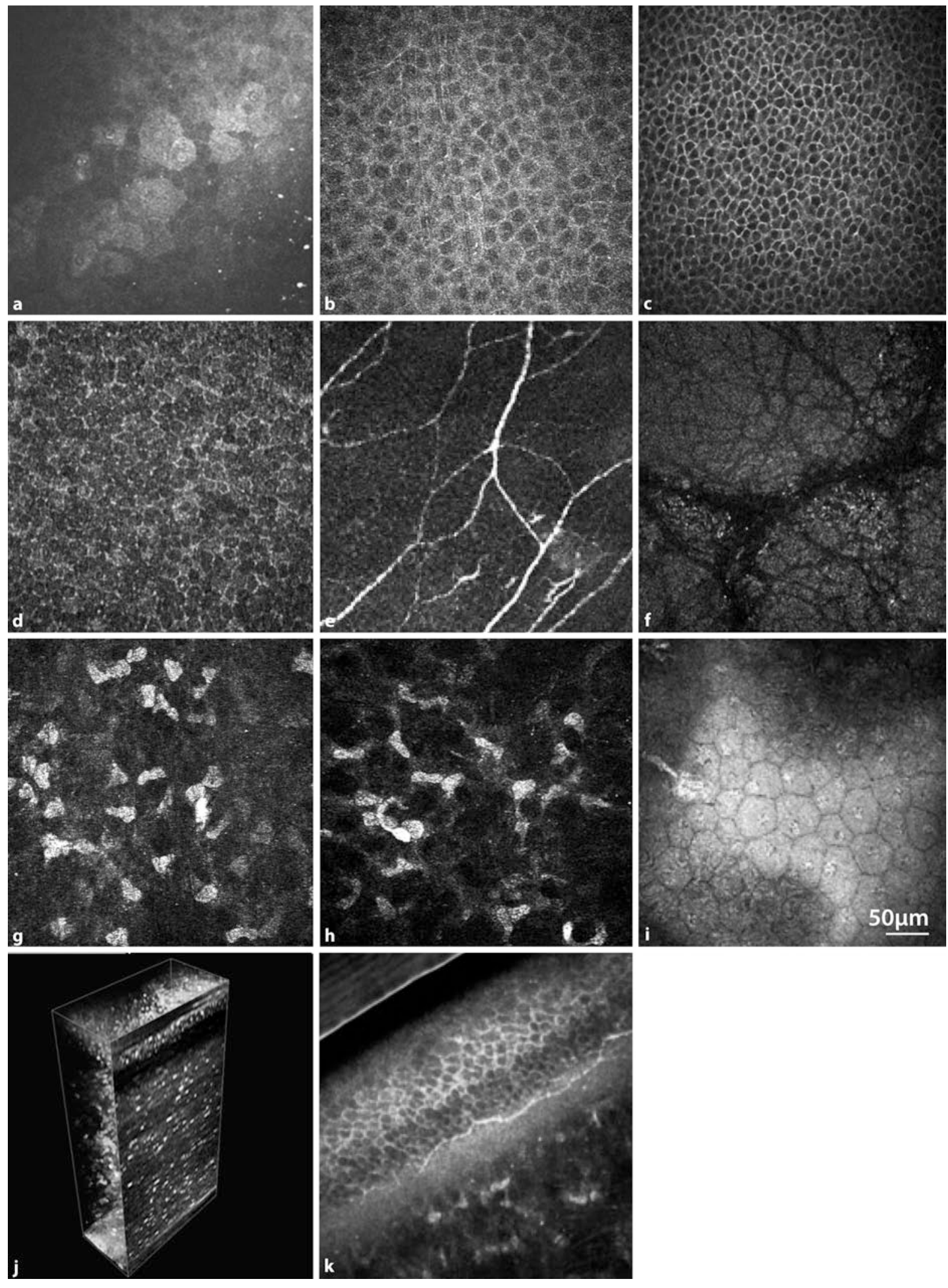


- Tab. 1.8 Konfokalmikroskopische Charakteristika der Hornhaut

\begin{tabular}{|c|c|c|}
\hline Hornhautschicht & Mikromorphologische Charakteristika & $\begin{array}{l}\text { Zelldichte zentral/peripher } \\
\left(\mathrm{Ze} / \mathrm{mm}^{2}\right)\end{array}$ \\
\hline \multicolumn{3}{|l|}{ Epithelium } \\
\hline Superfizialzellen & $\begin{array}{l}\text { Gut sichtbare Zellgrenzen, dunkler Zellkern. Das Zytoplasma erscheint im } \\
\text { Vergleich zum Kern hoch reflektiv. Die Zellen sind charakteristischerweise } \\
\text { polygonal. Die Größe der Zellen ist sehr variabel (bis zu } 50 \mu \mathrm{m} \text { ). }\end{array}$ & $850 / 1200$ \\
\hline Intermediärzellen & $\begin{array}{l}\text { Homogenes Muster, hoch reflektive Zellgrenzen und niedrig reflektives } \\
\text { Zytoplasma. Der Zellkern ist nicht sichtbar. Zellgröße bis etwa } 20 \mu \mathrm{m} \text {. Man } \\
\text { unterscheidet obere und untere Intermediärzellschicht, wobei die Größe } \\
\text { mit der Tiefe abnimmt. }\end{array}$ & $5000 / 5500$ \\
\hline Basalzellen & $\begin{array}{l}\text { Hoch reflektive Zellgrenzen, der Zellkern ist nicht sichtbar. Es treten Zellen } \\
\text { mit hoch und niedrig reflektivem Zytoplasma auf. Ein Verteilungsmuster ist } \\
\text { nicht erkennbar. Ähnlich den Intermediärzellen gibt es in Bezug auf Größe } \\
\text { (etwa } 8-10 \mu \mathrm{m} \text { ) und Form nur wenig Variabilität. }\end{array}$ & $6000-9000 / 10.000$ \\
\hline Stroma & $\begin{array}{l}\text { Hyperreflektive Keratozytenkerne, Kollagenfasern nicht darstellbar. Die } \\
\text { Keratozytendichte ist am höchsten im vorderen Stroma. }\end{array}$ & $20.500 \mathrm{Ze} / \mathrm{mm}^{3} \mathrm{im}$ Zentrum \\
\hline Endothelium & $\begin{array}{l}\text { Verband hexagonaler Zellen, Zellgröße und Form regelrecht, bei Normal- } \\
\text { probanden keine Zeichen von Polymegatismus und Pleomorphismus) }\end{array}$ & $2500-3000$ \\
\hline
\end{tabular}
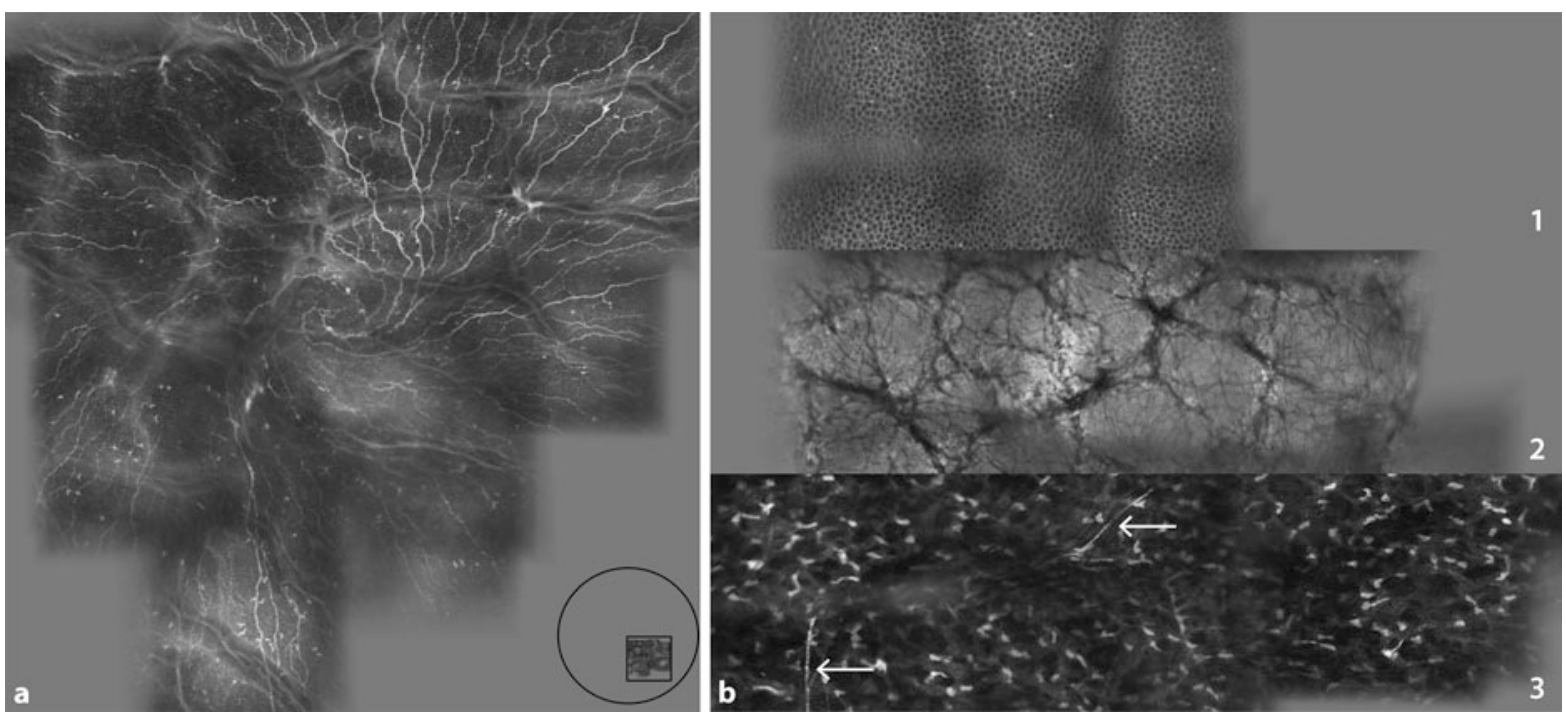

- Abb. 1.7a,b On-line 2D mapping bei Normalprobanden. a Ein verzweigtes Netzwerk von dünneren Fasern des subbasalen Nervenplexus verläuft exakt parallel zur Bowman-Membran und bildet einen Wirbel im nasal unteren Quadranten ( Bildgröße 1,6 x 1,6 mm), b Mapping des Epithels (Ebene der Intermediärzellen, (1), der Bowman-Membran (2), und des mittleren Stromas mit vereinzelten stromalen Nerven (Pfeil). Bildkante $1,6 \mathrm{~mm}$ )

Dieses Netz wird von zentripetal laufenden Fasern gebildet, die im nasal unteren Quadranten einen Wirbel bilden (• Abb. 1.7a). Im Gegensatz zu den stromalen Nerven, deren in vivo zusammenhängende Erfassung schwierig ist (• Abb. 1.7b), kann das Nervenfasernetzwerk parallel zur Bowman-Membran relativ einfach dargestellt werden.

Weiterhin erlaubt die moderne konfokale Mikroskopie eine off-line 2D- bzw. 3D-Rekonstruktion des untersuchten Gewebes und damit auch einen direkten Vergleich mit den Ergebnissen der traditionellen Histologie. Die ersten Versuche einer dreidimensionalen Rekonstruktion in vivo wurden von Masters et al. und Li durchgeführt. Hier konnten hochauflösende Hornhautbilder gewonnen und Streulichtmengen von beliebigen Schnitten ausgewertet werden. Verschiedene andere Gruppen haben Untersuchungen mit der in vivo Laser-Scanning-Mikroskopie mit anschließender Datenbearbeitung und dreidimensionaler Rekonstruktion publiziert. 

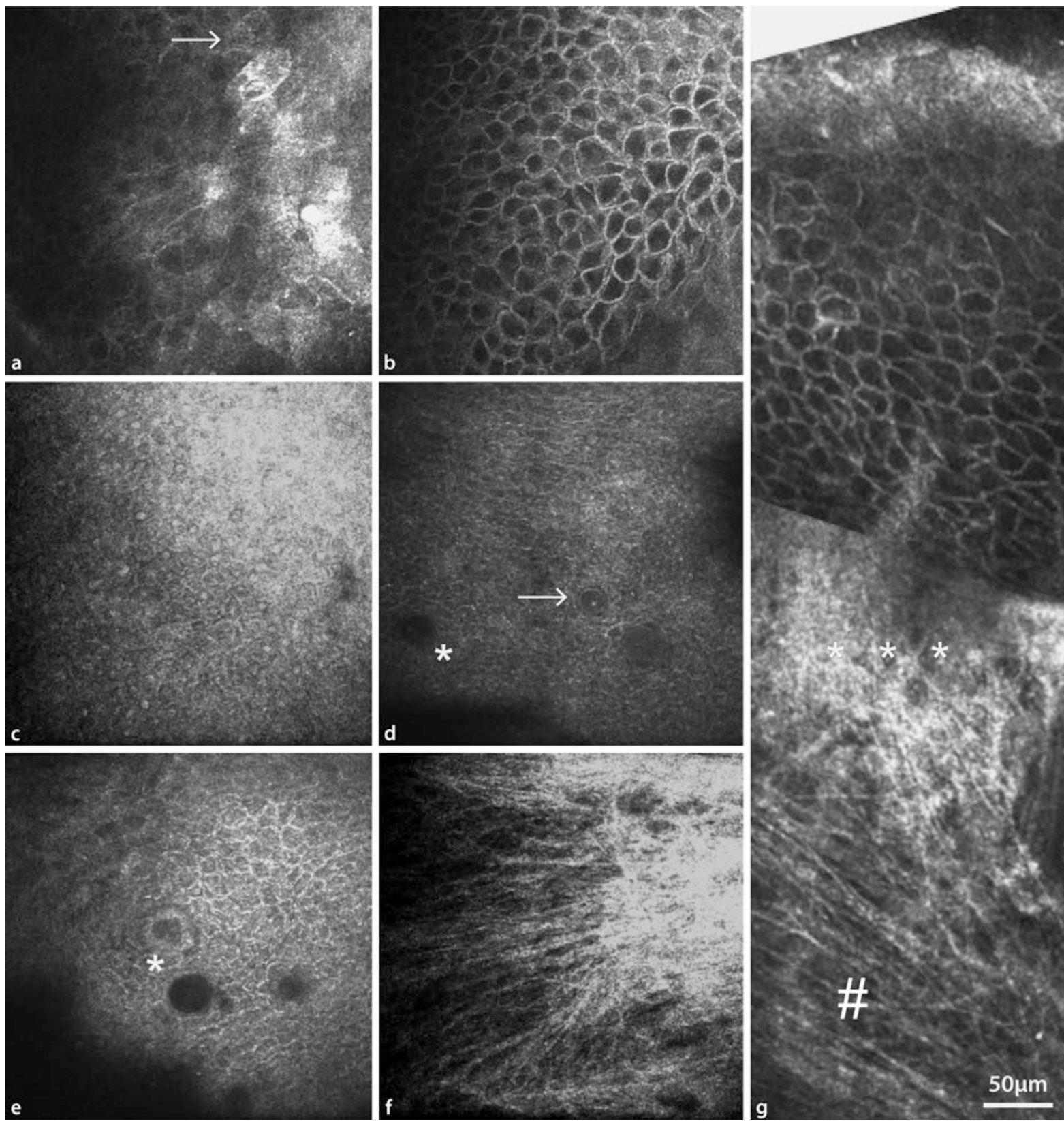

g

$50 \mu \mathrm{m}$

- Abb. 1.8a-g In vivo konfokale Mikroskopie der Bindehaut bei Normalprobanden. a-e Das Bindehautepithelium mit Superfizialzellen (Pfeil - desquamierte Zelle mit hyperreflektivem Kern) (a), Intermediärzellen (b,c) und Basalzellen (d,e). Der Zellendurchmesser nimmt mit der Tiefe ab, die Zellgrenzen erscheinen hyperreflektiv mit hyporeflektivem Zytoplasma. Man findet konfokalmikroskopisch Becherzellen (4d, Pfeil) sowie Zysten (Abb. 4d, e*). f Stroma der Bindehaut mit netzartigen Fasern. g Schrägschnitt durch die Bindehaut: Basalmembran (*), Stroma (\#)

Die letzte technische Weiterentwicklung ist die online 2D-Rekonstruktion mit der Bildgröße von bis zu 3,2 $\times 3,2 \mathrm{~mm}$. Diese Technologie erlaubt die Beurteilung von ca. 1/7 der Hornhautfläche in einem Bild.

Die Strukturen der Bindehaut beinhalten Epithel mit Superfizial-, Intermediär- und Basalzellen. Es kann zwischen der bulbären und tarsalen Bindehaut unterschieden werden: die bulbäre Bindehaut hat ca. 8 Epithelschichten im Gegensatz zur tarsalen Bindehaut mit 2-3 Schichten. Unterhalb des Epithels befinden sich netzartig organisierte Fasern des Stromas, zwischen Epithel und Stroma liegt die Basalmembran. - Abbildung 1.8a-g präsentiert die Befunde eines Normalprobanden. I. d. R. können kleine intraepitheliale Zysten sowie Becherzellen nachgewiesen werden. Die in vivo Darstellung der Becherzellen ist besonders interessant bei fraglicher Stammzellinsuffizienz. 
Tab. 1.9 Konfokalmikroskopische Diagnostik der entzündlichen Zellen

\begin{tabular}{|l|l|l|l|l|l}
\hline Zellentyp & Größe & Charakteristika \\
\hline $\begin{array}{l}\text { Typ d. Leukozyten } \\
\text { Granulozyten }\end{array}$ & $<10 \mu \mathrm{m}$ & $\begin{array}{l}\text { Die kleinste Gruppe von Leukozyten, charakterisiert durch unregelmäßig gelappte } \\
\text { Zellkerne und das Vorhandensein kleiner Partikel im Cytoplasma - mit CLSM nicht } \\
\text { darstellbar. }\end{array}$ \\
\hline Monozyten & Ca. $20 \mu \mathrm{m}$ & $\begin{array}{l}\text { Vorläufer der Makrophagen im Blut, große runde Zellen, typische Lokalisation in den } \\
\text { Blutgefäßen der Bindehaut oder der vaskularisierten Hornhaut }\end{array}$ \\
\hline Makrophagen & $12-15 \mu \mathrm{m}$ & $\begin{array}{l}\text { Hyperreflektive entrundete Zellen, typischerweise sichtbar bei Ulzera bzw. Infiltration } \\
\text { im Hornhautepithel }\end{array}$ \\
\hline Lymphozyten & $10-12 \mu \mathrm{m}$ & $\begin{array}{l}\text { Hypererflektive Zellen, kleiner als Makrophagen, typische Lokalisation in palpebraler } \\
\text { oder tarsaler Bindehaut }\end{array}$ \\
\hline Langerhans-Zellen & $\begin{array}{l}\text { Hyperreflektive Zellen ohne Ausläufer (unreife Form) bzw. mit spinnenähnlichen } \\
\text { Ausläufer bis } \\
20-30 \mu \mathrm{m}\end{array}$ & $\begin{array}{l}\text { Ausläufern (reife Form). Reife LZ bilden mit benachbarten Zellen und Nervenfasern } \\
\text { teilweise netzartige Strukturen. }\end{array}$ \\
\hline
\end{tabular}

\section{Zelldifferenzierung mit der konfokalen Mikroskopie bei entzündlichen Augenerkrankungen}

Die konfokale Mikroskopie ermöglicht eine in vivo Zelldifferenzierung. Typischerweise befinden sich die Entzündungszellen in einer Tiefe von 50 bis $70 \mu \mathrm{m}$ in der Ebene der unteren Intermediärzellen und Basalzellen des Epithels, Bowman-Membran sowie Strukturen des SNP der Hornhaut. Die typischen Charakteristika der entzündlichen Zellen wurden in $\bullet$ Tab. 1.9 zusammengefasst.

\section{Infiltrat der Hornhaut}

Bei einem Infiltrat zeigen sich die regelmäßigen Hornhautstrukturen des Epithels und des Stromas mit einer Infiltration von entzündlichen Zellen in der Ebene der Basalzellen und des SNP. Die Leukozyten (vermutlich Makrophagen) präsentieren sich als hyperreflektive, entrundete Zellkörper mit ca. 10-12 $\mu \mathrm{m}$ Durchmesser (• Abb. 1.9a, - Abb. 1.10b). Die reifen Langerhans-Zellen (LZ) stellen sich als spinnenähnliche Zellen dar, die mit benachbarten Zellen und Nervenfasern teilweise netzartige Strukturen bilden (• Abb. 1.9b, • Abb. 1.10c).

\section{Hornhautulzera}

Hornhautulzera können gelegentlich nach Infektionen, Tragen von Kontaktlinsen oder bei trockenen Augen beobachtet werden. Bei einer Hornhautulzeration unterscheidet man eine progressive, eine regressive sowie eine Heilungsphase. In der progressiven Phase lassen sich Gewebedefekte zeigen (• Abb. 1.11a). Die in vivo konfokale Mikroskopie ermöglicht die Unterscheidung zwischen intakter Hornhaut und krankhaft verändertem Epithel bzw. Stroma. Ein Hornhautödem weist auf der Ebene des Epithels starke Veränderungen von Superfizial- und Intermediärzellen, mit gestreckten und vergrößerten Zellen, auf. In den stromalen Schichten zeigen sich eine inhomogene Verteilung der Keratozyten und sichtbare Zellausläufer. Ein Polymorphismus des Endothels ist ebenfalls oft vorhanden. Bei einem ausgeprägten Befund besteht auch eine Epithel- sowie Gesamthornhautdickenzunahme. Unter der Epitheldicke verstehen wir den Abstand zwischen Superfizialzellen des Epithels und dem SNP. Die Epithelsowie die Gesamthornhautdicke können sich bei einem Hornhautödem verdoppeln. Bei diesen Patienten zeigt sich eine entzündliche Infiltration des Epithels sowie der Bindehaut mit Leukozyten und LZ. Letztere präsentieren sich entweder als große Zellen mit langen Dendriten oder als kleinere Zellen ohne Dendriten, die entsprechend als reife bzw. unreife Formen der LZ interpretiert werden können.

Während der regressiven Phase ist die entzündliche Infiltration rückläufig, die Gewebedefekte werden kleiner (• Abb. 1.11b). Die Heilungsphase ist mit einer Basalzellproliferation und dem Ersatz der BowmanMemran durch fibrosiertes Gewebe charakterisiert. Im Verlauf kann eine stromale sowie eine epitheliale Regeneration der Kornea mit entstehenden Narben nachgewiesen werden (• Abb. 1.11c-e). Die konfokale Mikroskopie erlaubt die Beurteilung des Ausmaßes der entzündlichen Infiltration im Verlauf bis hin zur kompletten Rückbildung.

\section{(Erregerbezogene) Differentialdiagnose der Keratitis}

Multiple exogene und endogene Ursachen können zu einem Epitheldefekt der Hornhaut und bei Progression zum Ulkus führen. Konfokalmikroskopisch lassen sich Hornhautulzera verschiedener Ätiologie unterscheiden: bakterielle, mykotische und durch Protozoen (Akanthamöben) bedingte (• Abb. 1.9a-e). 

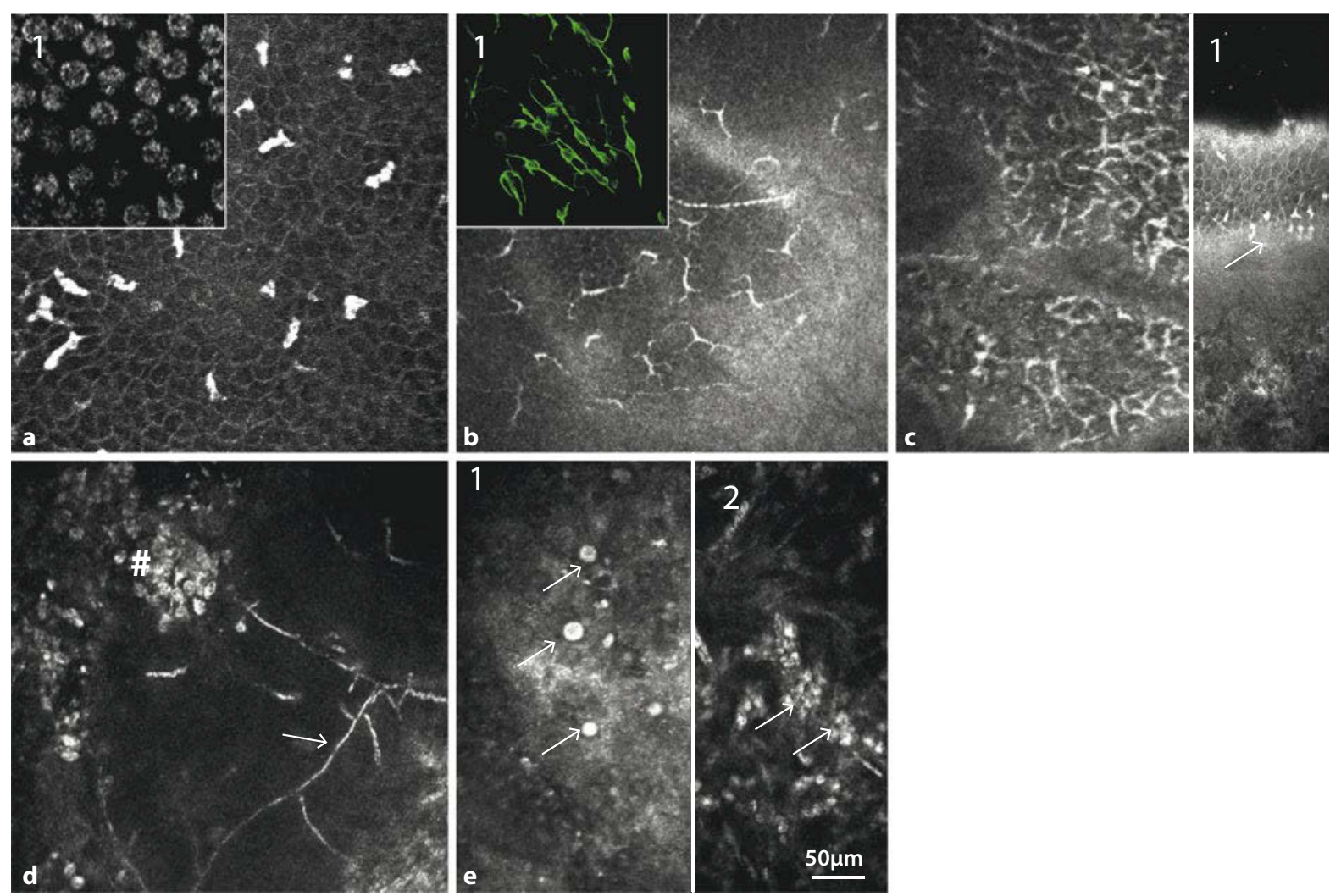

- Abb. 1.9a-e Zelldifferenzierung mit der in vivo konfokalen Mikroskopie. a Leukozyten: speckige hyperreflektive Zellen (ca. 12-15 $\mu \mathrm{m}$ ) ohne Ausläufer, vermutlich Makrophagen, (1) konfokale Mikroskopie vom Leukozyten im Blutausstrich. b Langerhans-Zellen: große Zellen (Zellkörper ca. $10 \mu \mathrm{m}$ ) mit langen Dendriten bis 15-20 $\mu \mathrm{m}$ im Hornhautepithel; (1) Darstellung mit Vimentin. c konfokalmikroskopische Darstellung der viralen Keratitis: eine genaue Differenzierung zwischen SNP-Strukturen und entzündlichen Zellen (Leukozyten, Langerhans-Zellen) ist nicht möglich. (1) Schrägschnitt durch das Epithel, die Bowman-Membran und das anteriore Stroma zeigt die Ansammlung von entzündlichen Zellen (Pfeil). d hyperreflektive Pilzhyphen im mittleren Stroma (Pfeil) begleitet mit massiver leukozytärer Infiltration des Stromas (\#). e Akanthamöben: (1) typische doppelwandige Zysten mit ca. 20 um Durchmesser innerhalb des Stromas (Pfeil), (2) zum Vergleich die Infiltration mit Leukozyten (Granulozyten) als Zeichen einer schweren Entzündung beim gleichen Patienten (Pfeil). (Modifiziert nach Zhivov 2006)


- Abb. 1.10a-c Infiltrat der Hornhaut. a,b Konfokalmikroskopische Bilder im Zentrum des Infiltrates (a) und am Übergang von intakter Hornhaut zum Infiltrat (b), massive Infiltration mit entzündlichen Zellen. c Mapping des Epithels: schräg angeschnittenes Infiltrat (Linie) mit angrenzender Infiltration von entzündlichen Zellen (Pfeil). (Modifiziert nach Zhivov 2008) 

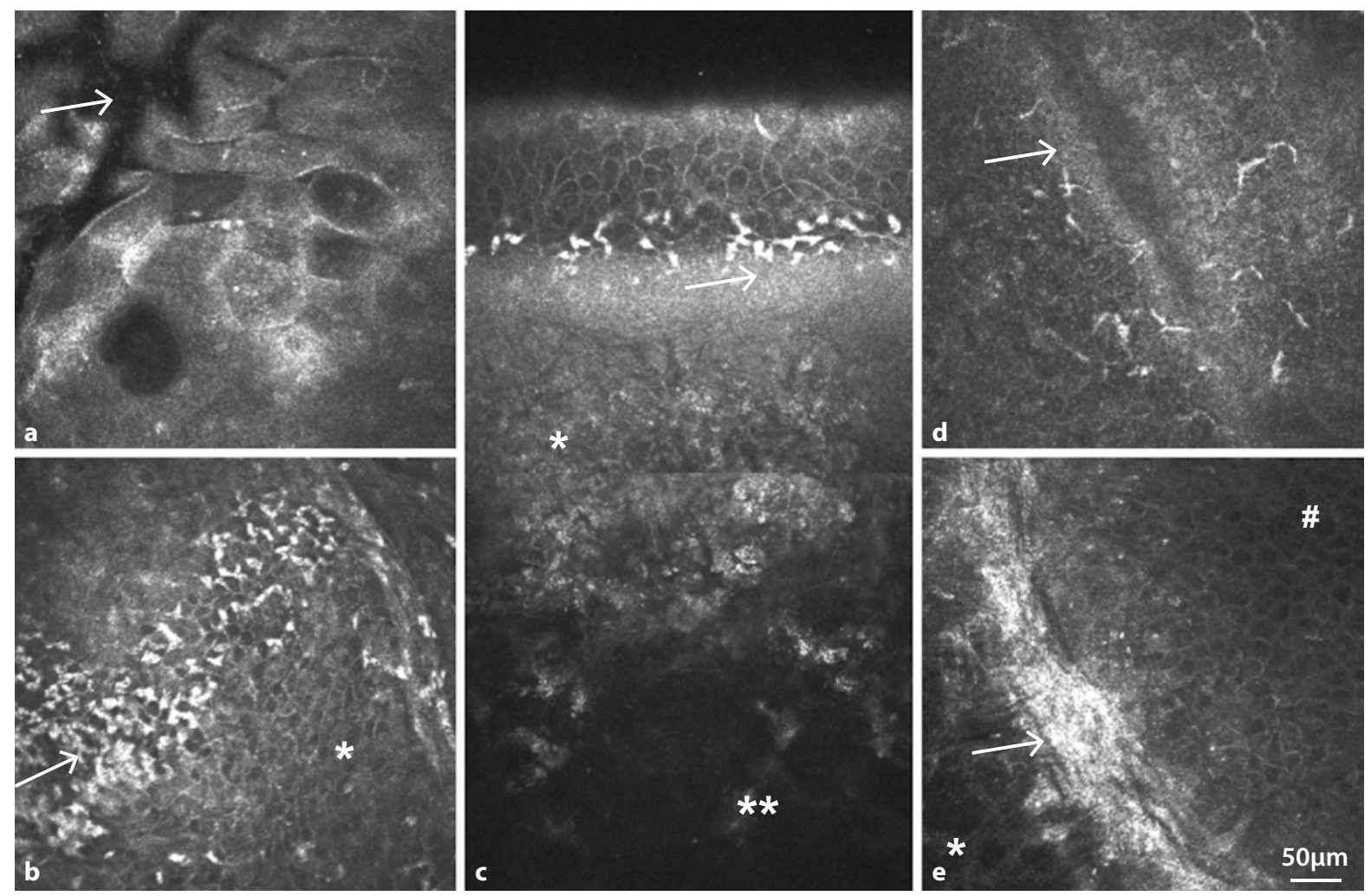

- Abb. 1.11a-e Phasen der Entwicklung und Heilung des Hornhautulkus. a,b Progressive Phase: massive Schwellung im Epithel und Stroma: a deutlich ödematöse Superfizialzellen, Grenze des Ulkus (Pfeil); b ödematöse Intermediär- und Basalzellen $(*)$, Infiltration mit entzündlichen Zellen (Langerhans-Zellen und Leukozyten) (Pfeil). c,d Regressive Phase: c Rekonstruktion eines Querschnittes: dezente Schwellung des Epithels, inflammatorische Zellen in der SEP-Ebene, Narbenbildung $\left({ }^{*}\right)$, intaktes Stroma ${ }^{* *}$ ); d Ulkusrand (Pfeil) mit entzündlicher Infiltration. e Heilungsphase, Ulkusrand. Intaktes Stroma mit regelrechtem Keratozytenmuster $\left(^{*}\right)$, Ulkusrand (Pfeil) und neue Flügelzellen (\#) sind dargestellt. Keine entzündlichen Zellen mehr sichtbar. Tiefenunterschied zwischen Stroma $\left(^{*}\right)$ und Flügelzellen (\#) ca. $40 \mu$ m. (Abbildung aus Zhivov 2008)

Bei einem bakteriellen Ulkus zeigt sich ein typischer hyperreflektiver Defekt ohne erkennbare Strukturen auf dem Ulkusboden (vergleichbar mit • Abb. 1.10a). Am Ulkusrand sieht man die Übergangszone mit geschwollenem Epithel. Die Ebene der Basalzellen und des SNP ist mit inflammatorischen Zellen (Leukozyten und dendritischen Zellen) infiltriert (- Abb. 1.9a,b). Die Bakterien selbst lassen sich nicht darstellen. Mykotische Ulzera weisen typischerweise hyperreflektive Pilzhyphen auf (• Abb. 1.9d). Laut Literatur ist eine Differentialdiagnostik zwischen Fusarium solani und Hefen möglich. • Abbildung 1.12a,b präsentiert zwei klinische Fälle mit hyperreflektiven netzartigen Pilzhyphen, deren Morphologie den Charakteristika der Gattung Fusarium solani entspricht.

(7) Mittels in vivo konfokaler Mikroskopie ist auch ein direkter Nachweis von Akanthamöbenzysten möglich.

Diese präsentieren sich als doppelwandige Zysten mit ca. $20 \mu \mathrm{m}$ Durchmesser (• Abb. 1.9e). Ein klinischer Fall ist in - Abb. $1.12 c$ dargestellt. Die Pilzhyphen sowie
Akanthamöbenzysten befinden sich typischerweise im Stroma der „intakten Hornhaut“, da die Mikroskopie im Ulkusbereich nur das hyperreflektive Gewebe des Ulkusgrundes darstellt (• Abb. 1.10a).

\section{(7) Es ist empfehlenswert zuerst den Rand des Defektes (Infiltrat, Ulkus etc.) darzustellen, die Tiefe anzupas- sen und danach langsam die „intakte Hornhaut" zu mikroskopieren.}

\section{Aktivierte Keratozyten}

Der Prozess der Wundheilung der Hornhaut ist ein komplexer biologischer Reparaturvorgang, bei dem eine Vielzahl von Zellen, Zytokinen, Wachstumsfaktoren, Proteasen und extrazelluläre Matrixbestandteile zusammenwirken, um die Integrität des Gewebes wiederherzustellen (28). Bei Verletzungen/Entzündungen des Stromas sterben Keratozyten ab (Apoptose), und Keratozyten in der Umgebung werden aktiviert.

Im Tierversuch wurden die aktivierten Keratozyten als langgestreckte, nadelartige Strukturen identifiziert. Die Mikroskopie der humanen Hornhaut zeigte ähnliche 

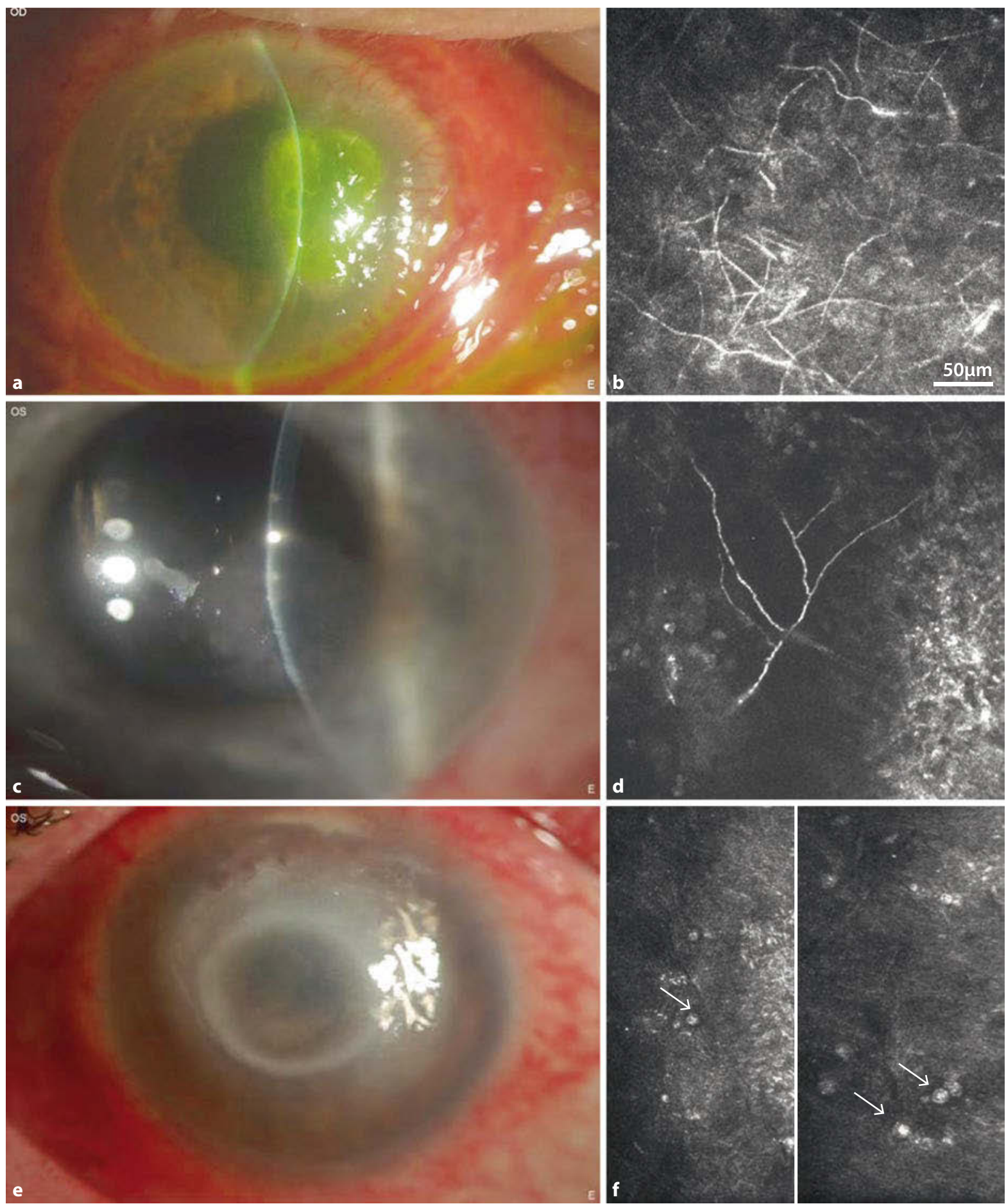

- Abb. 1.12a-f Klinische Fälle der HH-Ulzera verschiedener Genese. (Fall 1) Patientin L, 88 J. mit traumatischer Erosio der Hornhaut und anschließender Heilungsverzögerung. Es erfolgte eine Hornhautabrasio, 3 Tage post-op. zunehmende Sehverschlechterung auf HBW, deutliche Schmerzen (a). Konfokalmikroskopisch (b) zeigten sich hyperreflektive Pilzhyphen im vorderen und mittleren Stroma. Die histologische Untersuchung ergab einen Pilzbefall mit Fusarium solani. (Fall 2) Patient V, 53 J., Erstvorstellung bei Z. n. Hornhaut-Fremdkörper-Entfernung durch Hausarzt vor 1 Woche, Sehverschlechterung seit 3 Tagen auf 0,5 (c). Die konfokale Mikroskopie ergab einen Pilzbefall (netzartige hyperreflektive Hyphen) vergleichbar mit Fall 1 (d). (Fall 3) Patientin K, 45 J., Kontaktlinsenträgerin. Schmerzen seit 2 Wochen, Visus 0,05 (e). Konfokalmikroskopisch fanden sich typische Zysten (doppelwandig, Größe ca. 20 m, Pfeil) im vorderen Stroma (f). (Mit freundlicher Genehmigung von Dr. Falke/ Rostock) 



- Abb. 1.13a-d Konfokalmikroskopische Darstellung der aktivierten Keratozyten. (Fall 5) Patient M, 40 J. mit Verätzung durch Pflanzenflüssigkeit. Nach anfänglich aufgetretener Hornhautstippung zeigten sich spaltlampenmikroskopisch persistierende zarte Trübungen im Stroma (a). Konfokalmikroskopisch fanden sich bei intaktem Epithel langgestreckte, nadelartige Keratozyten im vorderen und mittleren Stroma (b). Sie bestanden auch noch nach 4 Monaten, jedoch in reduzierter Ausprägung. (Fall 6) Patient S, 56 J, rezidivierende Herpes-Simplex-Keratitis seit 1989. (c) Subepitheliale Narbenbildung korreliert mit konfokalmikroskopisch darstellbaren nadelartig veränderten Keratozyten (d). (Mit freundlicher Genehmigung von Dr. Falke/Rostock)

Befunde (• Abb. 1.13) (Falke, akzeptiert). Diese nadelartigen, langgestreckten Keratozyten (wie bei Z. n. Verätzung (• Abb. 1.13a,b) persistieren über Monate. Ähnliche morphologische Veränderungen findet man nach abgelaufener Entzündung (• Abb. 1.13c,d).

Interessanterweise wurden solche Strukturen ebenfalls nach Quervernetzung beschrieben. Unsere experimentellen Ergebnisse zeigen sternartig konfigurierte Keratozyten im behandelten vorderen und mittleren Stroma bei Z.n. Quervernetzung. Histochemische Untersuchungen im Tiermodel wiesen keine vitalen Keratozyten (Apoptose) ohne Anfärbung der Zellkerne mit DAPI (4',6-Diamidin-2-phenylindol) oder PI (Propidiumiodid) im vorderen und mittleren Stroma nach. Diese Zellen waren negativ für $\alpha$-SmoothMuscle-Actin. Eine Mitoseaktivität (Ki-67-positiv) wurde nur im hinteren Stroma, im Epithel der behandelten Zone sowie im intakten angrenzenden Stroma nachgewiesen. Es handelt sich um eine Transformation der Keratozyten in Myofibroblasten, die positiv für $\alpha$-Smooth-Muscle-Actin sind. Ähnliche Ergebnisse wurden auch in humaner Hornhaut nachgewiesen (• Abb. 1.14a-e). Nach Hassel et al. sind aktivierte Keratozyten Myofibroblasten mit einer sehr höheren Zelldichte und niedrigem Prozentsatz an extrazellulärer Matrix (EZM). Anschließend wird die Zelldichte der Myofibroblasten niedriger mit gleichzeitig erhöhter Produktion der EZM. Die schlechte Hornhauttransparenz ist durch erhöhte Hyaluronsäure- und Biglykanproduktion erklärt. Eine andere Fibroblastengruppe (wound fibroblast) produziert Kollagen sowie Proteoglykane, sodass eine EZM mit dicht gepackten Kollagenfasern entsteht, und die Hornhaut wieder an Transparenz zunimmt. Die Korrelation zwischen der Hornhauttransparenz und Vorhandensein aktivierter Keratozyten in der konfokalen Mikroskopie sollte in weiteren Studien geklärt werden.

Zusammenfassung Die konfokale in vivo Mikroskopie stellt mikromorphologische Veränderungen auf zellulärer Ebene dar, die zur Beurteilung pathologischer Veränderungen, der Defektgeometrie sowie des Heilungsverlaufes der Hornhaut von klinischem Interesse sind. Die nichtinvasive in vivo Differentialdiagnostik im Frühstadium, insbesondere bei mykotischen und durch Akanthamöben verursachte Prozesse, erlaubt eine frühere und effektive Behandlung des Krankheitsbildes. 

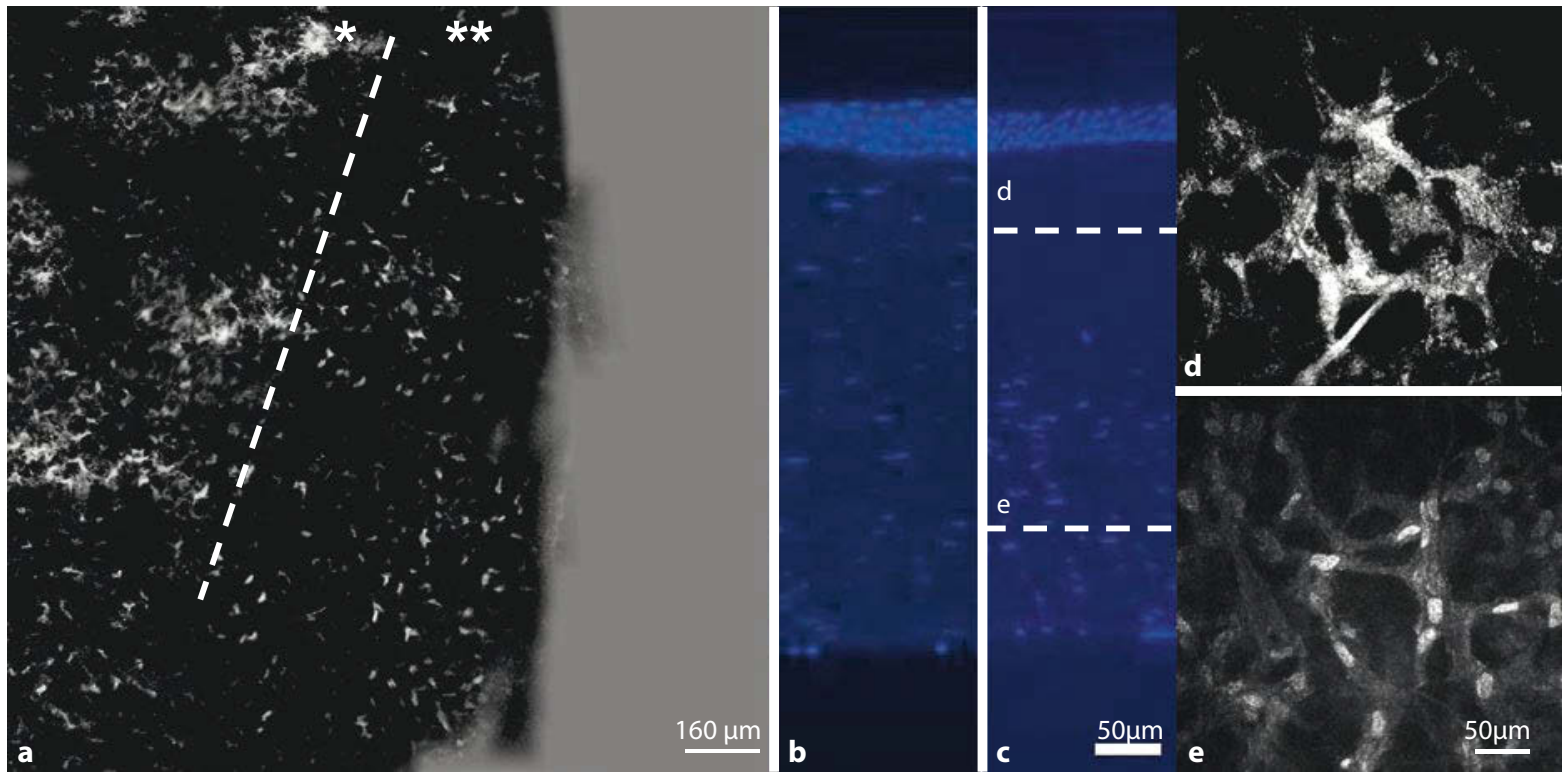

- Abb. 1.14a-e Konfokalmikroskopische und histochemische Veränderungen der Hornhaut bei Z.n. Quervernetzung. a Z.n. Quervernetzung, 2 Mo. Post-op: $\left({ }^{*}\right)$ quervernetztes und $\left({ }^{* *}\right)$ intaktes Stroma (Tiefe $\left.240 \mu \mathrm{m}\right)$. b, c Darstellung des intakten (b) und quervernetzten Stromas (c) mit DAPI. Das Epithelium ist regelrecht, keine darstellbaren Keratozyten im vorderen und mittleren Stroma (bis ca. 300 $\mu \mathrm{m}$ Tiefe), regelrechte Struktur der Keratozyten im hinteren Stroma. $\mathbf{d}$ typische hyperreflektive Strukturen des quervernetzten Stromas. e intaktes Stroma mit hyperreflektiven Keratozytenkernen

\subsection{Therapie: Grundkonzepte/Prinzipien}

\subsubsection{Antiinfektive Therapie bei Konjunktivitis und Keratitis (engl. conjunctivitis, keratitis, therapy)}

A. Kramer, O. Assadian, U. Pleyer

\section{Kriterien für die Entscheidung Antiseptik oder Chemotherapie}

(7) Kritische Vorbemerkung

Chemotherapie oder Antiseptik? Sofern der Entzündung von Konjunktiva und Kornea eine Infektion zugrunde liegt, ist erregerabhängig eine antibakterielle, antifungielle, antivirale oder amöbozide Therapie indiziert. Die Entscheidung zwischen Chemotherapie oder Antiseptik wird von der Tiefe der Infektion bestimmt. I. d. R. ist bei superfizieller Infektion die lokale Behandlung mit Antiseptika oder mit nicht resorbierbaren Antibiotika (sog. Lokalantibiotika) indiziert, weil durch lokale Applikation höhere Konzentrationen als bei systemischer Gabe erzielt werden. Bei intraokularer Beteiligung und Ausbreitung auf dem Blut-Lymph-Weg können zusätzlich antimikrobielle Chemotherapeutika oral oder parenteral eingesetzt werden.
Bei superfizieller Infektion ist mit wenigen Ausnahmen die lokale Anwendung von Chemotherapeutika wegen des Resistenzdrucks auf Bakterien kontraindiziert. Aber auch bei Lokalantibiotika kann die Resistenzentwicklung mit einer Kreuzresistenz zu systemisch eingesetzten Antibiotika verbunden sein und bei längerer Anwendung zum Therapieversagen führen.

Im Unterschied dazu ist für Antiseptika wie PVP-Iod und Polihexanid keine Resistenzentwicklung nachgewiesen und auf Grund des Wirkungsmechanismus nicht $\mathrm{zu}$ erwarten. Daher wurde in der Wundantiseptik die Anwendung von Lokalantibiotika zugunsten wirksamerer und gewebeverträglicherer Antiseptika verlassen. Abweichend von der Entwicklung in der Wundantiseptik besteht in der Ophthalmologie Bedarf für Therapiestudien zum direkten Vergleich von Antiseptika und Lokalantibiotika.

Aufgrund der derzeit nur spärlichen Datenlage ist die Evidenz für die Wirkstoffauswahl zur Antiseptik am Auge limitiert. Bei der Abwägung zwischen Antiseptika oder Lokalantibiotika ist zu berücksichtigen, dass die mikrobiozide Wirksamkeit von Antiseptika ein entscheidender Vorteil gegenüber Lokalantibiotika ist. Antiseptika sollen im quantitativen Suspensionstest und auf Prüfkörpern gegenüber $S$. aureus, E. faecalis, $P$. aeruginosa und C. albicans unter Belastung mit 4,5\% Albumin, $4.5 \%$ Blut und $1 \%$ Muzin eine Abtötung $>3 \log 10$ herbeiführen. Die therapeutische Eignung muss in Phase 2- und 3-Prüfungen (möglichst als RCT) ermittelt werden. Bei der Aus- 


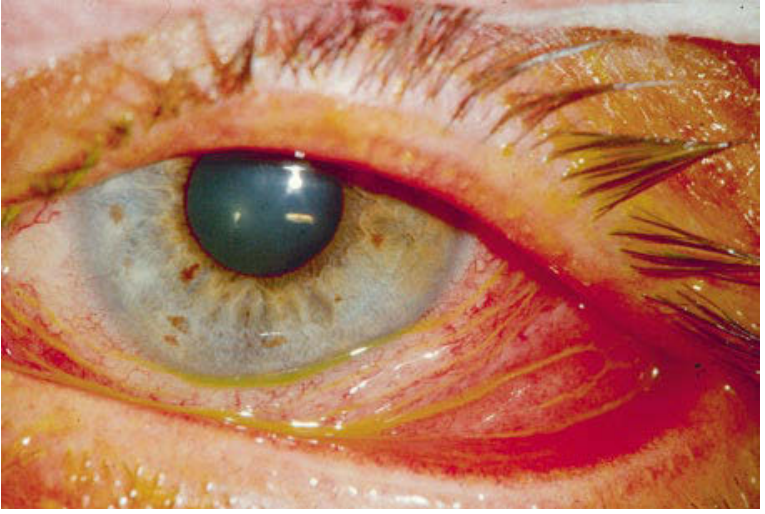

- Abb. 1.15 Akute bakterielle Konjunktivitis

wahl von Antiseptika ist zu beachten, dass abhängig vom Wirkungsmechanismus auch hier die Möglichkeit der R-Plasmid codierten Resistenzentwicklung mit Kreuzresistenzen gegenüber Antibiotika besteht, z. B. bei Chlorhexidin. Entgegen der z. T. noch anzutreffenden Annahme, die sich aus den Eigenschaften der vor der Einführung von PVP-Iod angewendeten Antiseptika einschließlich Silbernitrat ableitet, unterscheidet sich die Reizwirkung moderner Antiseptika wie Polihexanid und PVP-Iod in antiseptisch wirksamer Verdünnung nicht von Tetracyclin, Gentamycin und Neomycin bzw. sie ist sogar geringer. Auch die allergene Potenz ist geringer bzw. fehlend. Daher hat sich die präventive Anwendung xenobiotischer anstelle antibiotischer Antiseptika in der Ophthalmologie bereits zur präoperativen Antiseptik, MRSA-Sanierung, Dekontamination von Hornhautspendematerial, Credéschen Prophylaxe und als Sofortmaßnahme bei akzidenteller Kontamination durchgesetzt.

\section{Therapie der Konjunktivitis Akute bakterielle Konjunktivitis}

( Die akute bakterielle Konjunktivitis sollte wegen der zunehmenden Resistenzentwicklung zunächst ohne Antibiotika behandelt werden, da es bei bis zu $64 \%$ der Patienten auch ohne Antibiotikumgabe innerhalb von 5 Tagen zur Heilung kam. Erst wenn sich die Beschwerden innerhalb von 3-4 Tagen nicht mit Tränenersatzflüssigkeit und morgendlichen Augenreinigungen lindern lassen, sollte die antibiotische Gabe zur Linderung der Beschwerden und Verkürzung der Erkrankungsdauer begonnen werden. Für Erwachsene werden zunächst Gentamycin, Tobramycin oder Azithromycin empfohlen. Fluorchinolone und Ciprofloxacin sollen als Reserve-Antibiotika schweren Krankheitsverläufen vorbehalten bleiben. Für Neugeborene ist Moxifloxacin, für Kinder ab dem zweiten Lebensjahr Azithromycin Mittel der Wahl.

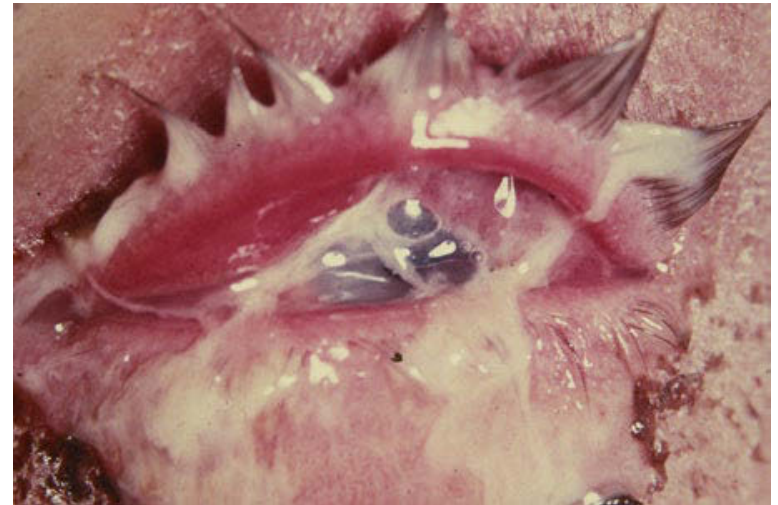

- Abb. 1.16 Hyperakute Konjunktivitis

Eine additive antientzündliche Therapie wird generell nicht empfohlen.

Typisch für die akute bakterielle Konjunktivitis ist das rote Auge mit mukopurulenter Sekretion und Chemosis, z. T. mit Brennen, Jucken, verstärktem Tränenfluss oder Fremdkörpergefühl (• Abb. 1.15). Häufigste Erreger sind S. aureus, S. epidermidis, S. pneumoniae, M. catarrhalis, Corynebacterium spp, H. influenzae (häufigster Erreger im Kindesalter) und Gram-negative Darmbakterien.

Aufgrund der deutlich besseren Studiendatenlage gelten Lokalantibiotika anstatt Antiseptika bei akuter bakterieller Konjunktivitis nach wie vor als Standard, wobei die Auswahl von der Ätiologie, Anwenderfreundlichkeit, Nebenwirkungen und Preis bestimmt wird. Zur Erreichung optimaler Wirkstoffspiegel werden die Lider nach Tropfenapplikation geschlossen gehalten. Bei negativem Erregernachweis oder Persistenz bzw. Zunahme der Symptomatik sollen Abstrich und Resistogramm wiederholt werden. Bekannte Allergie ist eine Kontraindikation.

In begrenztem Umfang wird auch PVP-Iod angewendet. Bibrocathol ist wegen der geringen in vitro-Wirksamkeit nicht als Antiseptikum einzustufen. Sulfonamide sind wegen ihrer Sensibilisierungspotenz obsolet.

\section{Hyperakute bakterielle Konjunktivitis}

Die hyperakute Form ist charakterisiert durch reichlich eitriges Sekret, Schmerzen und ausgeprägte okuläre Entzündung (• Abb. 1.16). Zur Klärung der Ätiologie sind Bindehautabstriche obligat. Bei hyperakuter Konjunktivitis ist die lokale antibiotische Therapie obligat; bei N.gonorrhoae werden Cephalosporine der 3. Generation oder Gyrasehemmer empfohlen.

\section{Chronische bakterielle Konjunktivitis}

Bei der chronischen Verlaufsform erscheint die Oberfläche ohne Chemosis aufgeraut. Typisch ist der chronisch rezidivierende Verlauf. Chronische Konjunktivitiden 
können mit Keratitis punctata superficialis und Hornhautrandinfiltraten assoziiert sein. Typische Erreger sind Koagulasepositive und -negative Staphylokokken. Bei Trägern weicher Kontaktlinsen dominieren Gram-negative Bakterien mit $P$. aeruginosa an der Spitze. Es ist auch eine MRSA-Infektion in Betracht zu ziehen, insbesondere bei Altenheimbewohnern. Sie muss vor geplanten chirurgischen Eingriffen innerhalb des Sanierungskonzepts zur MRSA-Dekontamination behandelt werden. Die chronisch rezidivierende follikuläre Konjunktivitis ist typisch für eine Einschlusskörperchenkonjunktivitis, verursacht durch $C$. trachomatis, und erfordert eine Chlamydiendiagnostik. Häufigste Manifestation ist die Ophthalmia neonatorum, die sich klinisch von der selteneren Gonoblennorhoe nicht unterscheidet (• Abb. 1.17). Letztere tritt meist $2-5 \mathrm{~d}$ post partum, die Chlamydienkonjunktivitis dagegen häufig erst nach der 2. Lebenswoche auf. Beim Erwachsenen ist der Verlauf nicht so schwer, aber dennoch häufig chronisch mit diskreten Hornhautinfiltrationen. Die Übertragung erfolgt durch Schmierinfektion, sexuellen Kontakt oder im Schwimmbad (sog. Schwimmbadkonjunktivitis).

Bei chronisch rezidivierender follikulärer Konjunktivitis durch $C$. trachomatis Serotypen $D-K$ ist die systemische Antibiose indiziert, weil andernfalls die Erreger während der intrazellulären Replikation nicht erreicht werden. Außerdem können sie im Bereich des Pharynx lokalisiert sein und von dort die Infektion unterhalten. In Absprache mit dem Gynäkologen/Hausarzt ist ggf. die Mitbehandlung des Lebenspartners bzw. der Familie erforderlich, um die Infektionsquelle zu eliminieren. Mittel der Wahl ist Azythromycin oral $500 \mathrm{mg} / \mathrm{d}$ x $3 \mathrm{~d}$ (manche Patienten benötigen mehr als einen Behandlungszyklus) bzw. bei schlechter Compliance einmalig $1 \mathrm{~g} / \mathrm{d}$ (Wirkspiegel für 14 d). Bei Kindern kann die Dosis gewichtsangepasst reduziert werden. Ist Azithromycin nicht verfügbar, z. B. in Entwicklungsländern, oder besteht Unverträglichkeit, kommen Doxycyclin $(2 \times 100 \mathrm{mg} / \mathrm{d} 3$ Wochen, kontraindiziert in der Gravidität), Cotrimoxazol, Tetrazykline oder Erythromycin in Frage. Wegen der z. T. beträchtlichen Nebenwirkungen ist häufig keine zuverlässige Einnahme gewährleistet. Auch Chlarothromycin, Levofloxacin and Ofloxacin (beide kontraindiziert in der Gravidität) erreichen hohe intrazelluläre Konzentrationen und sind daher wirksam. Zur Prophylaxe der Ophthalmia neonatorum ist PVP-Iod wegen der hohen Wirksamkeit gegen C. trachomatis Mittel der Wahl.

Weder für die akute bakterielle Konjunktivitis noch für die Chlamydienkonjunktivitis ist durch zusätzliche antientzündliche Therapie mit Kortikosteroiden bzw. nicht steroidalen Antiphlogistika eine Therapieverbesserung beschrieben.

Kurzcharakteristik ausgewählter Wirkstoffe (• Tab. 1.10):

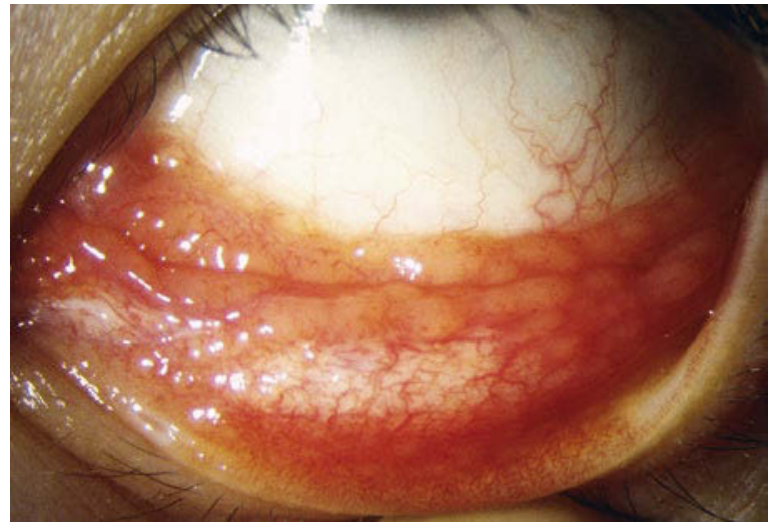

- Abb. 1.17 Durch Chlamydien verursachte chronisch rezidivierende follikuläre Einschlusskörperchenkonjunktivitis

Azithromycin Wirksam gegen $H$. influenzae, S. pneumoniae, S. aureus und Chlamydien, nicht gegen MRSA; Anwendung $1 \% 2 \times / d$ für $3 \mathrm{~d}$ - zur Behandlung der trachomatösen Konjunktivitis fehlen Studien zur Sicherheit und Wirksamkeit bei Kindern unter 1 Jahr, aber es sind keine Aspekte bekannt, die eine Anwendung bei Kindern unter 1 Jahr bei dieser Indikation ausschließen; gestützt auf den internationalen Konsensus zu Erkrankungen des Auges und des Genitaltrakts, die auf Neugeborene übertragen werden können, erfordert die durch C. trachomatis verursachte nicht-trachomatöse Konjunktivitis sowie die durch N. gonorrhoeae verursachte Konjunktivitis eine systemische Behandlung. Bei Neugeborenen und Kleinkindern unter 3 Monaten kann eine durch C. trachomatis hervorgerufene systemische Infektion gleichzeitig mit einer Konjunktivitis bestehen. Bei dringendem Verdacht ist eine systemische Behandlung notwendig. Diese Behandlung ist nicht zur prophylaktischen Anwendung bei bakterieller Konjunktivitis bei Neugeborenen vorgesehen.

Bacitracin Mit Ausnahme von Neisseria spp. und $H$. influenzae nur gegen Gram-positive Bakterien wirksam, langsame Resistenzentwicklung ohne Kreuzresistenz zu anderen Antibiotika, häufig Kontaktsensibilisierung, Anwendung nur noch in Kombination z. B. mit Neomycin und Polymyxin B.

Chloramphenicol Breitspektrumantibiotikum einschließlich sporenlose Anaerobier, Chlamydien, Mykoplasmen; unwirksam gegen Mykobakterien, Nocardien, P. aeruginosa; bei akuter infektiöser Konjunktivitis keine therapeutische Überlegenheit zu Plazebo; aufgrund des wenn auch bei lokaler Anwendung sehr geringen Risikos aplastischer Anämie, Panzytopenie, Leukopenie, Thrombozytopenie und Agranulozytose Anwendung am Auge nur vertretbar, wenn kein anderes Antibiotikum/Antiseptikum wirksam ist. 
- Tab. 1.10 Merkmale von zur Konjunktivitisbehandlung lokal eingesetzten Antibiotika

\begin{tabular}{|c|c|c|c|c|c|c|c|c|}
\hline \multirow[t]{2}{*}{ Antibiotikum } & \multicolumn{3}{|c|}{ Gram-positiv } & \multicolumn{4}{|c|}{ Gram-negativ } & \multirow[t]{2}{*}{ Nebenwirkungen } \\
\hline & \multicolumn{2}{|c|}{ MSSA, MRSA } & $\begin{array}{l}\text { S. pneumo- } \\
\text { niae }\end{array}$ & $\begin{array}{l}\text { H. influ- } \\
\text { enzae }\end{array}$ & $\begin{array}{l}\text { P. aerugi- } \\
\text { nosa }\end{array}$ & $\begin{array}{l}\text { Entero- } \\
\text { coccus }\end{array}$ & $\begin{array}{l}\text { C. tracho- } \\
\text { matis }\end{array}$ & \\
\hline Azithromycin & + & $\mathrm{R}$ & + & + & $(+)$ & + & + & $\begin{array}{l}\text { Jucken, Brennen, Ste- } \\
\text { chen, verschwommenes } \\
\text { Sehen, klebriges Gefühl } \\
\text { im Auge, Fremdkörper- } \\
\text { gefühl, Allergie }(<0,1 \%)\end{array}$ \\
\hline Bacitracin & + & $\mathrm{R}$ & + & + & $\mathrm{R}$ & $\mathrm{R}$ & $\mathrm{R}$ & Allergie \\
\hline $\begin{array}{l}\text { Chloramphe- } \\
\text { nicol }\end{array}$ & + & $\mathrm{R}$ & + & + & $\mathrm{R}$ & + & + & Knochenmarktoxizität \\
\hline Ciprofloxacin & + & + & + & + & + & + & $(+)$ & $\begin{array}{l}\text { Verschwommenes } \\
\text { Sehen, Photosensibili- } \\
\text { sierung }\end{array}$ \\
\hline $\begin{array}{l}\text { Tetracycline/ } \\
\text { Doxycyclin }\end{array}$ & + & $\mathrm{R}$ & + & + & + & + & + & Allergie $(<0,1 \%)$ \\
\hline Erythromycin & $(+)$ & $\mathrm{R}$ & + & $\mathrm{R}$ & $\mathrm{R}$ & $\mathrm{R}$ & + & Allergie $(<1 \%)$ \\
\hline Fusidinsäure & + & + & $(+)$ & $\mathrm{R}$ & $\mathrm{R}$ & $\mathrm{R}$ & $\mathrm{R}$ & Augenbrennen \\
\hline $\begin{array}{l}\text { Gentamycin/ } \\
\text { Tobramycin }\end{array}$ & + & $\mathrm{R}$ & $\mathrm{R}$ & + & + & + & $\mathrm{R}$ & Keratitis, Allergie \\
\hline Gramicidin & + & $\mathrm{R}$ & + & $\mathrm{R}$ & $\mathrm{R}$ & $\mathrm{R}$ & $\mathrm{R}$ & $\begin{array}{l}\text { Jucken, Brennen, Rötung } \\
\text { oder Schwellung des Lids } \\
\text { (in Komb. mit Neomycin) }\end{array}$ \\
\hline $\begin{array}{l}\text { Levofloxacin, } \\
\text { Moxifloxacin }\end{array}$ & + & $\mathrm{R}$ & + & + & + & + & + & $\begin{array}{l}\text { Leichte Augenreizungen, } \\
\text { Fremdkörpergefühl, } \\
\text { Allergie }\end{array}$ \\
\hline Neomycin & $(+)$ & $\mathrm{R}$ & $\mathrm{R}$ & + & $\mathrm{R}$ & + & $\mathrm{R}$ & Allergie \\
\hline Rifampicin & + & + & + & + & $\mathrm{R}$ & $\mathrm{R}$ & + & Allergie \\
\hline $\begin{array}{l}\text { Polymyxin B/ } \\
\text { Colistin }\end{array}$ & $\mathrm{R}$ & $\mathrm{R}$ & $\mathrm{R}$ & $\mathrm{R}$ & + & $(+)$ & $\mathrm{R}$ & Allergie \\
\hline Trimethoprim & + & + & $(+)$ & + & $\mathrm{R}$ & + & $\mathrm{R}$ & Allergie \\
\hline
\end{tabular}

Chlortetracyclin und Oxytetracyclin Wirksam gegen die meisten Gram-negativen und Gram-positiven Kokkenbakterien, H. influenzae, K. pneumoniae, Enterobacter, Proteus spp., E. coli, E. faecalis, P. aeruginosa, Spirochäten, Leptospiren, Rickettsien, Aktinomyzeten, Mykoplasmen, Chlamydien und Entamoeba spp.; Kreuzresistenz innerhalb der Tetracycline; werden bei topischer Anwendung (Salbe) nur wenig resorbiert, erreichen hohe Konzentration in Tränenflüssigkeit und Kammerwasser.

Erythromycin Wegen des schmalen Wirkungsspektrums (Staphylococcus, Streptococcus spp., C. trachomatis) und Resistenzzunahme kaum noch im Einsatz.

Gentamicin und Tobramycin Wirksam gegen Staphylococcus spp., Gram-negative Enterobakterien, P. aeruginosa; wenig sensibel oder resistent sind MRSA, Streptokokken und Anaerobier; 3-4mal stündlich für 7-10 d; bei häufiger Anwendung Risiko von Keratitis punctata superficialis und Allergie.

Gramicidin Wirksam nur gegen Gram-positive Kokkenund Stäbchenbakterien, Anwendung nur noch in Kombination z. B. mit Neomycin und Polymyxin B.

Fusidinsäure Wirksam gegen Staphylococcus spp. (auch Penicillinase bildende und z. T. MRSA), Streptococcus spp. sind schwach empfindlich, Gram-negative Bakterien sind resistent.

Kanamycinsulfat Wegen geringer bzw. erregerabhängig fehlender Wirksamkeit und toxischer Risiken entbehrlich. 


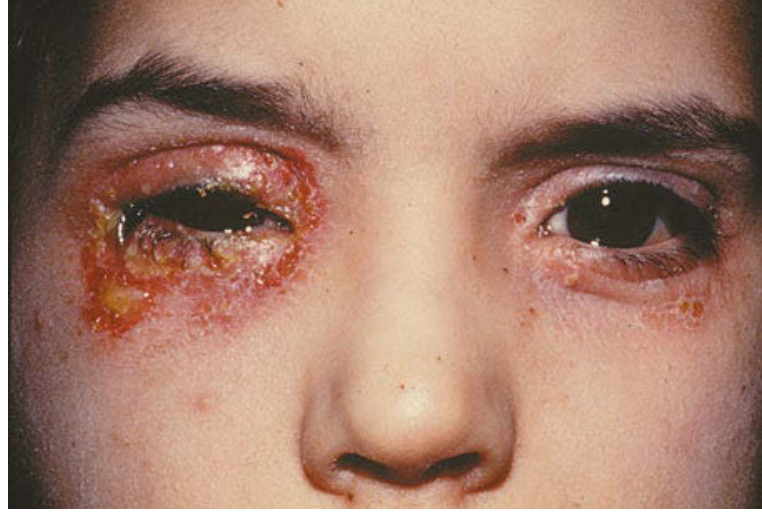

- Abb. 1.18 Durch Herpesviren verursachte akute Konjunktivitis

Moxifloxacin Breites Wirkungsspektrum gegen aerobe und anaerobe, Gram-negative und Gram-positive Erreger.

(2) Moxifloxacin ist das einzige für Neugeborene zugelassene Antibiotikum!

Neomycin Wirksam gegen Gram-negative Bakterien, z. T. Staphylokokken (aber bis zu $30 \%$ Plasmid vermittelte Resistenz), unwirksam gegen Streptococcus und Pseudomonas spp. sowie Anaerobier; langsame Resistenzentwicklung mit Kreuzresistenz zu Kanamycin, Paromomycin, teilweise auch Streptomycin und Gentamicin; hohes Sensibilisierungsrisiko mit Kreuzallergie zu anderen Aminoglycosiden; Anwendung (Salbe) häufig in Kombination mit Bacitracin.

Rifampicin Wirksam gegen multiresistente Staphylokokken, Chlamydien, Neisserien, atypische Mykobakterien; Synergismus mit Amphothericin B.

Polymyxin B und Colistin Wirksam nur gegen Gram-negative Bakterien, die z. T. resistent sind, z. B. H. influenzae, Proteus spp.; zur Erweiterung des Wirkungsspektrums Komb. mit Gramicidin/Neomycin oder Bacitracin/Neomycin bzw. Colistin/Erythromycin.

PVP-lod Breitspektrumantiseptikum einschließich Candida spp., 1,25 \%ig der Kombination Neomycin/Polymyxin B/Gramicidin gleichwertig, gegen Chlamydien wirksamer.

Trimethoprim Wirksam gegen S. aureus und MRSA; zur Erweiterung des Wirkungsspektrums meist in Komb. mit Polymyxin B.

\section{Akute virale Konjunktivitis}

( Die Problematik der virostatischen Antiseptik besteht darin, dass die Virus replizierende Wirtszelle nur mit gleichzeitiger Zellschädigung inaktiviert

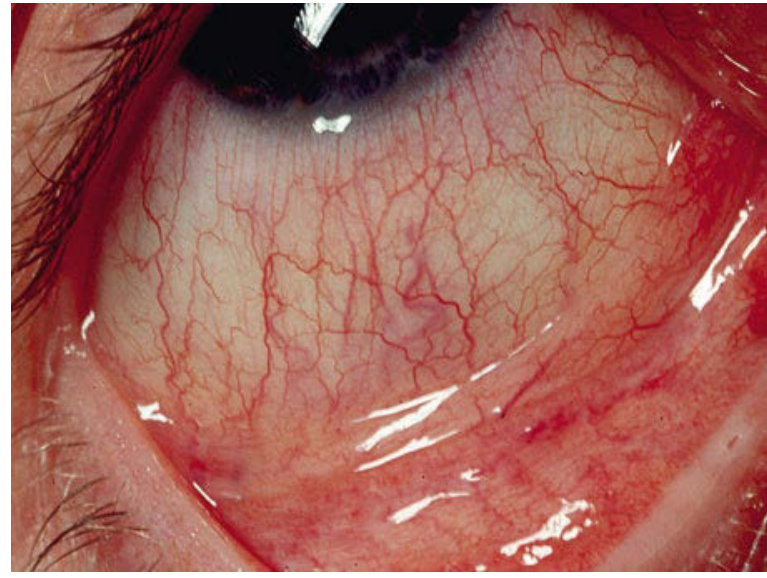

- Abb. 1.19 Durch Adenoviren verursachte akute Konjunktivitis

werden kann und viele Virusinfektionen erst klinisch manifest werden, nachdem die Wirtszellen infolge des Virusbefalls irreversibel geschädigt sind. Eine selektive Wirkung wäre nur möglich, wenn die Virionen vor Infektion der Wirtszelle zerstört werden. Da durch lokale Anwendung von Virostatika am Wirkort höhere Konzentrationen als bei systemischer Anwendung erreicht werden, und es zurzeit keine Wirkstoffe gibt, die Viren im Körper abtöten, ohne den Wirtsorganismus erheblich zu belasten, sind systemische Virostatika die letzte Therapieoption.

Als Symptome können ein- oder beidseitige Rötung, Juckreiz, Brennen, Augentränen, Fremdkörpergefühl, Lymphknotenschwellung und Blutungen auftreten (• Abb. 1.18). Im Vergleich zur bakteriellen Konjunktivitis tritt eher wässriger als eitriger Ausfluss auf und die Augen sind am Morgen weniger verklebt. Eine Abgrenzung aufgrund der klinischen Zeichen ist im Allgemeinen jedoch schwierig. Als Erreger kommen Herpes-, Adeno-, Varizella-Zoster(Zoster ophthalmicus), Epstein-Barr-, Masern-, Rubella-, Molluscum-contagiosum-, Papilloma- und Influenzaviren infrage. Unkomplizierte Bindehautentzündungen heilen meist nach ein bis zwei Wochen folgenlos ab.

Gegen Herpesviren sind Aciclovir, Gancyclovir und Trifluridin wirksam. Glucocortocoide sind kontraindiziert. Künstliche Tränen und Augentrost-Präparate können die Beschwerden symptomatisch lindern. Bei akuter hämmorrhagischer Konjunktivitis durch Enteroviren, insbes. Enterovirus 70 und Coxsackie A24v, ist keine virozide Therapie bekannt. Gegen Herpes wirksame Wirkstoffe sind bei Keratokonjunktivitis epidemica (KCE) unwirksam, Interferone waren z. T. wirksam, z. T. unwirksam.

Aus augenärztlicher Sicht wird die Infektion durch Adenoviren (•Abb. 1.19) gefürchtet, da sie hochinfektiös ist und bei Hornhautbeteiligung auch visusrelevante Komplikationen auftreten. Sie wird überwiegend durch Adenovirus- 

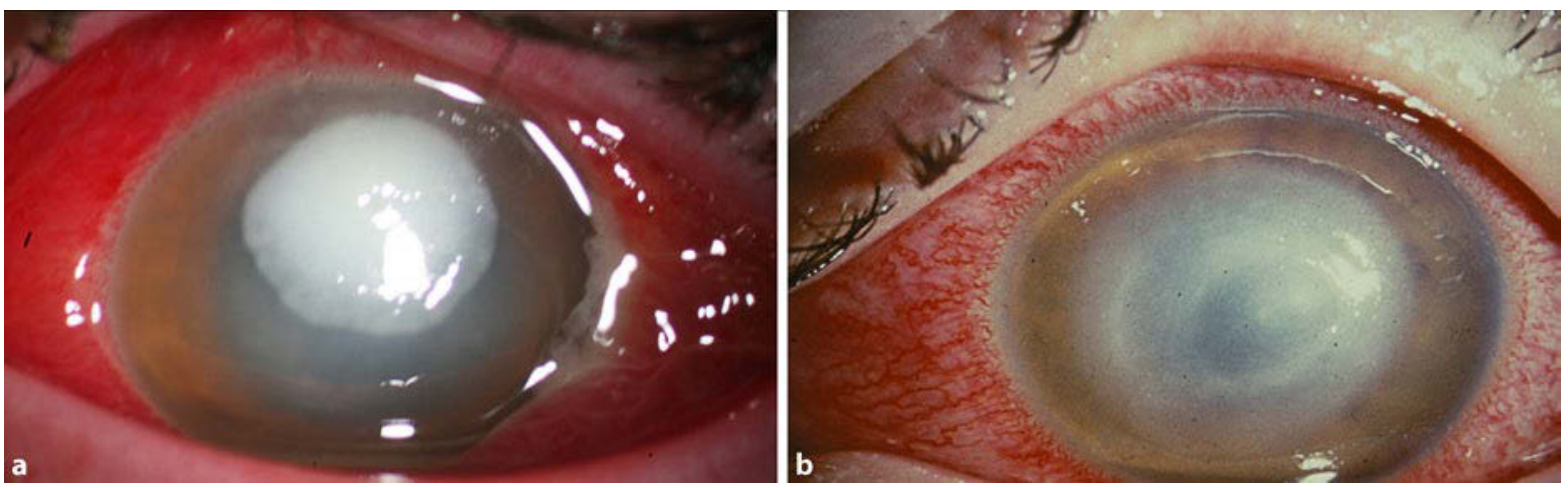

- Abb. 1.20a,b Durch P. aeruginosa verursachte Kontaktlinsen-assoziierte Keratitis

Serotypen 8, 19 oder 37 der Subgruppe D verursacht. Für den Erregernachweis besteht seit 2001 Meldepflicht gemäß $\$ 7$ (1). Therapeutisch stehen zunächst hygienische und unterstützende Maßnahmen im Vordergrund ( $\triangleright$ Abschn. 3.2). Es gibt keine kausale Therapie. Eine antivirale Lokaltherapie mit Cidovovir war zwar wirksam, jedoch zu toxisch; Ganciclovir hat sich in ex vivo Studien als eingeschränkt wirksam erwiesen, eindeutige klinische Studien fehlen. In Kohortenstudien konnte mit lokal appliziertem Povidon-Iod die Erkrankungsdauer gering verkürzt werden. Problematisch ist die Therapie der Keratitis (Nummuli) ( $\triangleright$ Abschn. 1.2.1).

\section{Therapie der Keratitis Bakterielle ulzeröse Keratitis}

( Bei bakterieller ulzeröser Keratitis werden je nach Stadium topisch Breitspektrumantibiotika (- Tab. 1.10) stündlich bis viertelstündlich empfohlen. Sind tiefere Augenabschnitte mit betroffen, ist die gleichzeitige systemische Gabe erforderlich.

Bei Trägern weicher Kontaktlinsen ist das Erkrankungsrisiko für eine Kontaktlinsen-assoziierte Keratitis (• Abb. 1.20a,b) 80mal höher als beim Brillenträger.

Zur kalkulierten Therapie hat sich der Magdeburger Dreistufenplan bewährt. Bei Chlamydieninfektion ist die systemische Antibiose z. B. mit Azytromycin $(500$ mg/d für $3 \mathrm{~d}$ ) indiziert.

\section{Keratomykosen}

(7) Im Vergleich zur bakteriellen Keratitis sind Keratomykosen schwieriger zu behandeln (• Abb. 1.21a,b). Voraussetzung für die Wirkstoffauswahl ist die infektiologische Diagnosesicherung. Abhängig von der Schwere und Ätiologie sind die viertelstündliche bis stündliche (C. albicans) Applikation, bei fortgeleiteter Endophthalmitis die wiederholte intrakamerale bzw. intravitreale Applikation erforderlich, wobei die systemische Gabe unterstützend wirkt. Weil Wirkstoffe mit einem Molekulargewicht (MG) $>500$ die Hornhaut entweder nicht oder nur gering penetrieren, ist für diese die wiederholte abrasio corneae erforderlich.

Besonderheiten der Pharmakokinetik im Kindesalter finden sich bei Jullien 2011, Vorschriften zur Herstellung von Augentropfen aus systemischen Antimykotika in BehrensBaumann 2009.

\section{Kurzcharakteristik ausgewählter Wirkstoffe:}

Amphotericin B (MG 924) Wirksam gegen Candida (einige Species sind resistent), Aspergillus (Versagen bei A. fumigatus- und $F$. solani möglich, vermutlich wegen unzureichender Penetration), Blastomyces, Cryptococcus, Histoplasma, Mucor, Ovadendron spp.; unterschiedlich empfindlich sind Curvularia, Alternaria, Wangiella und Cladosporium spp.; Paecilomyces spp. und $P$. boydii sind oft resistent; nach iv.Gabe (1 mg/kg KM) Übergang in Kammerwasser, subkonjunktival kein ausreichender Übergang; Augentropfen (0,2-0.7 \%), in Salbenform (0,5\%) Brennen möglich; bei Candida spp. wirksamer als Natamycin; bei exogener Endophthalmitis war die direkte Injektion in Vorderkammer oder Glaskörper (5-10 $\mu \mathrm{g} / \mathrm{ml}$ ) (bei Candida einmalig, bei Aspergillus ggf. wiederholt) ohne Vitrektomie der parenteralen Applikation wegen höherer Konzentration und besserer Verträglichkeit überlegen; systemische Gabe wegen Nephrotoxizität kritisch; durch Kombination mit subkonj. Gabe von Fluconazol (2\%) Reduktion auf 0,2 \% lokal bei höherer Wirksamkeit.

Caspofungin (MG 1094) Wirksam gegen Candida, Aspergillus, Alternaria spp.; unwirksam gegen C. neoformans und Fusarium spp.; lokal und intrastromal wirksam gegen Alternaria spp. einzeln und in Komb. mit Voriconazol intrastromal.

Chlorhexidindigluconat (MG 506) Ca. $1 \mu \mathrm{g} / \mathrm{ml}$ bakteriostatisch, $\geq 20 \mu \mathrm{g} / \mathrm{ml}$ bakteriozid mit großen Speziesdifferen- 

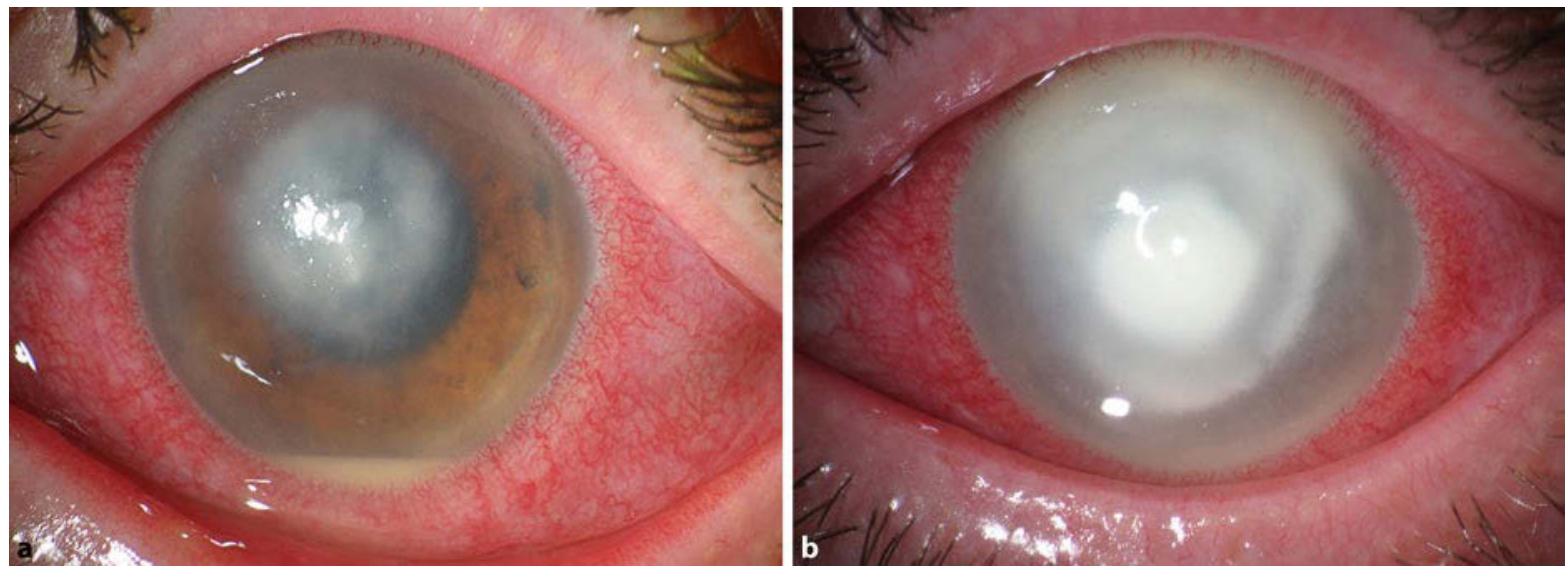

- Abb. 1.21a,b Durch Fusarium oxysporum verursachte schwer verlaufende Keratomykose

zen; wirksam gegen C. albicans in vitro; war lokal 0,2 \% in randomisierter Studie Natamycin überlegen.

Fluconazol (MG 306) Viele Non-Candida-albicans-Arten und Paecilomyces spp. sind resistent; Mittel der 1. Wahl bei C. albicans; wirksam gegen Alternaria spp.; Tropfen oder über Nacht als Gel (2\%), auch systemisch (2mal $400 \mathrm{mg}$ ).

Flucytosin (MG 129) $1 \mathrm{mg} / \mathrm{ml}$ lokal bei Candidakeratitis 12-32 Wochen, wirksam auch bei Blepharokonjunktivitis; unwirksam bei Paecilomyces spp.; Mittel 2. oder 3. Wahl.

Natamycin (Pimaricin) (MG 666) Wirksam gegen Dermatophyten, C. albicans, A. fumigatus, F. solani; wirksamer als Azole, unwirksam bei Alternaria spp.; wirksam vor allem bei oberflächlichen Keratomykosen einschließlich S. brevicaulis (5\%), ist bei Fusarium und Aspergillus spp. Amphotericin B überlegen; in Kombination mit Miconazol wirksam gegen Paecilomyces spp.; Gleichwertigkeit der Kombination $1 \%$ Natamycin/Nystatin ist nicht bewiesen; wurde auch in Komb. mit Chlorhexidin eingesetzt.

Nystatin (MG 926) Wirksam gegen Candida spp., B. dermatitidis , B. brasiliensis, C. immitis, C. neoformans, $H$. capsulatum, Geotrichum spp., Aspergillus spp.; unwirksam gegen Dermatophyten; Kreuzresistenz zu anderen Polyenen; Lokalbehandlung (100.000 IU), bei Generalisierung systemisch; gilt nicht als Mittel 1. Wahl (Reserve).

Voriconazol (MG 349) Wirksam gegen alle Candida spp., Cryptococcus, Aspergillus, Paecilomyces spp.; Resistenzentwicklung vereinzelt gegen Non-Candida-albicans-Arten, z. B. C. glabrata; nach oraler Gabe von $2 \mathrm{mal} 400 \mathrm{mg} \mathrm{Kam}-$ merwasser- bzw. Glaskörperspiegel in Höhe der minimalen Hemmkonzentration (MHK90) der meisten Pilze inklusive Aspergillus ssp.; kombinierte systemische und topische (2\%) Therapie bei Fusarium- und Scedosporium-
apiospermum-Keratitis; systemische Standarddosierung $2 \mathrm{mal} 200 \mathrm{mg}$ oral oder $2 \mathrm{mal} 4 \mathrm{mg} / \mathrm{kg} \mathrm{KM}$ als Kurzinfusion, kann auf $600 \mathrm{mg}$ oral bzw. $2 \mathrm{mal} 6 \mathrm{mg} / \mathrm{kg}$ KM erhöht werden (sog. Hirndosierung ); da das Isoenzym CYP3A4 für den Metabolismus von Voriconazol hauptverantwortlich ist, sind Interaktionen z. B. mit Ciclosporin, Tacrolimus, Warfarin bzw. Kumarin, Omeprazol zu beachten; häufigste Nebenwirkungen sind Erhöhung der Leberwerte und reversible Sehstörungen.

Wegen Resistenzentwicklung werden ältere Azole wie Clotrimazol (MG 345), Miconazol (MG 479), Ketoconazol (MG 538) oder Itraconazol (MG 706) kaum noch verwendet, allerdings ist Miconazol offenbar als einziges wirksam gegen Paecilomyces lilacinus. Polihexanid ist tierexp. mäßig wirksam bei Aspergillus- und Fusarium-Keratitis, PVP-Iod ist unwirksam. Für das Auge unverträglich sind Bifonazol, Econazol, Fenticonazol, Isoconazol, Ketoconazol, Naftifin, Oxiconazol, Terbinafin und Tioconazol.

\section{Akanthamöbenkeratitis}

Die Akanthamöben-Keratitis ( Abschn. 3.5) ist eine relativ seltene, aber schwer verlaufende, meist einseitig auftretende, sich progredient entwickelte Keratitisform mit Abszedierung (• Abb. 1.22a,b). Besonders gefährdet sind Träger weicher Kontaktlinsen.

Polihexanid (MG 2300-3600) Breitbandantiseptikum; wirksam gegen Zysten und Trophozoiten, min. zystizide Konz. (MCC) bei 8, 24 bzw. 48 h Einwirkzeit 9,4, 5,6 bzw. 2,4 $\mu \mathrm{g} /$ $\mathrm{ml}$, wie Chlorhexidin in vitro innerhalb $3 \mathrm{~h}$ amöbozid; Mittel der 1. Wahl; ist wegen besserer lokaler Verträglichkeit, geringerer Zytotoxizität und fehlender Resistenzentwicklung Chlorhexidin überlegen; lokal wirksam als Einzelwirkstoff sowie in Kombination mit 0,1 \% Propamidin (MG 317), 0,1 \% Hexamidin (MG 345) oder mit Neomycin; beschrieben sind therapieresistente Formen, insbesondere bei zu spätem Behandlungsbeginn und tiefer Stromainfek- 

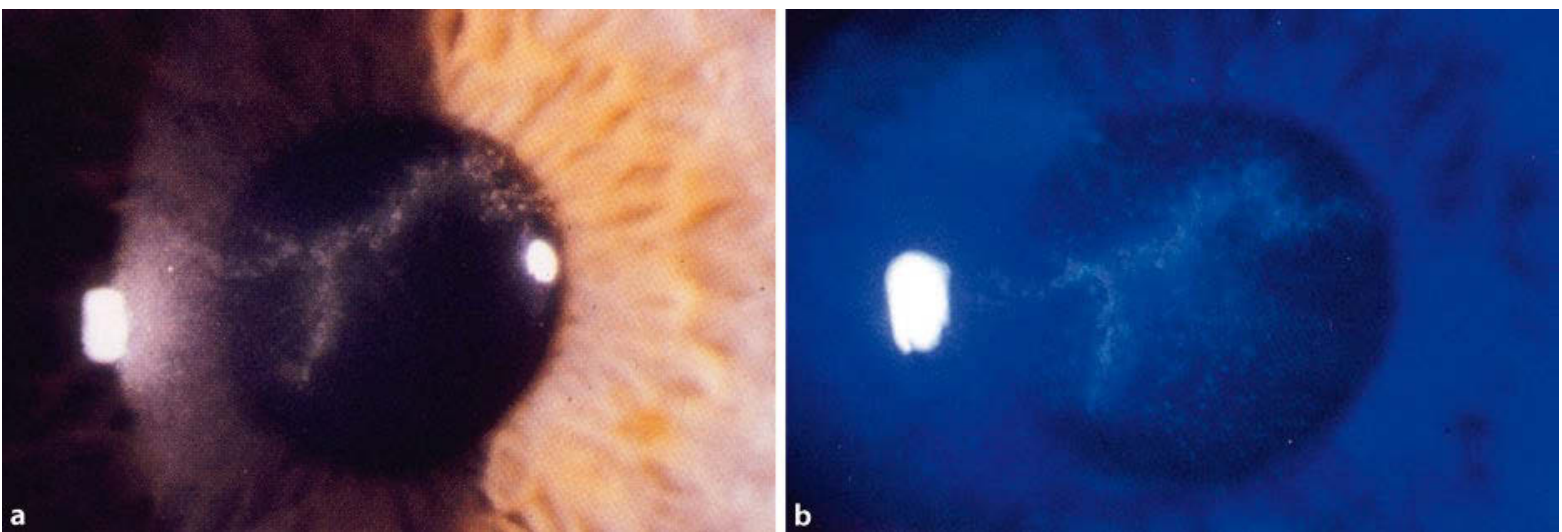

- Abb. 1.22a,b Akanthamöbenkeratitis mit Pseudodentritika Keratopathie

tion, aufgrund primärer Resistenz ohne Zusammenhang zur vitro Empfindlichkeit. Im Neuen Rezeptur-Formularium des Deutschen Arzneimittel-Codex sind Rezepturen für Polihexanid-Augentropfen $0,02 \%$ und -Augenbad $0,04 \%$ angegeben.

Chlorhexidindigluconat (MG 506) MCC bei 8, 24 bzw. $48 \mathrm{~h}$ 24,3, 10 bzw. $7 \mu \mathrm{g} / \mathrm{ml}$; lokal $0,02 \%$ oder $0,006 \%$.

\section{Viruskeratitis}

Häufigste Erreger sind Adenoviren (vor allem die Serotypen 8,19 und 37), H. simplex- und Varizella-Zoster-Viren, seltener Zytomegalie- (vor allem bei Immunsuppression und HIV), Röteln- und Masernviren.

\section{Keratokonjunktivitis epidemica (KCE)}

Die KCE beginnt typischerweise mit einseitigem Fremdkörpergefühl, das sich innerhalb weniger Stunden oder Tage zu beidseitiger Binde- und Hornhautentzündung mit starker Chemosis, Tränenträufeln, Lichtscheue, Lidbeteiligung und cornealen subepithelialen Infiltraten entwickelt (- Abb. 1.23). Meist finden sich eine exsudative Konjunktivitis sowie präaurikuläre Lymphknotenschwellungen. Mit dem Abklingen der akuten Symptomatik entwickelt sich in etwa $20 \%$ als chronische Verlaufsform die Keratitis nummularis mit münzförmigen Infiltraten direkt unterhalb des Hornhautepithels mit damit verbundener Sehverschlechterung.

Die üblichen Virostatika sind bei der KCE unwirksam. Nur Povidon-Iod führte bei guter Verträglichkeit zu geringer Reduktion der Krankheitsdauer sowie etwas reduzierter Nummulihäufigkeit, sodass Povidon-Iod trotz Fehlens kontrollierter Studien eine Therapiealternative darstellt. $\mathrm{N}$-Chlortaurin $1 \%$ führte in einer kleinen doppelblinden Phase-2-Studie nur bei Patienten mit schweren Verläufen zu einem signifikant besseren Verlauf, wobei die Entstehung von Nummuli nicht verhindert werden konnte.

Lokale Steroide werden kontrovers diskutiert, da sie nach dem Absetzen zu Rezidiven führen können und vermutlich auch die kontagiöse Phase verlängern. Nebenwirkungen, wie Oberflächenstörung des Auges, Katarakt und Augendruckanstieg, sind bei Langzeitanwendung zu bedenken. Andererseits kann eine erhebliche subjektive und objektive (visusrelevante!) Besserung mit vorzugsweise oberflächenwirksamen Steroiden (Loteprednol, Fluormetholon) erreicht werden (Prefered practice pattern der AAO http://one.aao.org/CE/PracticeGuidelines). Alternativ hat sich die lokale Gabe von Ciclosporin A $2 \%$ Augentropfen als effektiv und sicher erwiesen, wenn sich bei nummulibedingter Visusminderung innerhalb von 6 Wochen keine Tendenz zur spontanen Besserung zeigt. Für Kinder und Patienten, die diese Konzentration nicht tolerieren, können $1 \%$ ige Tropfen angewendet werden.

Eine Behandlungsoption im Spätverlauf ( $>6$ Monate) ist die chirurgische Laserabtragung der Nummuli sowie die topische Behandlung mit Mitomycin-C in Verbindung mit photorefraktiver Keratektomie. Sialinsäure enthaltende Moleküle und multivalente Sialinsäurekonstrukte auf der Basis von 10,12-Pentacosadiynoicsäure schützen vor der Infektion durch Adhäsionshemmung.

\section{H. simplex-Keratitis (HSK)}

Die HSK manifestiert sich im Allgemeinen als endogenes Rezidiv einer latenten Trigeminusinfektion epithelial (Keratitis dendritica, - Abb. 1.24) oder stromal. Bei letzterer Verlaufsform werden der nicht nekrotisierende und der nekrotisierende Typ (• Abb. 1.25a,b) sowie ein Mischtyp unterschieden.

Bei der Keratitis dendritica ist die topische Applikation ausreichend. Wirksam sind Aciclovir (ACV), Ganciclovir und Trifluridin (s. u.), wobei es gegen ACV resistente Stämme gibt. Die Applikation von Trifluridin (TFT) oder ACV führt nicht zu erhöhter bakterieller Infektionsrate. Idoxuridin, Iododexoxytidine und Adenin-Arabinosid sind aufgrund ihrer Toxizität obsolet.

Bei der tiefen stromalen Herpes simplex-Keratitis muss das Virostatikum in die Tiefe penetrieren. Da TFT nicht 


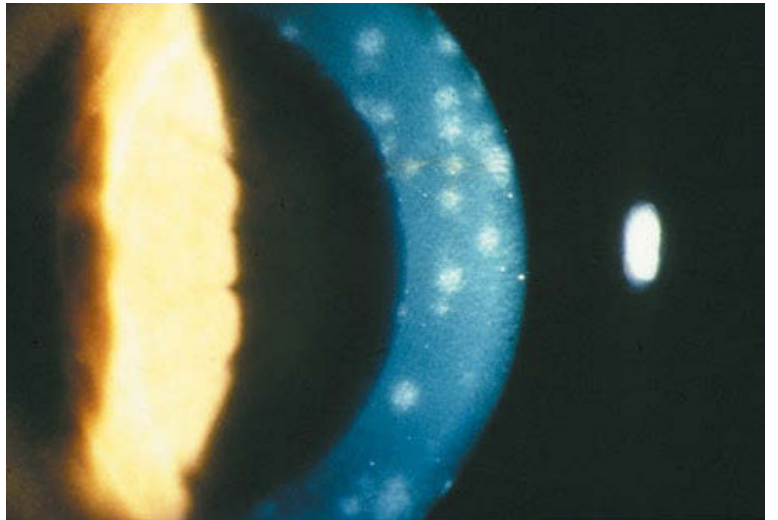

- Abb. 1.23 Durch Adenoviren verursachte Keratitis nummularis

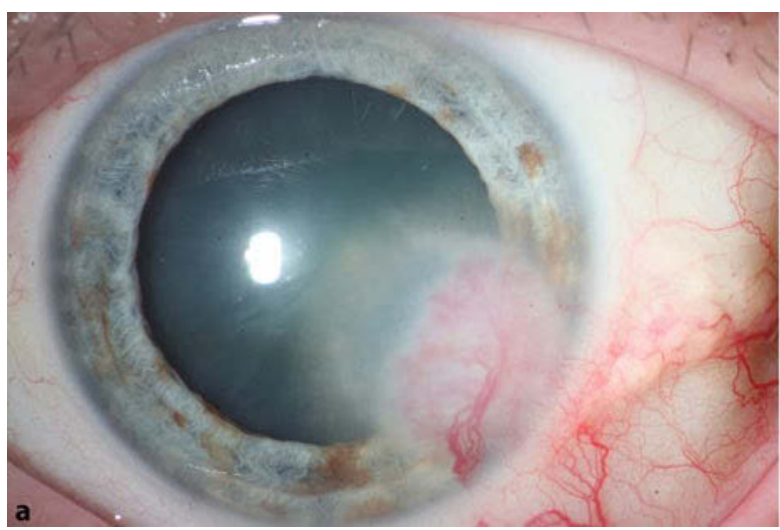

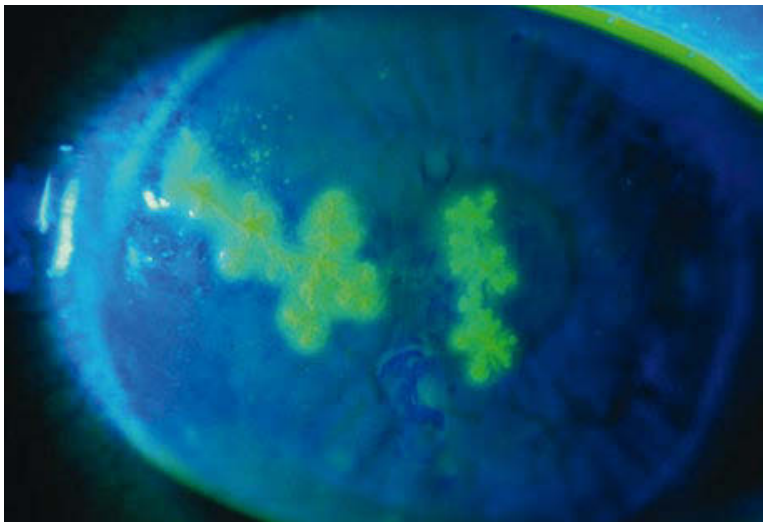

- Abb. 1.24 Durch H. simplex verursachte Keratitis dendritica

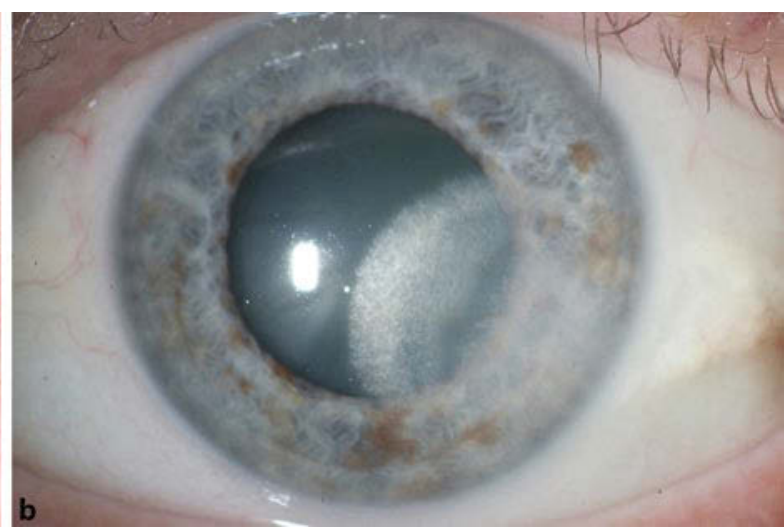

- Abb. 1.25a,b Durch H. simplex verursachte nekrotisierende Herpeskeratitis

- Tab. 1.11 Therapieschema zur Behandlung der H. simplex-Keratitis

\begin{tabular}{|c|c|c|c|c|c|c|}
\hline \multirow[t]{2}{*}{ Indikation } & \multicolumn{2}{|l|}{ ACV } & \multirow[t]{2}{*}{ GCV topisch } & \multirow[t]{2}{*}{ TFT topisch } & \multicolumn{2}{|l|}{ Steroide } \\
\hline & Topisch & Systemisch & & & Topisch & systemisch \\
\hline Epitheliale HSK & $5 \times / d$ & - & Alternativ & $\begin{array}{l}\text { Bei Therapieversagen } \\
\text { nach ACV oder GCV }\end{array}$ & - & - \\
\hline $\begin{array}{l}\text { Stromale Inter- } \\
\text { stitielle HSK }\end{array}$ & $5 \times / d$ & - & & - & $\begin{array}{l}\text { Anfangs } \\
\text { z. B. } 3-5 \times / d\end{array}$ & - \\
\hline $\begin{array}{l}\text { Stromale } \\
\text { ulzerierende } \\
\text { HSK }\end{array}$ & $5 \times / d$ & $5 \times 400 \mathrm{mg} / \mathrm{d}$ & & & - & $\begin{array}{l}\text { Nach Keratoplastik } \\
\text { z. B. } 80 \text { mg Pred- } \\
\text { nisolon }\end{array}$ \\
\hline $\begin{array}{l}\text { Endotheliitis mit } \\
\text { K. disciformis }\end{array}$ & $5 \times / d$ & $\begin{array}{l}5 \times 400 \mathrm{mg} / \mathrm{d} \\
\text { anfangs }\end{array}$ & & & z. B. $5 \times / d$ & - \\
\hline $\begin{array}{l}\text { Rezidivpro- } \\
\text { phylaxe }\end{array}$ & $5 \times / d$ & $\begin{array}{l}2 \times 400 \mathrm{mg} / \\
\text { über Monate }\end{array}$ & & & - & - \\
\hline $\begin{array}{l}\text { Metaherpe- } \\
\text { tische HSK }\end{array}$ & \multicolumn{6}{|c|}{ Nur künstliche Tränen, Vit. A, Eigenserum usw. } \\
\hline
\end{tabular}


durch das Epithel in das Stroma gelangt, ist ACV Mittel der ersten Wahl. Zugleich muss die überschießende Immunantwort durch topische Kortikosteroide gehemmt werden (• Tab. 1.11). Bei der Kombinationstherapie müssen die Steroide langsam, z. B. über 10 Wochen, reduziert werden. Gelegentlich ist eine niedrig dosierte Steroidgabe (z. B. 1 Tr. jeden 2. Tag) langfristig oder permanent notwendig. Bei Nichtansprechen kann topisch Ciclosporin A 2 \%ig (oder 0,05\%), gelöst in künstlichen Tränen oder in Erdnussöl, gegeben werden. Eine weitere Therapiemöglichkeit besteht, besonders bei nekrotisierender HSK, in der Amniontransplantation. ACV oral führt langfristig (> $12 \mathrm{Mo-}$ nate) zu deutlicher Reduzierung der HSK-Rezidivrate. Bei ACV-resistenten HSV-Stämmen muss auf Thymidinkinase unabhängige Medikamente (z. B. Foscarnet $3 \times 40 \mathrm{mg} / \mathrm{kg}$ $\mathrm{KM} / \mathrm{d}$ ) umgestellt werden. Da Rezidive häufig nach Augenoperationen auftreten, ist die ACV-Prophylaxe $(2 \times 400 \mathrm{mg}$ $\mathrm{ACV} / \mathrm{d}$ ) bei entsprechender Anamnese sinnvoll. Das gilt besonders für Hornhauttransplantationen. Da die meisten Rezidive innerhalb des ersten postoperativen Jahres auftreten, wird ACV mindestens für diesen Zeitraum empfohlen. Auch mit topischen antiviralen Mitteln konnte die Rezidivrate reduziert werden.

\section{Varicella zoster (VZV)-Keratitis}

Therapie mit Acyclovir systemisch (800 mg 5x/Tag für $10 \mathrm{~d}$ ), alternativ Valaciclovir ( $1 \mathrm{~g} 3 \times / \mathrm{d}$ oral mind. $7 \mathrm{~d}$ ) bzw. Famciclovir (500 mg 3x/d oral mind. 7 d).

\section{Kurzcharakteristik ausgewählter virostatischer Wirk-} stoffe:

Aciclovir (ACV) Wirksam gegen HSV-1, HSV-2, Varicella Zoster Virus (VZV), Epstein-Barr-Virus, unwirksam gegen eher seltene Thymidinkinase negative Viren, RNAund Adenoviren; Resistenzentwicklung im Anstieg, meist bei Immungeschwächten mit der Folge rezidivierender HSV-1 Keratitis; Mittel der ersten Wahl bei HSV-Keratitis; ist aufgrund der Bioverfügbarkeit im kornealem Stroma und Vorderkammer (analog wie Gancyclovir) sowie der geringen Toxizität, da es intakte nicht infizierte Zellen praktisch nicht beeinflusst, TFT überlegen. Bei VZVKeratitis war in der akuten Phase lokales Aciclovir der systemischen Gabe deutlich unterlegen; bei Epstein-BarrVirus-Keratitis ist lokale Anwendung in Komb. mit lokalen Steroiden wirksam; in Kombination mit Interferon bessere Therapieergebnisse. Anwendung bei Keratitis dendritica $3 \% 5 \times /$ d. Nachteilig ist bei Formulierung als Augensalbe die Visusbeeinträchtigung und dadurch reduzierte Compliance. Bei Komplikationen tieferer Abschnitte und foudroyantem Verlauf oral $5 \times /$ d $800 \mathrm{mg}$ mind. 3 Wochen, bei stromaler und/oder epithelialer Variante $5 \times / 400 \mathrm{mg}$ mind. 3 Wochen; trotz guter Verträglichkeit sind korneale Epitheliopathie und punktförmige superfizielle Keratitis möglich.
Acyclovir, Brivudin, Ganciclovir und TFT sind vergleichbar wirksam gegen $H S V$, Idoxuridin und Vidarabin sind geringer wirksam.

Bromovinyldeoxyuridin (BVDU) BVDU (0,1\% Augentropfen $5 \times / d$ ) ist 500 - bis 1000 fach wirksamer als ACV, erfasst allerdings nicht $H S V$-2, d. h. etwa $5 \%$ der HSK-Fälle. Allergie möglich.

$\mathrm{N}$-Chlortaurin In vitro wirksam gegen Herpes- und Adenoviren.

Foscarnet Es ist gut verträglich und blockiert die virusspezifische DNA-Polymerase, sodass auch ACV-resistente Viren erfasst werden.

Cidofovir War in klinischer Pilotstudie im Akutstadium zur Prävention der schweren Keratitis nummularis geeignet. Wegen der hohen Lokaltoxizität wurde dieser Ansatz bislang nicht weiter verfolgt.

Ganciclovir Wirkmechanismus und Wirksamkeit $(5 \times / d)$ sind vergleichbar mit ACV. 0,15\% wässriges Gel war bei akuter ulceröser Herpeskeratitis bei gleicher Wirksamkeit besser verträglich als $3 \% \mathrm{ACV}$. Die Formulierung als Carbomer erlaubt eine lange Kontaktzeit und erleichtert die Aufnahme. Tierexperimentell penetriert es in Hornhaut und Kammerwasser.

PVP-lod (MG I-254) Breitspektrumantiseptikum einschließlich C. trachomatis, HSV-1, HSV-2, Adeno- und Coxsackieviren, $10 \%$ mittels Tupferapplikation oder $5 \%$ als Tropfen gut verträglich, in prospektiver, interventioneller, nicht kontrollierter Studie $2 \% 4 \times / \mathrm{d}$ für $7 \mathrm{~d}$ bei KCE klinische Besserung, die Kombination 0,4\% PVP-Iod mit 0,1\% Dexamethason übertraf im Kaninchenmodell Cidofovir und Tobramycin/Dexamethason und in Phase-II-Prüfung ( $4 \times / d$ für mind. 5 d) sign. Reduktion des Adenovirustiters und klinische Besserung.

Trifluridin (TFT) TFT hemmt die Thymidylat-Synthetase sowohl von $H S V$ als auch von nicht infizierten Zellen und ist daher relativ (epithel-)toxisch; mögliche Nebenwirkungen sind Keratinisation der Lidkanten und Verschluss der Tränenpünktchen; daher sollte ACV bevorzugt werden.

Valaciclovir Es wird nach oraler Einnahme $(3 \times 1 \mathrm{~g} / \mathrm{d}) \mathrm{zu}$ ACV transformiert, wobei die Bioverfügbarkeit 3-5mal höher ist als bei oralem ACV. Die Verträglichkeit ist gut, sodass es bei Personen, die topisches ACV nicht tolerieren (z. B. Kinder, Parkinsonkranke), unter Berücksichtigung der hohen Kosten eine Alternative ist. 


\section{Ausblick}

In Anbetracht der für die meisten Antiseptika fehlenden Resistenzentwicklung erscheint es auf Grund des breiten Wirkungsspektrums insbesondere für PVP-Iod und Polihexanid aussichtsreich, die therapeutische Effektivität vertieft zu untersuchen. Für PVP-Iod sind insbesondere liposomale Formulierungen, für Polihexanid Phosphatidylbasierte Emulsionen aussichtsreich, weil in diesen Zubereitungen bei ausreichender antimikrobieller Wirksamkeit die Zytotoxizität noch weiter reduziert wird. Auch Antibiotika sind in liposomaler Form wirksamer.

\subsubsection{Antientzündliche und Immunmodulatorische Therapie bei Konjunktivitis und Keratitis (engl. Anti-inflammatory agents, immune modulation, immunmodulatory, keratitis, conjunctivitis)}

\section{P. Steven}

Entzündungen des vorderen Augensegmentes gehen zumeist mit einer Schädigung der Augenoberfläche einher. Dies betrifft zum einen chronisch-entzündliche Erkrankungen, wie Trockenes Auge, okuläre Allergie, Blepharitis, Sjögren-Syndrom, okuläre Graft-vs.-Host Erkrankung, u. a., aber auch akute entzündliche Erkrankungen, wie die stromale oder endotheliale Herpes-Keratitis.

Da im Rahmen der einzelnen Erkrankungen teilweise unterschiedliche „Arme“ des Immunsystems bevorzugt aktiviert werden, ist die Therapie dementsprechend komplex und sollte individuell abgestimmt werden. Grundsätzlich sind folgende Entzündungs-assoziierte Mechanismen denkbar, die einer anti-entzündlichen Therapie als Ansatz dienen können ( $\bullet$ Tab. 1.12, $\triangleright$ Abschn. 1.1.2):

1. Aktivierung von Matrixmetalloproteinasen

2. Aktivierung autoreaktiver T-Zellen

3. Ausschüttung pro-entzündlicher Faktoren (Interleukine, Chemokine, etc.)

4. Lymph- und Hämangiongenese

5. Anflutung und Aktivierung von Antigen-präsentierenden Zellen

6. Bildung immunregulatorischer T-Zellen

7. Expression von Chemokin- und Homingrezeptoren

Im Folgenden werden bereits verfügbare und in unmittelbarer klinischer Erprobung befindliche Therapeutika einzeln und entsprechend ihrem Einfluss auf die genannten Mechanismen beschrieben.

\section{Nicht-steroidale Antirheumatika (NSAR)}

NSAR hemmen spezifisch oder nicht-spezifisch die Cyclooxygenase und dadurch die Synthese pro-entzündlicher
Prostaglandine. Das Wirkspektrum in Bezug auf die Entzündungskaskade ist damit schmaler als bei den Kortikosteroiden. Für Entzündungen und Entzündungs-assoziierte Schmerzen des Auges, z. B. Trockenes Auge, Allergie, Uveitis, Episkleritis, Skleritis, etc. werden NSAR oral-systemisch oder topisch jedoch verabreicht. Eine Langzeitanwendung von NSAR wir aufgrund beschriebener schwerer Nebenwirkungen nicht empfohlen.

\section{Kortikosteroide}

Kortikosteroide werden seit langem zur Behandlung von Entzündungen der Augenoberfläche eingesetzt und haben ihre Wirksamkeit in zahlreichen klinischen Studien auch gegenüber nicht-steroidalen Antiphlogistika bewiesen. $\mathrm{Zu}$ beachten ist, dass eine Langzeitanwendung über Wochen bis Monate allerdings häufig mit einem Anstieg des Augendrucks eine Kataraktogenese und mit einer Infektionsgefahr einhergeht. Einige Substanzen, wie z. B. Rimexolon (Vexol ${ }^{\circledR}$, Alcon) oder Loteprednol Etabonat (Lotemax ${ }^{\circledR}$, Bausch \& Lomb), haben ein reduziertes Nebenwirkungsprofil, müssen jedoch teilweise aufgrund eines schmalen Indikationsspektrums im Rahmen einer Off-Label Therapie appliziert werden.

Kortikosteroide sind insgesamt äußerst potente Wirkstoffe, die in zahlreiche Entzündungsmechanismen eingreifen. Über den Kortikoidrezeptors und durch Eingriff in den sog. NFkB-Pathway wird die Bildung von Zytokinen und Chemokinen vermindert. Weitherhin kommt es zu einer Verringerung der Expression von HomingRezeptoren und damit zu einer verringerten Anflutung von Entzündungszellen und weiterhin zu einer Apoptoseinduktion von aktivierten T-Zellen. Derzeit werden topische Steroide zumeist nur kurzfristig eingesetzt, um die Entzündungskomponente auf breiter Fläche schnell zu reduzieren. Ausnahmen sind hier Langzeitanwendungen als lokale Immunsuppressiva nach perforierender oder lamellärer Keratoplastik.

\section{Calcineurin-Inhibitoren}

Entzündungen der Augenoberfläche weisen häufig eine TZell Antwort als zentralen Immunmechanimus auf. Insofern liegt es nahe, Therapeutika zu verwenden, die speziell diesen Arm der Immunreaktion hemmen. Als klassischer Vertreter der Substanzgrupper der Calcineurin-Inhibitoren vermittelt Ciclosporin A seine Wirkung speziell über den TZell-Rezeptor und über eine Calcineurin-Inhibition im Zytoplasma von T-Zellen. Mehrere klinische Studien belegen die Wirksamkeit von Ciclosporin A beim Trockenen Auge, okulärer Allergie, posteriorer Blepharitis, okulärer Graftvs.-Host Erkrankunge etc. während einer Applikationsdauer von bis zu mehreren Monaten. Obwohl Ciclosporin A bei einer systemischen Gabe schwere Nebenwirkungen, wie Blutbildveränderungen, Nephrotoxizität etc., hervor- 
rufen kann, wurden diese bei der topischen Gabe bislang nicht beschrieben. In Deutschland ist topisches Ciclosporin A aktuell nur in einer Öl-basierten Herstellung erhältlich, die ärztlich rezeptiert werden muss, jedoch keine „OffLabel“" Therapie darstellt. Als Alterantive zum Ciclosporin A wurden auch andere T-Zell spezifische Inhibitoren, wie Tacrolimus bereits klinisch oder Sirolimus und Everolimus experimentell, topisch zur Immunsuppression an der $\mathrm{Au}$ genoberfläche angewendet.

\section{Antibiotika}

Antibiotika, wie Tetrazykline oder Makrolide, wirken nicht nur antimikrobiell, sondern auch anti-entzündlich. Der Wirkmechanismus bezieht sich dabei auf eine Reduktion der Aktivierung von B-Zellen und eine Inhibition von Matrixmetalloproteinasen (MMP) und Kollagenasen. Vor allem letztere führen bei Entzündungen zu einer Antigen-unabhängigen Gewebedestruktion und sind durch Steroide oder Ciclosporin A nicht zu inhibieren. Makrolide greifen außerdem in den NFkB Signalweg ein und können hierdurch die Sekretion von pro-inflammatorischen Faktoren reduzieren. Ein weiterer Wirkmechanismus ist die Inhibition von bakteriellen Lipasen und die dadurch bedingte Reduktion schädigender freien Fettsäuren und Fettsäurederivaten. Systemische Tetrazykline werden über Wochen bis Monate zumeist zur Behandlung von Blepharitiden und Meibomitiden eingesetzt. Makrolide können auch topisch als Azithromycin appliziert werden und haben im Tiermodell eine signifikante Reduktion der Leukozyteninfiltration, sowie eine verminderte Expression von Adhäsionsmolekülen und pro-entzündlichen Zytokinen in der Hornhaut gezeigt.

\section{Omega-3 und -6 Fettsäuren}

Omega-3- und -6-Fettsäuren sind essentielle, ungesättigte Fettsäuren, die über die Nahrung zugeführt werden müssen, da sie vom Körper nicht selbst synthetisiert werden können. Beide Fettsäuren können zu Prostaglandin E1/ E3 und Leukotrien B5 verstoffwechselt werden, die eine antientzündliche Wirkung entfalten können. Die orale Einnahme von Omega-3- und Omega-6-Fettsäuren über einen Zeitraum von mehreren Wochen konnte in der klinischen Anwendung beim Trockenen Auge eine assoziierte Entzündung der Augenoberfläche und Krankheitsbedingte Symptome signifikant reduzieren.

Aktuelle tierexperimentelle Daten zeigen zudem, dass topisch appliziertes Resolvin E1, ein Omega-3-Fettsäure Metabolit mit ausgeprägter immunmodulatorischer und anti-inflammatorischer Wirkung ebenfalls eine klinische signifikante Wirkung aufweist.

\section{Serumaugentropfen}

Serumaugentropfen enthalten außer wundheilungsfördernden auch zahlreiche antientzündliche Faktoren wie
IL-1 Rezeptorantagonisten und MMP-Inhibitoren. Die wundheilungsfördernden Moleküle wie TGFß, FGF, PDGF, etc. führen außerdem zu einer Reduktion von EpithelzellApoptosen und damit indirekt zu einer Entzündungsinhibition. Da die Herstellung und Applikation von Serumaugentropfen gemäß den gesetzlichen Bestimmungen eine Herstellungserlaubnis voraussetzt, ist die ambulante Bereitstellung dieser Therapie bislang in Deutschland nur auf wenige Zentren beschränkt.

\section{Inhibition der Lymph- und Hämangiogenese als neue Therapieoptionen}

Bei chronischen Entzündungen der Augenoberfläche, wie beim Trockenen Auge, rezidivierenden Herpeskeratitiden und gemäß aktueller bislang unpublizierter Forschungsergebnissen auch bei der okulären Allergie, werden Lymphund z. T. Blutgefäße in der Hornhaut gebildet, über die aktivierte Antigen-präsentierende Zellen (APCs) in regionale Lymphknoten migrieren und dort eine autoreaktive Immunantwort induzieren. Eine Inhibition der Angiogenese, insbesondere der Lymphgefäße, würde im Gegensatz zu den oben beschriebenen Optionen die Entzündungsreaktion auf Seite der Antigenpräsentation und damit an einer zentralen Schaltstelle vor Aktivierung autoreaktiver T-Zellen angreifen. Kortikosteroiden inhibieren eine corneale Lymphangiogenese wahrscheinlich indirekt mittels einer Reduktion pro-inflammatorischer Makrophagen in der Hornhaut, wohingegen der humanisierte monoklonale Antikörper Bevacizumab bei topischer Applikation die entzündungs-assoziierte korneale Lymphangiogenese durch eine Bindung an VEGF-A inhibiert. Aktuell sind verschiedene andere Substanzen (z. B. das anti-sense Oligonukleotid GS101) innerhalb klinischer Studien in Erprobung, die erste sehr vielversprechende Ergebnisse zeigen.

\section{Biologika}

Biologika sind Substanzen, die in lebenden Organismen hergestellt werden und ihre Wirksamkeit sehr spezifisch gegen bestimmte biologische Strukturen richten (z. B. Rezeptoren, Wachstumsfaktoren).

"Small-Molecules" Als vielversprechende Therapie wird die Applikation von sog. Small-Molecule Antagonisten aktuell in klinischen Studien erprobt. Small-Molecules sind Stoffe mit einem Gewicht $<500$ Dalton, die im Gegensatz zu anderen Substanzen die Zellmembran in Targetgeweben leichter durchdringen sollen. Ein neues Small-Molecule ist das Lifitegrast ${ }^{\oplus}$ (SARcode Bioscience), das die Interaktion des Leukozytenfunktions-assoziierten Faktors LFA-1 mit dem Adhäsionsmolekül ICAM-1inhibiert und so die TZell Aktivierung, Proliferation, Migration und Chemokin Sekretion hemmen soll. Interessanterweise hemmt Lifitegrast dabei nicht nur die Migration der Leukozyten in die 
Tab. 1.12 Wirkmechanismen pharmakologischer Therapeutika

\begin{tabular}{|c|c|c|}
\hline Wirkstoffgruppe/Therapieverfahren & Beispiele & Wirkmechanismus \\
\hline Nicht-steroidale Antirheumatika & Diclofenac & COX-Hemmung, Reduktion von Prostaglandinen \\
\hline Kortikosteroide & Dexamethason & $\begin{array}{l}\text { Hemmung von Zytokinen und Chemokinen, Reduktion von } \\
\text { Adhäsionsmolekülen, Reduktion der Leukozyteninfiltration }\end{array}$ \\
\hline Calcineurin-Inhibitoren & $\begin{array}{l}\text { Ciclosporin, Tacrolimus, } \\
\text { Sirolimus }\end{array}$ & T-Zell Inhibition \\
\hline Antibiotika & Tetrazykline, Makrolide & $\begin{array}{l}\text { MMP-Inhibition, Reduktion von Adhäsionsmolekülen, Reduk- } \\
\text { tion der Leukozyteninfiltration }\end{array}$ \\
\hline Omega-3/6 Fettsäuren & & $\begin{array}{l}\text { Verstoffwechselung zu anti-entzündlichen Prostaglandinen } \\
\text { und Leukotrienen }\end{array}$ \\
\hline Serumaugentropfen & & $\begin{array}{l}\text { MMP-Inhibition, Hemmung der Entzündung durch IL-1 } \\
\text { Rezeptorantagonisten, Apoptosereduktion }\end{array}$ \\
\hline Anti-Lymph und Anti-Hämangiogenese & Bevacizumab, GS101 & Bindung an VEGF-Rezeptoren oder Insulinrezeptorsubstrat-1 \\
\hline \multirow[t]{3}{*}{ Biologika } & Lifitegrast & Inhibition der LFA-1/ICAM-1 Interaktion \\
\hline & Mycofenolat Mofetil & $\begin{array}{l}\text { Hemmung der Lymphozytenproliferation durch Pyrimidin- } \\
\text { Synthese Hemmung }\end{array}$ \\
\hline & $\begin{array}{l}\text { Adenosin-Rezeptor } \\
\text { Agonisten }\end{array}$ & Inhibition aktivierter B-Zellen und autoreaktiver T-Zellen \\
\hline Induktion regulatorischer T-Zellen & IL-2, TGF-ß, Rapamycin & Induktion regulatorischer T-Zellen \\
\hline Amnionmembrantransplantation & & $\begin{array}{l}\text { Anti-entzündliche Wirkung durch enthaltene IL-10, IL-1 } \\
\text { Rezeptorantagonisten, etc. }\end{array}$ \\
\hline
\end{tabular}

entzündeten Gewebe, sondern zudem die Antigenpräsentation durch APCs.

Mycofenolat-Mofetil (MMF) Mycofenolat-Mofetil ist ein Mycophenolsäureester und hemmt über einen Eingriff in die Pyrimidin Synthese die Proliferation von Lymphozyten. Anwendung findet es insbesondere bei Autoimmunerkrankungen wie dem systemischen Lupus erythematodes. Da topisch appliziertes MMF im Tiermodell praktisch nur in die Augenoberfläche und die vorderen Augensegmente penetriert, ist eine Anwendung im Rahmen von Entzündungen der Augenoberfläche und der Vorderkammer naheliegend.

Adenosin-Rezeptor-Agonist (IB-MECA, CF101) Oral eingenommene Adenosin-Rezeptor-Agonisten wie IB-MECA binden an einen Adenosin-Rezeptor, inhibieren die Proteinkinase B- oder NFkB-abhängig aktivierte B-Zellen sowie eine Proliferation autoreaktiver T-Zellen im Tiermodell der Uveitis. Ein topischer Therapieansatz im Rahmen eines Trockenen Auges befindet sich noch in der klinischen Testphase (Clinical Trial No. NCT01235234)

\section{Induktion regulatorischer T-Zellen}

Regulatorische T-Zellen (Tregs) nehmen einen wichtigen Platz in der körpereigenen Immunregulation ein. Eine Zu- nahme oder Induktion von Tregs wird als therapeutisch nutzbare Option zur Verminderung autoreaktiver Entzündung diskutiert. Erste präklinische Studien beweisen dabei, dass die Infusion von Tregs Autoimmunerkrankungen, wie Diabetes Typ 1, Rheumatoide Arthritis, Chronisch entzündliche Darmerkrankungen etc., verhindert und Abstoßungsreaktionen nach Knochenmark-, Inselzellen und Hauttransplantationen verzögert oder sogar aufhält. In Bezug auf Entzündungen des vorderen Augenabschnitts gibt es bislang keine experimentellen Daten, allerdings konnte kürzlich gezeigt werden, dass eine Kombination von IL-2, TGF-ß und Rapamycin Tregs induzieren konnte und damit einer möglichen therapeutischen Anwendung zur Verfügung steht.

\section{Amnionmembrantransplantation}

In schweren Fällen von Entzündungen des vorderen $\mathrm{Au}$ gensegments werden kryokonservierte Amnionmembranen auf die Augenoberfläche transplantiert. Die Membranen enthalten eine Vielzahl an anti-entzündlichen und wachstumsfördernden Faktoren, wie IL-10, IL-1 Rezeptor Antagonisten oder Nerven Wachstumsfaktor (NGF) und supprimieren so die lokale Entzündung des unterliegenden Empfängergewebes. Die Reaktion bezieht auch die Inhibition aktivierter T-Zellen mit ein, die ebenfalls in Folge der Amnionmembrantransplantation supprimiert werden. 


\subsection{Chirurgische Maßnahmen bei entzündlichen Erkrankungen des vorderen Augenabschnitts (VAA)}

\subsubsection{Photodynamische Therapie (PDT) bei infektiöser Keratitis (engl. surgery, inflammatory disease, anterior eye segment)}

N. Szentmáry, B. Seitz

Die photodynamische Therapie (PDT) wird seit etwa zehn Jahren in vielen medizinischen Disziplinen eingesetzt. Das Prinzip der PDT beruht darauf, dass ein Photosensibilisator nach Reaktion mit Licht einer bestimmten Wellenlänge freie Sauerstoffradikale erzeugt, die durch oxidative Schäden Zellen (eukaryontische Zellen, Bakterienmembranen etc.) aufbrechen und so eine Nekrose - oder, bei Wirkung auf die Mitochondrienmembran - eine Apoptose induzieren können (• Abb. 1.26). Es resultiert typischerweise eine rasche Reduktion der Entzündungsparameter.

Bei der „klassischen PDT“ an der Makula werden als Photosensibilisatoren überwiegend (z. B. Verteporfin) Porphyrine eingesetzt, die bei Bestrahlung mit rotem Licht einer Wellenlänge von $690 \mathrm{~nm}$ aktiviert werden (• Tab. 1.13).

Crosslinking (CXL) wird bereits seit 2006 in der Augenheilkunde eingesetzt. Durch CXL wird eine Quervernetzung der Kollagenfasern der Kornea erreicht, was die Progression des Keratokonus oder einer iatrogenen Keratektasie aufhalten kann. Bei CXL wird als Photosensibilisator Riboflavin eingesetzt, das durch UVA-Licht der Wellenlänge $370 \mathrm{~nm}$ aktiviert wird (• Tab. 1.13).

Aufgrund des rapiden Anstiegs der Resistenzbildung gegen Antibiotika sind alternative Therapiemöglichkeiten bei infektiösen Keratititiden gefordert. Photodynamische Therapie (PDT) oder photodynamische Inaktivierung (PDI) kann eine mögliche Therapie der infektiösen Keratitis darstellen.

\section{Riboflavin-UVA-Crosslinking}

Bereits 2009 zeigten Micelli Ferrari et al., dass CXL ein potentielles Therapieverfahren bei bakterieller Keratitis ist. Die Anzahl von klinischen Studien, die Riboflavin-UVACrosslinking als wirksame Therapieoption bei therapieresistenten und auch therapiesensiblen bakteriellen Keratitiden beschreiben, ist derzeit steigend. Durch Crosslinking konnten durch Escherichia coli, Pseudomonas aeruginosa, Staphylococcus aureus, Staphylococcus epidermidis, Mikrokokkus, Korynebakterien, Propionibakterien oder atypische Mycobakterien verursachte Keratitiden saniert werden. Weiterhin beschrieben Makdoumi et al. in ihrer Arbeit eine Vernarbung von Hornhautinfiltraten nach Crosslin-



Abb. 1.26 Therapeutisches Prinzip der Photodynamischer Therapie

Tab. 1.13 Varianten der Photodynamischen Therapie (PDT) in der Augenheilkunde

Photosensibilisator Bestrahlung

Riboflavin (Crosslinking) $370 \mathrm{~nm}$

Verteporfin $690 \mathrm{~nm}$

Chlorin e6 $670 \mathrm{~nm}$

king, ohne dass zusätzlich topische Antibiotika angewendet wurden (• Abb. 1.27). Khan et al. berichteten über die Wirksamkeit von adjuvantem Crosslinking als Therapie der Akanthamoebenkeratitis bei drei Patienten.

Weiterhin publizierten Iseli et al. und Müller et al., dass CXL als zusätzliche Therapieoption bei einem einschmelzenden Hornhautulkus Erfolg zeigte.

Der Einfluss von CXL Therapie bei Mikroorganismen wurde in mehreren in vitro Studien analysiert. Die Arbeitsgruppe um Ashley Behrens zeigte in ihrer Studie, dass die Kombination von UVA und Riboflavin bei Crosslinking schädigende Eigenschaften gegen Bakterien wie Pseudomonas aeruginosa, Staphylococcus aureus, Staphylococcus epidermidis und Streptococcus pneumoniae in vitro hat (• Tab. 1.14). Es zeigte sich, dass nicht die Zellmembran geschädigt wird, sondern die Nukleinsäure.

Makdoumi et al. berichteten, dass Riboflavin-UVA Crosslinking Akanthamöben in vitro abtötet und dass sich die Abtötungsrate nicht signifikant unterscheidet, wenn nur UVA Licht ohne Riboflavin verwendet wird.

Nebenwirkungen auf gesundes umliegendes Gewebe grenzen das Anwendungsspektrum des CXL ein. Wollensak et al. analysierten den Effekt von Crosslinking auf humane Keratozytenkulturen. Es zeigte sich ein zytotoxischer Effekt von Riboflavin und UVA-Strahlung ab einer Flächenleistungsdichte von $0,5 \mathrm{~mW} / \mathrm{cm} 2$. Diese Flächen- 



- Abb. 1.27a,b Staphylococcus-aureus-Keratitis mit Hornhautinfiltrat vor (a) und mit Hornhautnarbe 14 Tage nach (b) Einsetzen lokaler antibiotischer Therapie

- Tab. 1.14 Konzentrationen des Photosensibilizators

\begin{tabular}{|c|c|c|}
\hline & Chlorin e 6 + $670 \mathrm{~nm}$ (13 min) & Riboflavin + $370 \mathrm{~nm}$ (30 $\mathrm{min})$ \\
\hline \multicolumn{3}{|l|}{ Keratozyten } \\
\hline Viabilität & $\downarrow 100$ nM (human) & nicht bekannt \\
\hline a-smooth actin & $\downarrow 250 \mathrm{nM}$ (human) & nicht bekannt \\
\hline Proliferation & $\downarrow 250$ nM (human) & nicht bekannt \\
\hline Apoptose & $\uparrow 500 \mathrm{nM}$ (human) & $\uparrow 500 \mu \mathrm{M}\left(\mathrm{ab} 0,5 \mathrm{~mW} / \mathrm{cm}^{2}\right)$ (Schwein) \\
\hline \multicolumn{3}{|l|}{ Endothelzellen } \\
\hline Viabilität & $\downarrow 150$ nM (human) & nicht bekannt \\
\hline Apoptose & $\uparrow 250 \mathrm{nM}$ (human) & $\uparrow 500 \mu \mathrm{M}\left(\mathrm{ab} 0,35 \mathrm{~mW} / \mathrm{cm}^{2}\right)$ (Schwein) \\
\hline \multicolumn{3}{|l|}{ Mikroorganismen } \\
\hline Bakterien CFU/GIZ & $\downarrow 64 \mu \mathrm{M}$ & $\downarrow 2 \mathrm{mM}$ \\
\hline Pilze CFU/ GIZ & $\downarrow 32 \mu \mathrm{M}$ & nicht bekannt ( 2 mM ineffektive) \\
\hline Protozoen & nicht bekannt & $\downarrow 0$ (nur Bestrahlung!) \\
\hline
\end{tabular}

leistungsdichte wird bei einer Bestrahlung der Hornhaut mit $3 \mathrm{~mW} / \mathrm{cm} 2$ in einer Tiefe von $300 \mu \mathrm{m}$ erreicht. Reichl et al. beschrieben, dass die Schäden an Keratozyten mit der Höhe der Bestrahlungsenergie durch CXL ansteigen: Die Prozentzahl der Zellen, die apoptotisch oder nekrotisch sind, wird zunehmen. Ein zytotoxischer Effekt auf das Hornhautendothel ist nach Wollensak et al. ab einer Hornhautdicke von unter $400 \mu \mathrm{m}$ zu erwarten.

In vivo durchgeführte, konfokalmikroskopische Studien zeigen nach CXL-Behandlung ähnliche Ergebnisse wie die in vitro Studien: Die Keratozytendichte sinkt direkt nach der CXL Therapie. Immunohistochemische Studien zeigen, dass 5 bis 30 Monate nach CXL in den Keratozyten eine erhöhte Präsenz von antiapoptotischem survivin und proapoptotischem bax nachgewiesen wurde sowie auch eine erniedrigte Keratozytendichte.
Die Grenzen der Zytotoxizytät bei humanen Keratozyten und Mikroorganismen sind bei dem Photosensibilisator Riboflavin und bei der im klinischen Alltag verwendeten UVA im mikromolaren Bereich bei Keratozyten (0,025 \% Riboflavin) und im millimolaren Bereich bei Mikroorganismen ( $2 \mathrm{mM}$, was der therapeutisch eingesetzten Konzentration von $0,1 \%$ entspricht) (• Tab. 1.14).

\section{Porphyrin (Chlorin e6)-rotes Licht-PDI}

In früheren experimentellen Studien haben wir bereits die Wirkung des Photosensibilisators Chlorine e6 (Ce6) auf humane Keratozyten und Endothelzellen in der Zellkultur nach einer 13-minutigen $670 \mathrm{~nm}$ Bestrahlung getestet. Dabei konnten wir einen Anstieg der Apoptoserate ab $250 \mathrm{nM}$, eine erniedrigte Vitalität ab $100 \mathrm{nM}$ bei Keratozyten und ab $150 \mathrm{nM}$ bei Endothelzellen nachweisen (• Tab. 1.14). 
Bei einer Konzentration des Photosensibilisators von $32 \mu \mathrm{M}$ konnte bei 16 Candida albicans Isolaten eine Abtötung von 99,99\% nachgewiesen werden, bei einer Konzentration von $>64 \mu \mathrm{M}$ bei 20 Staphylococcus aureus Isolaten und bei einer Konzentration von $>128 \mu \mathrm{M}$ bei 20 Pseudomonas aeruginosa Isolaten (• Tab. 1.14).

Interessanterweise hat die Photodynamische Therapie (PDT) auch Einfluss auf die Aktivierung von Keratozyten. Es konnte eine Reduktion von alpha-smooth muscle actin positiven Keratozyten ab $250 \mathrm{nM}$ Chlorin e6 Konzentration in vitro nachgewiesen werden. Mit ähnlichen Effekten könnte auch CXL als PDT die inflammatorische Antwort und Aktivierung von Keratozyten bei der infektiösen Keratitis verändern.

Um den Schaden an humanen Zellen zu reduzieren und die Zytotoxizität an Mikroorganismen zu erhöhen, bietet sich ein mit einem Photosensibilisator gekoppelter Antikörper an, der spezifisch an Mikroorganismen bindet. Diese modifizierten Photosensibilisatoren könnten Mikroorganismen effizienter schädigen, als direkt eingesetzte Photosensibilisatoren und so einen geringeren zytotoxischen Effekte auf die eukaryonten Zellen zeigen. Die Entwicklung von spezifischen Photosensibilisatoren mit gekoppelten Antikörpern könnte ein Weg der Zukunft sein.

Zusammenfassend stellt die Riboflavin-UVA Photodynamische Therapie in Hinblick auf die erhöhte Resistenzbildung gegenüber topischer Antibiotika bei infektiöser Keratitis eine mögliche adjuvante Therapieoption dar. CXL bewirkt durch die Bildung von freien Sauerstoffradikalen eine Schädigung der Zellmembranen von Bakterien, Pilzen und Protozoen und fördert so deren Abtötung. Zum jetzigen Zeitpunkt kann die PDI keinesfalls schon als eine probate Therapie der infektiösen Keratitis bezeichnet werden. Ob und wann PDI als adjuvante Standardtherapie bei Keratitis zugelassen werden kann, bleibt noch abzuwarten. Vor- und Nachteile sowie die Grenzen der PDI bei infektiöser Keratitis müssen in experimentellen und klinischen Studien evaluiert werden. Bis dahin bleibt sie eine alternative Therapieoption für die therapieresistente Keratitis als potentieller Off-label Einsatz in Sinne eines individuellen Heilversuchs.

\section{Literatur}

Literatur zu Abschn. 1.1.1

Behring E, Kitasato S (1890) Ueber das Zustandekommen der Diphtherie-Immunität und der Tetanus-Immunität bei Thieren. Dtsch Med Wochenschr 16:1113-4

Caspi RR, Roberge FG, Chan CC, Wiggert B, Chader GJ, Rozenszajn LA, Lando Z, Nussenblatt RB (1988) A new model of autoimmune disease. Experimental autoimmune uveoretinitis induced in mice with two different retinal antigens. J Immunol 140:1490-1495

Chiang Y, Bassi L, Javitt J (1992) Federal budgetary costs of blindness. Milbank Q 70:319-340

Cunningham ET Jr. (2010) Exogenous factors influencing endogenous inflammation: what can patients do to improve control of their own uveitis? Br J Ophthalmol 94:813-814

Ehrlich P, Morgenroth J (1904) Wirkung und Entstehung der aktiven Stoffe im Serum nach der Seitenkettentheorie. Handbuch der pathogenen Mikroorganismen 1:430-451

Elschnig A (1910) Studien zur sympathischen Ophthalmie. Die antigene Wirkung des Augenpigmentes. Graefes Arch Clin Exp Ophthalmol 76:509-46

Ebbell B (1939) Die altägyptische Chirurgie. Die chirurgischen Abschnitte des Papyrus. E. Smith and Papyrus Ebers. Oslo, Dybwad, 1939. In: Hirschberg J (Hrsg) The History of Ophthalmology, Bd. 1. Wayenborgh, Bonn

Von Goldmann H, Witmer R (1954) Antikörper im Kammerwasser. Ophthalmologica 127:323

Gordon D (1956) Prednisone and prednisolone in ocular inflammatory disease. Am J Ophthalmol; 41: 593-600. Continuous cultures of fused cells secreting antibody of predefined specificity. Nature; 256:495-497

Leistikow L (1880) Über Bakterien bei den venerischen Krankheiten. Charité Ann 7:750-754

MacKenzie W (1830) A Practical Treatise on the Diseases of the Eye. Longman, Rees, Orme, Brown \& Green, London, S 422-457

Medawar PB (1944) The behaviour and fate of skin autografts and skin homografts in rabbits. J Anat 78:176-199

Newell FW, Krill AE (1967) Treatment of uveitis with azathioprine (Imuran). Trans Ophthalmol Soc UK 87:499-511

Nussenblatt RB, Palestine AG, Rook AH (1983) Treatment of intraocular inflammation with Cyclosporine A. Lancet 1:235-238

Ortho Multicenter Transplant Study Group (1985) A randomized clinical trial of OKT3 monoclonal antibody for acute rejection of cadaveric renal transplants. N Engl J Med 8(313):337-42

Streilein JW (1996) Ocular immune privilege and the Faustian dilemma. The Proctor lecture. Invest Ophthalmol Vis Sci 37:1940-42

Von Szily A (1914) Die Anaphylaxie in der Augenheilkunde. Enke, Stuttgart

Wessely K (1911) Ueber anapyhlaktische Erscheinungen an der Hornhaut (Experimentelle Erzeugung einer parenchymatösen Keratitis durch artfremdes Serum). Muench Med Wochenschr 58:1713-4

Wong VG, Hersh EM (1965) Methotrexate in the therapy of cyclitis. Trans Am Acad Ophthalmol Otolaryngol 69:279-293

Literatur zu Abschn. 1.1.2

Bals R (2000) Epithelial antimicrobial peptides in host defense against infection. Respir Res 1(3):141-50

Berthelot JM et al (2013) Regulatory B cells play a key role in immune system balance. Joint Bone Spine 80(1):18-22

Bock F et al (2013) Novel anti(lymph)angiogenic treatment strategies for corneal and ocular surface diseases. Prog Retin Eye Res, 2013 
Brandtzaeg P (2010) Function of mucosa-associated lymphoid tissue in antibody formation. Immunol Invest 39(4-5):303-55

Brauer L et al (2007) Detection of surfactant proteins A and D in human tear fluid and the human lacrimal system. Invest Ophthalmol Vis Sci 48(9):3945-53

Bron AJ, Seal DV (1986) The defences of the ocular surface. Trans Ophthalmol Soc U K 105(1):18-25

Buning J et al (2006) Antigen targeting to MHC class II-enriched late endosomes in colonic epithelial cells: trafficking of luminal antigens studied in vivo in Crohn's colitis patients. FASEB J 20(2):359-61

Cunningham AC et al (1997) A comparison of the antigen-presenting capabilities of class II MHC-expressing human lung epithelial and endothelial cells. Immunology 91(3):458-63

Dartt DA (2002) Regulation of mucin and fluid secretion by conjunctival epithelial cells. Prog Retin Eye Res 21(6):555-76

Donshik PC, Ballow M (1983) Tear immunoglobulins in giant papillary conjunctivitis induced by contact lenses. Am J Ophthalmol 96(4):460-6

Garreis F, Gottschalt M, Paulsen FP (2010) Antimicrobial peptides as a major part of the innate immune defense at the ocular surface. Dev Ophthalmol 45:16-22

Gehlsen U, Huttmann G, Steven P (2010) ntravital multidimensional realtime imaging of the conjunctival immune system. Dev Ophthalmol 45:40-8

Guzman-Aranguez A, Argueso P (2010) Structure and biological roles of mucin-type O-glycans at the ocular surface. Ocul Surf 8(1):8-17

Jump RL, Levine AD (2002) Murine Peyer's patches favor development of an IL-10-secreting, regulatory $T$ cell population. J Immunol 168(12):6113-9

Li J, Shen J, Beuerman RW (2007) Expression of toll-like receptors in human limbal and conjunctival epithelial cells. Mol Vis 13:813-22

Osterlind G (1944) An investigation into the presence of lymphatic tissue in the human conjunctiva, and its biological and clinical importance. Acta Ophthalmol (Copenh) 23:1-79

Paulsen FP, Berry MS (2006) Mucins and TFF peptides of the tear film and lacrimal apparatus. Prog Histochem Cytochem 41(1):1-53

Paulsen FP et al (2008) Intestinal trefoil factor/TFF3 promotes re-epithelialization of corneal wounds. J Biol Chem 283(19):13418-27

Siebelmann S et al. (2010) Development and antigen-related modulation of conjunctiva-associated lymphoid tissue (CALT), in World Ophthalmology Congress2010: Berlin

Steven P, Cursiefen C (2012) Anti-inflammatory treatment in dry eye disease. Klin Monbl Augenheilkd 229(5):500-5

Steven P, Gebert A (2009) Conjunctiva-associated lymphoid tissue current knowledge, animal models and experimental prospects. Ophthalmic Res 42(1):2-8

Steven P et al (2004) Distribution of TFF peptides in corneal disease and pterygium. Peptides 25(5):819-25

Tewary $P$ et al (2010) Granulysin activates antigen-presenting cells through TLR4 and acts as an immune alarmin. Blood 116(18):346574

Wright JR (2004) Host defense functions of pulmonary surfactant. Biol Neonate 85(4):326-32

Yu FS, Hazlett LD (2006) Toll-like receptors and the eye. Invest Ophthalmol Vis Sci 47(4):1255-63

Literatur zu Abschn. 1.1.4

Abe T, Nakajima A, Matsunaga M, Sakuragi S, Komatsu M (1999) Decreased tear Lactoferrin concentration in patients with chronic hepatitis C. Br J Ophthalmol 83:684-7

Arbeitsgemeinschaft der Wissenschaftlichen Medizinischen Fachgesellschaften e. V. (AWMF). Leitlinie der Deutschen Gesellschaft für Hygiene und Mikrobiologie (DGHM) in Zusammenarbeit mit der deutschsprachigen Gesellschaft für Virologie (GfV), der Deutschen Gesellschaft zur Verhütung von Viruskrankheiten (DVV) und der Deutschen Ophthalmologischen Gesellschaft (DOG). S2-Leitlinie "Mikrobiologische Diagnostik bei Infektionen des Auges", AWMFRegister Nr. 067/008, erstellt: 07/2011; nächste Überprüfung: 05/2016. URL: www.awmf.org

Behrens-Baumann W (2007) Chlamydienerkrankungen des Auges - Eine kurze Übersicht. Ophthalmologe 2007; 104:28-34

Behrens-Baumann W (2010) Zur klinischen Diagnose der Pilzkeratitis. Z prakt Augenheilkd 31:577-580

Boukes RJ, Boonstra A, Breebaart AC, Reits D, Glasius E, Luyendyk L, Kijlstra A (1987) Analysis of human tear protein profiles using high performance liquid chromatography (HPLC). Doc Ophthalmol 67:105-13

Carter JD, Hudson AP (2009) Reactive arthritis: clinical aspects and medical management. Infect Dis Clin North Am 2009; 35:21-44

Daniel E, Duriasamy M, Ebenezer GJ, ShobhanaJob CK (2004) Elevated free tear lactoferrin levels in leprosy are associated with Type 2 reactions. Indian J Ophthalmol 2004; 52:51-6

Epling J (2012) Bacterial conjunctivitis. Clin Evid 2012; 2012 pii: 0704

Flagagan JL, Willcox MDP (2009) Role of lactoferrin in the tear film. Biochemie 2009; 91:35-43

Garg P (2012) Fungal, Mycobacterial, and Nocardia infections and the eye: an update. Eye (Lond) 2012; 26:245-51

Kijlstra A, Jeurissen SH, Koning KM (1993) Lactoferrin levels in normal human tears. Br J Ophthalmol 67:199-202

Liekfeld A, Schweig F, Jaeckel C, Wernecke KD, Hartmann C, Pleyer U (2000) Intraocular antibody production in intraocular inflammation. Graefes Arch Clin Exp Ophthalmol 238:222-7

Mackie IA, Seal DV (1984) Diagnostic implications of tear protein profiles. Br J Ophthalmol 1984; 68:321-4

Pleyer U, Behrens-Baumann W (2007) Bakterielle Keratitis - Aktuelle Aspekte zur Diagnostik. Ophthalmologe 2007; 104:9-14

Robert PY, Liekfeld A, Metzner S, Ranger-Rogez S, Adenis JP, Denis F, Hartmann C, Pleyer U (2006) Specific antibody production in herpes keratitis: intraocular inflammation and corneal neovascularisation as predicting factors. Graefes Arch Clin Exp Ophthalmol 244:210-5

Sonntag HG (2002) Sampling and transport of specimens for microbial diagnosis of ocular infections. Dev Ophtahlmol 2002; 33:362-7

Tsung PK, Hong BS, Holly FJ, Gordon W Jr (1983) Decrease of lactoferrin concentration in the tears of myotonic muscular dystrophy patients. Clin Chim Acta 1983; 134:213-9

Literatur zu Abschn. 1.1.5

Brasnu E, Bourcier T, Dupas B, Degorge S, Rodallec T, Laroche $L$ et al (2007) In vivo confocal microscopy in fungal keratitis. BrJOphthalmol 91:588-91

Guthoff RF, Zhivov A, Stachs O (2009) In vivo confocal microscopy, an inner vision of the cornea - a major review. ClinExperimentOphthalmol 37:100-17

Hassell JR, Birk DE (2010) The molecular basis of corneal transparency. ExpEye Res 91:326-35

Hovakimyan M, Guthoff R, Reichard M, Wree A, Nolte I, Stachs O (2001) In vivo confocal laser-scanning microscopy to characterize wound repair in rabbit corneas after collagen cross-linking. ClinExperimentOphthalmol 39:899-909

Hovakimyan M, Guthoff RF, Stachs O (2012) Collagen cross-linking: current status and future directions. JOphthalmol (2012:406850)

Hassell JR, Birk DE (2010) The molecular basis of corneal transparency. ExpEye Res 91:326-35

Knappe S, Stachs O, Zhivov A, Hovakimyan M, Guthoff R (2011) Results of confocal microscopy examinations after collagen cross-linking with 
riboflavin and UVA light in patients with progressive keratoconus. Ophthalmologica 225:95-104

Labbe A, Liang H, Martin C, Brignole-Baudouin F, Warnet JM, Baudouin C (2006) Comparative anatomy of laboratory animal corneas with a new-generation high-resolution in vivo confocal microscope. CurrEye Res 31:501-9

Labbe A, Khammari C, Dupas B, Gabison E, Brasnu E, Labetoulle M et al (2009) Contribution of in vivo confocal microscopy to the diagnosis and management of infectious keratitis. OculSurf 7:41-52

Li J, Jester JV, Cavanagh HD, Black TD, Petroll WM (2000) On-line 3-dimensional confocal imaging in vivo. Invest OphthalmolVisSci 41:2945-53

Masters BR, Bohnke M (2001) Three-dimensional confocal microscopy of the human cornea in vivo. Ophthalmic Res 33:125-35

Masters BR, Bohnke M (2002) Three-dimensional confocal microscopy of the living human eye. AnnuRevBiomedEng 4:69-91

Masters BR, Farmer MA (1993) Three-dimensional confocal microscopy and visualization of the in situ cornea. ComputMedlmaging Graph 17:211-9

Messmer EM (2012) In vivo confocal microscopy - correlation to histology. KlinMonblAugenheilkd 229:696-704

Messmer EM, Mackert MJ, Zapp DM, Kampik A (2006) In vivo confocal microscopy of normal conjunctiva and conjunctivitis. Cornea 25:781-8

Patel DV, McGhee CN (2006) Mapping the corneal sub-basal nerve plexus in keratoconus by in vivo laser scanning confocal microscopy. Invest OphthalmolVisSci 47:1348-51

Patel DV, McGhee CN (2007) Contemporary in vivo confocal microscopy of the living human cornea using white light and laser scanning techniques: a major review. ClinExperimentOphthalmol 35:71-88

Petroll WM, Yu A, Li J, Jester JV, Cavanagh HD, Black T (2002) A prototype two-detector confocal microscope for in vivo corneal imaging. Scanning 24:163-70

Reichard M, Hovakimyan M, Wree A, Meyer-Lindenberg A, Nolte I, Junghans $C$ et al (2010) Comparative in vivo confocal microscopical study of the cornea anatomy of different laboratory animals. CurrEye Res 35:1072-80

Scarpa F, Fiorin D, Ruggeri A. In vivo three-dimensional reconstruction of the cornea from confocal microscopy images. Conf.Proc.IEEE Eng Med.Biol.Soc. 2007;2007:747-50

Stachs O, Zhivov A, Kraak R, Stave J, Guthoff R (2007) In vivo threedimensional confocal laser scanning microscopy of the epithelial nerve structure in the human cornea. Graefes ArchClinExpOphthalmol 245:569-75

Zhivov A, Blum M, Guthoff R, Stachs O (2010) Real-time mapping of the subepithelial nerve plexus by in vivo confocal laser scanning microscopy. BrJOphthalmol 94:1133-5

Zhivov A, Guthoff RF, Stachs O (2010) In vivo confocal microscopy of the ocular surface: from bench to bedside and back again. BrJOphthalmol 94:1557-8

Zhivov A, Guthoff R, Stachs O (2009) On-line mapping of corneal structures with in vivo laser scanning microscopy. KlinMonblAugenheilkd 226:980-3

Zhivov A, Stachs O, Kraak R, Guthoff R (2008) Cellular laser microscopy of corneal ulcer and infiltrate. KlinMonblAugenheilkd 225:86-90

Zhivov A, Stachs O, Kraak R, Stave J, Guthoff RF (2006) In vivo confocal microscopy of the ocular surface. OculSurf 4:81-93

Zhivov A, Stachs O, Stave J, Guthoff RF (2009) In vivo three-dimensional confocal laser scanning microscopy of corneal surface and epithelium. BrJOphthalmol 93:667-72
Literatur zu Abschn. 1.2.1

Alevi D, Barsam A, Kruh J et al (2012) Photorefractive keratectomy with mitomycin- $\mathrm{C}$ for the combined treatment of myopia and subepithelial infiltrates after epidemic keratoconjunctivitis. J Cataract Refract Surg 38(6):1028-1033

American Academy of Ophthalmology (2008) Preferred Practice Patterns. Conjunctivitis; $1-30$

Aplander K, Marttila M, Manner S et al (2011) Molecular wipes: application to epidemic keratoconjuctivitis. J Med Chem 2011; 54(19):6670-6675

Assadian O, Kramer A (2008) Antiseptik. In: Kramer A, Assadian O (Hrsg) Praxis der Sterilisation, Desinfektion, Antiseptik und Konservierung. Thieme, Stuttgart, S 208-254

Assadian O, Kramer A (2011) Antiseptik. In: Kramer A, Assadian O, Exner $M$, Hübner NO, Simon A (Hrsg) Krankenhaus- und Praxishygiene. Elsevier, München, S 15-20

Azuara-Blanco A, Sadiq AS, Hussain M et al (1997) Successful medical treatment of acanthamoeba keratitis. Int Ophthalmol 21:223-227

Behrens-Baumann W (2002) Topical Antimycotic Drugs. Dev Ophthalmol 33:263-280

Behrens-Baumann W (2007) Chlamydienerkrankungen des Auges. Ophthalmologe 104:28-34

Behrens-Baumann W (2009) Diagnostik und Therapie der Keratomykose. Ophthalmol 106:471-481

Behrens-Baumann W (2010) Herpes-simplex-Keratitis. Ein kurzer Überblock zur aktuellen Therapie. Klin Monatsbl Augenheilkd 2010; 227:388-392

Behrens-Baumann W (2010), http://www.med.uni-magdeburg.de/fme/ kauge/Dreistufenplan2010.pdf

Behrens-Baumann W, Kramer A (2002) Anti-infectives against amebic keratitis. Der Ophthalmologe 33:297-303

Benevento WJ, Murray P, Reed CA et al (1990) The sensitivity of Neisseria gonorrhoeae, Chlamydia trachomatis, and herpes simplex type II to disinfection with povidone-iodine. Am J Ophthalmol 109(3):329-333

Berufsverband der Augenärzte Deutschlands und Deutsche Ophthalmologische Gesellschaft (2011) Leitlinie Nr. 12 Bakterielle Konjunktivitis, http://www.dog.org/wp-content/uploads/2009/09/LeitlinieNr.-12-Bakterielle, Konjunktivitis.pdf

15. Berufsverband der Augenärzte Deutschlands und Deutsche Ophthalmologische Gesellschaft (2011) Leitlinie Nr. 13 Keratitis. http:// www.dog.org/wp-content/uploads/2009/09/Leitlinie-Nr.-13-Keratitis.pdf

Böhringer D, Birnbaum F, Reinhard T (2008) Cyclosporin-A-Augentropfen bei Nummuli nach Adenovirus-Keratokonjunktivitis. Ophthalmologe 105:592-594

Clement C, Capriotti JA, Kumar M et al (2011) Clinical and antiviral efficacy of an ophthalmic formulation of dexamethasone povidoneiodine in a rabbit model of adenoviral keratoconjunctivitis. Invest Ophthalmol Vis Sci 52(1):339-344

Croxtall JD (2011) Ganciclovir ophthalmic gel $0.15 \%$ : in acute herpetic keratitis (dendritic ulcers). Drugs 71(5):603-610

Debbasch C, Chaumeil C, Quesnot S et al (1998) A study on the activity of antiseptics and antibiotic on two isolates of acanthamoeba from corneal ulcerations. J Franc Ophtalmol 21:577-582

Donoso R, Mura JJ, Lopez M (2002) Acanthamoeba keratitis treated with propamidine and polyhexamethyl biguanide. Revista Med Chile 130:396-401

Duguid IGM, Dart JKG, Morlet N et al (1997) Outcome of acanthamoeba keratitis treated with polyhexamethyl biguanide and propamidine. Ophthalmol 104:1587-1592 
Elder MJ, Kilvington S, Dart JKG (1994) A clinicopathological study of in-vitro sensitivity testing and acanthamoeba-keratitis. Investig Ophthalmol Visual Sci 35:1059-1064

EN 14561 (2006) Chemische Desinfektionsmittel und Antiseptika Quantitativer Keimträgerversuch zur Prüfung der bakteriziden Wirkung für Instrumente im humanmedizinischen Bereich - Prüfverfahren und Anforderungen (Phase 2, Stufe 2)

EN 14561 (2006) Chemische Desinfektionsmittel und Antiseptika Quantitativer Keimträgerversuch zur Prüfung der bakteriziden Wirkung für Instrumente im humanmedizinischen Bereich - Prüfverfahren und Anforderungen (Phase 2, Stufe 2)

Erb C, Schlote T (2010) Medikamentöse Augentherapie. Thieme, Stuttgart

Fiscella RG, Moshifar M, Messick CR et al (1997) Polyhexamethylene biguanide (phmb) in the treatment of experimental fusarium keratomycosis. Cornea 16:447-449

Geerling G, Baatz J, Harder D et al (2002) Local Tolerance. Dev Ophthalmol 33:32-56

Gilbert P, Moore LE (2005) Cationic antiseptics: Diversity of action under a common epithet. J Appl Microbiol 99:703-715

Gray TB, Gross KA, Cursons RTM et al (1994) Acanthamoeba-keratitis - a sobering case and a promising new treatment. Austral New Zeal J Ophthalmol 22:73-76

Gray TB, Kilvington S, Dart JKG (1996) Amoebicidal, efficacy of hexamidine, compared with phmb chlorhexidine, propamidine and paromomycin. Investig Ophthalmol Visual Sci 37:4050-4050

Hansmann F, Kramer A, Ohgke $\mathrm{H}$ et al (2005) Lavasept as an alternative to PVP-iodine as a preoperative antiseptic in ophthalmic surgery. Randomized, controlled, prospective double-blind trial. Ophthalmologe 102(11):1043-1050

Hansmann F, Kramer A, Ohgke H et al (2004) Polyhexamethylbiguanid (PHMB) zur präoperativen Antisepsis bei Cataract Operation. Ophthalmologe 101:377-383

Hillenkamp J, Reinhard T, Ross RS et al (2002) The effects of cidofovir $1 \%$ with and without Cyclosporin A $1 \%$ as a topical treatment of acute adenoviral keratoconjunctivitis: a controlled clinical pilot study. Ophthalmology 109:845-850

Hübner NO, Kramer A (2010) Review on the efficacy, safety and clinical applications of polihexanide, a modern wound antiseptic. Skin Pharmacol Physiol 23:17-27

Hurtado-Sarrio M, Duch-Samper A, Cisneros-Lanuza A et al (2010) Successful topical application of caspofungin in the treatment of fungal keratitis refractory to voriconazole. Arch Ophthalmol 128(7):941-942

Hutter H (1990) Epidemic keratoconjunctivitis: treatment results during an epidemic. Klin Monbl Augenheilkd 197:214-217

Isenberg SJ, Apt L, Campeas D (2002) Ocular applications of povidoneiodine. Dermatol 204(1):92-95

Isenberg SJ, Apt L, Valenton $\mathrm{M}$ et al (2002) A controlled trial of povidoneiodine to treat infectious conjunctivitis in children. Am J Ophthalmol 134(5):681-688

Jeong HJ, Lee SJ, Kim JH et al (2007) Acanthamoeba: Keratopathogenicity of isolates from domestic tap water in Korea. Exp parasitol 117:357-367

Jullien V (2011) Pharmacokinetics and pharmacodynamics of antifungal drugs in children. Arch Pediatr 18(1):42-47

Kalteis T, Luring C, Schaumburger J et al (2003) Gewebetoxizitat lokaler Antiseptika. Z Orthop Grenzgeb 141:233-238

Kawakami H, Inuzuka H, Mochizuki K et al (2012) Clinical manifestations, treatment and outcome of ocular infections caused by Paecilomyces species. Nihon Ganka Gakkai Zasshi 116(7):613-622

Kramer A, Adrian V, Rudolph P et al (1998) Explant test with skin and peritoneum of the neonatal rat as a predictive test of tolerance of local anti-infective agents in wounds and body cavities. Chirurg 1998; 69(8):840-845

Kramer A, Aspöck C, Assadian O et al (2002) Prophylaxis against Ophthalmia Neonatorum. Dev Ophthalmol 33:223-232

Kramer A, Assadian O, Below H et al (2013) Wound antiseptics today - an overview. In: Willy C (Hrsg) Antiseptics in Surgery - Update 2013. Lindqvist, Berlin, S 85-111

Kramer A, Behrens-Baumann W (1997) Prophylactic use of topical antiinfectives in ophthalmology. Ophthalmologica 211(1):68-76

Kramer A, Behrens-Baumann W (2002) Antisepsis versus antimicrobial chemotherapy and indications for eye antisepsis. Dev Ophthalmol 33:14-27

Kramer A, Höh H, Roth HW et al (2002) Häufigkeit, Ursachen und Prävention der Kontaktlinsen-assoziierten infektiösen Keratitis. Hyg Med 11:439-449

Kramer A, Nürnberg W, Assadian O et al (2008) Lokal angewandte Antibiotika. In: Kramer A, Assadian O (Hrsg) Praxis der Sterilisation, Desinfektion, Antiseptik und Konservierung. Thieme, Stuttgart, $S$ 856-870

Kramer A, Reichwagen S, Heldt P et al (2008) Oxidantien. In: Kramer A, Assadian O (Hrsg) Praxis der Sterilisation, Desinfektion, Antiseptik und Konservierung. Thieme, Stuttgart, S 713-745

Kramer A, Reichwagen S, Widulle $\mathrm{H}$ et al (2008) Chlorhexidindiacetat, Chlorhexidindihydrochlorid, Chlorhexidindigluconat. In: Kramer A, Assadian O (Hrsg) Praxis der Sterilisation, Desinfektion, Antiseptik und Konservierung. Thieme, Stuttgart, S 793-798

Kramer A, Wilhelm F (2002) Antimikrobielle Maßnahmen zur Vorbereitung von Hornhauttransplantaten. In: Wilhelm F, Duncker GIW, Bredehorn T (Hrsg) Augenbanken. Walter de Gruyter, Berlin, S 52-56

Lanker Klossner B, Widmer HR, Frey F (1997) Nondevelopment of resistance by bacteria during hospital use of povidone-iodine. Dermatol 195(2):10-13

Larkin DFP, Kilvington S, Dart JKG (1992) Treatment of acanthamoeba keratitis with polyhexamethylene biguanide. Ophthalmol 99:185191

Lee JE, Hahn TW, Oum BS et al (2007) Acanthamoeba keratitis related to orthokeratology. Int Ophthalmol 27(1):45-49

Lim N, Goh D, Bunce C et al (2008) Comparison of polyhexamethylene biguanide and chlorhexidine as monotherapy agents in the treatment of acanthamoeba keratitis. Am J Ophthalmol 145:130-135

Lindquist TD (1998) Treatment of acanthamoeba keratitis. Cornea 17:11-16

Mahdy RA, Nada WM, Wageh MM et al (2010) Assessment safety and efficacy of a combination therapy of topical amphotericin B and subconjunctival fluconazole for the treatment of fungal keratitis. Cutan Ocul Toxicol 29(3):193-197

Mahdy RA, Nada WM, Wageh MM (2010) Topical amphotericin B and subconjunctival injection of fluconazole (combination therapy) versus topical amphotericin B (monotherapy) in treatment of keratomycosis. J Ocul Pharmacol Ther 26(3):281-285

Malecha MA (2004) Fungal keratitis caused by Scopulariopsis brevicaulis treated successfully with natamycin. Cornea 23(2):201-203

Maurice DM (1960) The Permeability of the Cornea. In: Duke-Elder SS, Perkins E (Hrsg) The Transparency of the Cornea. Blackwell, Oxford, S 67-71

Messmer EM (2012) Bakterielle Konjunktivitis - Update zu Diagnose und Therapie. Klin Monatsbl Augenheilkd 229(5):529-533

Meyer-Rüsenberg B, Loderstädt U, Richard G et al (2011) Keratokonjunktivitis epidemica: Infektionslage und aktuelle Hinweise zu Prophylaxe. Dt Ärztebl Int 08(27):475-480

Müller G, Koburger T, Kramer A (2013) Interaction of polyhexamethylene biguanide hydrochloride (PHMB) with phosphatidylcholine contai- 
ning o/w emulsion and consequences for microbicidal efficacy and cytotoxicity. Chem Biol Interact 201:58-64

Müller G, Kramer A, Schmitt J et al (2011) Reduced cytotoxicity of polyhexamethylene biguanide hydrochloride (PHMB) by egg phosphatidylcholine while maintaining antimicrobial efficacy. Chem Biol Interact 190(2-3):171-178

Murdoch D, Gray TB, Cursons R et al (1998) Acanthamoeba keratitis in new zealand, including two cases with in vivo resistance to polyhexamethylene biguanide. Austral New Zeal J Ophthalmol 26:231-236

Nagl M, Larcher C, Gottardi W (1998) Activity of N-chlorotaurine against herpes simplex- and adenoviruses. Antiviral Res 38:25-30

Neoh CF, Leung L, Vajpayee RB et al (2011) Treatment of Alternaria keratitis with intrastromal and topical caspofungin in combination with intrastromal, topical, and oral voriconazole. Ann Pharmacother 45(5):24

Panda A, Ahuja R, Biswas NR et al (2003) Role of $0.02 \%$ polyhexamethylene biguanide and $1 \%$ povidone iodine in experimental aspergillus keratitis. Cornea 22:138-141

Pelletier JS, Stewart K, Trattler W et al (2009) A combination povidonelodine $0.4 \%$ /dexamethasone $0.1 \%$ ophthalmic suspension in the treatment of adenoviral conjunctivitis. Adv Ther 26(8):776-783

Perez-Santonja JJ, Kilvington S, Hughes R et al (2003) Persistently culture positive acanthamoeba keratitis - in vivo resistance and in vitro sensitivity. Ophthalmol 110:1593-1600

Pitten FA, Werner HP, Kramer A (2003) A standardized test to assess the impact of different organic challenges on the antimicrobial activity of antiseptics. J Hosp Inf 55:108-115

Pleyer U (2002) Viral Ocular Infections. Dev Ophthalmol 33:281-296

Postexpositionelle Prophylaxe der HIV-Infektion. Deutsch-Österreichische Empfehlungen. Aktualisierung Januar 2008; http://www.daignet.de/site-content/hiv-therapie/leitlinien-1/Leitlinien\%20zur\%20 postexpositionellen\%20Prophylaxe\%20der\%20HIV-Infektion.pdf

Quiroga LP, Lansingh V, Laspina F et al (2010) A prospective study demonstrating the effect of $5 \%$ povidone-iodine application for anterior segment intraocular surgery in Paraguay. Arq Bras Oftalmol 73(2): $125-128$

Rahman MR, Johnson GJ, Husain R et al (1998) Randomised trial of $0.2 \%$ chlorhexidine gluconate and $2.5 \%$ natamycin for fungal keratitis in Bangladesh. Br J Ophthalmol 82(8):919-925

Reichwagen S, Kramer A (2008) Lokale Antimykotika. In: Kramer A, Assadian O (Hrsg) Praxis der Sterilisation, Desinfektion, Antiseptik und Konservierung. Thieme, Stuttgart, S 878-883

Reinhard T, Hansen LL, Pache M et al (2005) Antiinfektive medikamentöse Therapie in der Augenheilkunde - Teil 2:Virale Infektionen. Klin Monatsbl Augenheilkd 222(2):81-89

Richter R, Below H, Kadow I et al (2006) Effect of topical 1.25\% PVPiodine eyedrops used for prophylaxis of ophthalmia neonatorum in healthy term newborns on renal iodine excretion and TSH level. J Pediat 148(3):401-403

Seal D (2003) Treatment of acanthamoeba keratitis. Expert Rev Anti Infect Ther 1:205-208

Sheikh A, Hurwitz B (2001) Topical antibiotics for acute bacterial conjunctivitis: a systematic review. Br J Gen Pract 51:473-477

Speaker MG, Menikoff JA (1991) Prophylaxis of endophthalmitis with topical povidone-iodine. Ophthalmol 98(12):1769-1775

Stock I, Henrichfreise B (2012) Infektionen mit Chlamydia trachomatis. Med Monatsschr Pharm 35(6):209-222

Taylor JB, Fintelmann RE, Jeng BH (2011) Subconjunctival injections and povidone-iodine washings for the treatment of giant fornix syndrome. Cornea 30(4):479-480

Teuchner B, Nagl M, Schidlbauer A et al (2005) Tolerability and efficacy of $\mathrm{N}$-chlorotaurine in epidemic keratoconjunctivitis - a double- blind, randomized, phase-2 clinical trial. J Ocul Pharmacol Ther 21:157-165

Trinavarat A, Atchaneeyasakul LO (2012) Treatment of epidemic keratoconjunctivitis with $2 \%$ povidone-iodine: a pilot study. J Ocul Pharmacol Ther 28(1):53-58

Touvron G, Denis D, Doat M et al (2009) Successful treatment of resistant Fusarium solani keratitis with liposomal amphotericin B. J Fr Ophtalmol 32(10):721-726

Tu EY (2009) Alternaria keratitis: clinical presentation and resolution with topical fluconazole or intrastromal voriconazole and topical caspofungin. Cornea 28(1):116-119

Vogt PM, Reimer K, Hauser J et al (2006) PVP-iodine in hydrosomes and hydrogel - a novel concept in wound therapy leads to enhanced epithelialization and reduced loss of skin grafts. Burns 32(6):698705

Walochnik J, Duchene M, Eibl H (2003) Treatment of acanthamoeba keratitis: Standard, problems, and new approaches. Wien Klin Wschr 115:10-17

Wilhelmus KR (2008) Therapeutic interventions for herpes simplex virus epithelial keratitis. Cochrane Database Syst Rev (1) pCD002898

Wilhelmus KR (2010) Antiviral treatment and other therapeutic interventions for herpes simplex virus epithelial keratitis. Cochrane Database Syst Rev (12) pCD002898

Wilhelmus KR, Gee L, Hauck WW et al (1994) Herpetic eye disease study. Ophthalmol 1994; 101:1883-1896

Wutzler P, Sauerbrei A, Klöcking R et al (2000) Virucidal and chlamydicidal activities of eye drops with povidone-iodine liposome complex. Ophthalmic Res 32(2-3):118-125

Wutzler P, Sauerbrei A, Klöcking R et al (2002) Virucidal activity and cytotoxicity of the liposomal formulation of povidone-iodine. Antiviral Res 54(2):89-97

\section{Literatur zu Abschn. 1.2.2}

Aragona P et al (2005) Systemic omega-6 essential fatty acid treatment and pge 1 tear content in Sjogren's syndrome patients. Invest Ophthalmol Vis Sci 46(12):4474-9

Avunduk AM et al (2003) The comparison of efficacies of topical corticosteroids and nonsteroidal anti-inflammatory drops on dry eye patients: a clinical and immunocytochemical study. Am J Ophthalmol 136(4):593-602

Barabino $S$ et al (2003) Systemic linoleic and gamma-linolenic acid therapy in dry eye syndrome with an inflammatory component. Cornea 22(2):97-101

Barnes PJ (2006) Corticosteroid effects on cell signalling. Eur Respir J 27(2):413-26

Baspinar $Y$ et al (2008) Corneal permeation studies of everolimus microemulsion. J Ocul Pharmacol Ther 24(4):399-402

Bertelmann E et al (2003) Transcorneal-paracorneal penetration route for topical application of drugs to the eyt. Mycophenolate mofetil as a model substance. Ophthalmologe 100(9):696-701

Bock F et al (2008) Bevacizumab (Avastin) eye drops inhibit corneal neovascularization. Graefes Arch Clin Exp Ophthalmol 246(2):281-4

Bock F et al (2007) Bevacizumab as a potent inhibitor of inflammatory corneal angiogenesis and lymphangiogenesis. Invest Ophthalmol Vis Sci 48(6):2545-52

Canonica GW et al (1997) Molecular events in allergic inflammation: experimental models and possible modulation. Allergy 52(34):25-30

Cursiefen C et al (2004) VEGF-A stimulates lymphangiogenesis and hemangiogenesis in inflammatory neovascularization via macrophage recruitment. J Clin Invest 113(7):1040-50

Cursiefen $C$ et al (2011) Thrombospondin 1 inhibits inflammatory lymphangiogenesis by CD36 ligation on monocytes. J Exp Med 208(5):1083-92 
De Bosscher K et al (1997) Glucocorticoid-mediated repression of nuclear factor-kappaB-dependent transcription involves direct interference with transactivation. Proc Natl Acad Sci U S A 94(25):13504-9

De Paiva CS et al (2006) Corticosteroid and doxycycline suppress MMP-9 and inflammatory cytokine expression, MAPK activation in the corneal epithelium in experimental dry eye. Exp Eye Res 83(3):526-35

De Paiva CS et al (2012) Resolvin E1 (RX-10001) Reduces Corneal Epithelial Barrier Disruption and Protects Against Goblet Cell Loss in a Murine Model of Dry Eye. Cornea. 2012 Nov;31(11):1299-303 doi: 10.1097/ICO.0b013e31823f789e

Dietrich T et al (2008) Manufacture of autologous serum eye drops for out-patient therapy : cooperation between ophthalmic clinic and transfusion medicine department. Ophthalmologe. 2008 Nov;105(11):1036-8, 1040-2. doi: 10.1007/s00347-008-1692-4

Donnenfeld E, Pflugfelder SC (2009) Topical ophthalmic cyclosporine: pharmacology and clinical uses. Surv Ophthalmol 54(3):321-38

Dougherty JM et al (1991) The role of tetracycline in chronic blepharitis. Inhibition of lipase production in staphylococci. Invest Ophthalmol Vis Sci 32(11):2970-5

Dursun D et al (2001) Treatment of recalcitrant recurrent corneal erosions with inhibitors of matrix metalloproteinase-9, doxycycline and corticosteroids. Am J Ophthalmol 132(1):8-13

Fox Rl et al (1984) Beneficial effect of artificial tears made with autologous serum in patients with keratoconjunctivitis sicca. Arthritis Rheum 27(4):459-61

Goyal S et al (2010) Evidence of corneal lymphangiogenesis in dry eye disease: a potential link to adaptive immunity? Arch Ophthalmol 128(7):819-24

Hos D et al (2011) Suppression of inflammatory corneal lymphangiogenesis by application of topical corticosteroids. Arch Ophthalmol 129(4):445-52

Jhunjhunwala $S$ et al. (2012) Controlled release formulations of IL-2, TGF-beta1 and rapamycin for the induction of regulatory $T$ cells. J Control Release, 2012

Kim SJ, Flach AJ, Jampol LM (2010) Nonsteroidal anti-inflammatory drugs in ophthalmology. Surv Ophthalmol 55(2):108-33

Kuzin II et al (2001) Tetracyclines inhibit activated B cell function. Int Immunol 13(7):921-31

Lohr J, Knoechel B, Abbas AK (2006) Regulatory T cells in the periphery. Immunol Rev 212:149-62

Marsh P, Pflugfelder SC (1999) Topical nonpreserved methylprednisolone therapy for keratoconjunctivitis sicca in Sjogren syndrome. Ophthalmology 106(4):811-6

Meller D et al (2011) Amniotic membrane transplantation in the human eye. Dtsch Arztebl Int 108(14):243-8

Olsen TW et al (1994) Rapamycin inhibits corneal allograft rejection and neovascularization. Arch Ophthalmol 112(11):1471-5

Pflugfelder SC et al (2004) A randomized, double-masked, placebocontrolled, multicenter comparison of loteprednol etabonate ophthalmic suspension, $0.5 \% \%$, and placebo for treatment of keratoconjunctivitis sicca in patients with delayed tear clearance. Am J Ophthalmol 138(3):444-57

Pucci N et al (2010) Long-term safety and efficacy of topical cyclosporine in 156 children with vernal keratoconjunctivitis. Int J Immunopathol Pharmacol 23(3):865-71

Regenfuss B et al (2009) Topical inhibition of angiogenesis at the cornea. Safety and efficacy. Ophthalmologe 106(5):399-406

Roncarolo MG, Battaglia M (2007) Regulatory T-cell immunotherapy for tolerance to self antigens and alloantigens in humans. Nat Rev Immunol 7(8):585-98

Sadrai Z et al (2011) Effect of topical azithromycin on corneal innate immune responses. Invest Ophthalmol Vis Sci 52(5):2525-31
Sall K et al (2000) Two multicenter, randomized studies of the efficacy and safety of cyclosporine ophthalmic emulsion in moderate to severe dry eye disease. CsA Phase 3 Study Group. Ophthalmology 107(4):631-9

Steven P et al (2013) Immune Reactions after DMEK, DSAEK and DALK. Klin Monbl Augenheilkd 494-499

Sun Y, Zhang R, Gadek T R, O'Neill C A, and Pearlman E (2013) Corneal inflammation is inhibited by the LFA-1 antagonist, lifitegrast (SAR 1118). J Ocul Pharmacol Ther 29 (4):395-402

Thomasen $\mathrm{H}$ et al (2011) The effect of long-term storage on the biological and histological properties of cryopreserved amniotic membrane. Curr Eye Res 36(3):247-55

Tsubota K et al (1999) Treatment of dry eye by autologous serum application in Sjogren's syndrome. Br J Ophthalmol 83(4):390-5

Tzu JH et al (2012) Topical calcineurin inhibitors in the treatment of steroid-dependent atopic keratoconjunctivitis. Cornea 31(6):649-54

Ueta $M$ et al (2002) Immunosuppressive properties of human amniotic membrane for mixed lymphocyte reaction. Clin Exp Immunol 129(3):464-70

Utine CA, Stern M, Akpek EK (2010) Clinical Review:Topical Ophthalmic Use of Cyclosporin A. Ocular Immunology and Inflammation 18(5):352-361

Weisbach V et al (2007) HIV and hepatitis B/C infections in patients donating blood for use as autologous serum eye drops. $\mathrm{Br} J$ Ophthalmol 91(12):1724-5

Literatur zu Abschn. 1.3.1

Al-Sabai N, Koppen C, Tassignon MJ (2010) UVA/riboflavin crosslinking as treatment for corneal melting. Bull Soc Belg Ophthalmol 2010; 315:13-7

Anwar HM, El-Danasoury AM, Hashem AN (2011) Corneal collagen crosslinking in the treatment of infectious keratitis. Clin Ophthalmol 2011; 5:1277-80

Cursiefen C (2009) Corneal crosslinking: „Safe and effective?“. Ophthalmologe 106:164-5

Demidova TN, Hamblin MR (2004) Phyotodynamic therapy targeted to pathogens. Int J Immunopathol Pharmacol 2004; 17:245-54

Embleton ML, Nair SP, Cookson BD, Wilson M (2004) Antibody-directed photodynamic therapy of methicillin-resistant Staphylococcus aureus. Microbial Drug Resistance 2004; 10:92-97

Fuchs SM, Fluhr JW, Bankova L, Tittelbach J, Hoffmann G, Elsner P (2004) Photodynamic therapy (PDT) and waterfiltered infrared A (WIRA) in patients with recalcitrant common hand and foot warts. Ger Med Sci (Doc08)

Grobe GM, Reichl S (2011) Examining the suitability of riboflavin/UVA treatment for strengthening the stromal bioequivalent of the human cornea construct. Curr Eye Res 2011; 36:217-31

Hovakimyan M, Guthoff RF, Stachs O (2012) Collagen cross-linking: Current status and future directions. J Ophthalmol (ID 406850, in press)

Iseli HP, Thiel MA, Hafezi F, Kampmeier J, Seiler T (2008) Ultraviolet A/ riboflavin corneal cross-linking for infectious keratitis associated with corneal melts. Cornea 2008; 27:590-4

Kashiwabuchi RT, Carvalho FR, Khan YA, Hirai F, Campos MS, McDonnell PJ (2013) Assessment of fungal viability after long-wave ultraviolet light irradiation combined with riboflavin administration. Graefes Arch Clin Exp Ophthalmol 251 (2):521-527

Khan YA, Kashiwabuchi RT, Martins SA, Castro-Combs JM, Kalyani S, Stanley P, Flikier D, Behrens A (2011) Riboflavin and ultraviolet light $A$ therapy as an adjuvant treatment for medically refractive Acanthamoeba keratitis: report of 3 cases. Ophthalmology 2011; 118:324-31

Kymionis GD, Kamkariya VP, Georgios A, Kontakadis GA (2012) Combined treatment with flap amputation, phototherapeutic kerate- 
ctomy, and collagen crosslinking in severe intractable post-LASIK atypical mycobacterial infection with corneal melt. J Cat Refract Surg 2012; 38:713-15

Makdoumi K, Mortensen J, Sorkhabi O, Malmvall BE, and Crafoord S (2012) UVA-riboflavin photochemical therapy of bacterial keratitis: a pilot study. Graefes Arch Clin Exp Ophthalmol 250 (1):95-102

Makdoumi K, Backman A, Mortensen J, Magnuson A, and Crafoord S (2013) Comparison of UVA- and UVA/riboflavin-induced growth inhibition of Acanthamoeba castellanii. Graefes Arch Clin Exp Ophthalmol. 251 (2):509-514

Martins SA, Combs JC, Noguera G, Camacho W, Wittmann P, Walther R, Cano M, Dick J, Behrens A (2008) Antimicrobial efficacy of riboflavin/UVA combination ( $365 \mathrm{~nm}$ ) in vitro. Invest Ophthalmol Vis Sci 2008; 49:3402-8

Messmer EM, Meyer P, Herwig MC, Loeffler KU, Schirra F, Seitz B, Thiel M, Reinhard T, Kampik A, and Auw-Haedrich C (2013) Morphological and immunohistochemical changes after corneal cross-linking. Cornea 32 (2):111-117

Micelli Ferrari T, Leozappa M, Lorusso M, Epifani E, Micelli Ferrari L (2009) Eschericia coli keratitis treated with ultraviolet A/riboflavin corneal crosslinking: a case report. Eur J Ophthalmol 19:295-7

Morén H, Malmsjö M, Mortensen J, Ohrström A (2010) Riboflavin and ultraviolet A collagen crosslinking of the cornea for the treatment of keratitis. Cornea 2010; 29:102-4

Müller L, Thiel MA, Kipfer-Kauer Al, Kaufmann C (2012) Corneal crosslinking as a supplementary treatment option in melting keratitis: a case series. Klin Monatsbl Augenheilkd 2012; 229:411-415

Szentmáry N, Goebels S, Bischoff M, Seitz B (2012) Photodynamische Therapie bei infektiöser Keratitis. Ophthalmologe 2012; 109:165-70

Szentmáry N, Stachon T, Wang J, Eppig T, Langenbucher A, Seitz B (2012) Photodynamic inactivation (PDI) triggers expression of haemapoetic stem cell marker CD34 of keratocytes. ARVO Kongress, Fort Lauderdale, Florida, USA, 2012, Poster Nr. 1078/A114

von Felbert V, Hoffmann G, Hoff-Lesch S, Abuzahra F, Renn CN, Braathen LR, Merk HF (2010) Photodynamic therapy of multiple actinic keratoses: Reduced pain through use of visible light plus water-filtered infrared-A (wIRA) compared to light from light-emitting diodes. $\mathrm{Br}$ J Dermatol 2010; 163:607-15

Wang J, Stachon T, Eppig T, Langenbucher A, Seitz B and Szentmary N (2013) Impact of photodynamic inactivation (PDI) using the photosensitizer chlorin e6 on viability, apoptosis, and proliferation of human keratocytes in vitro. Graefes Arch Clin Exp Ophthalmol. 251 (12):2725-2731

Wollensak G, Spörl E, Reber F, Pillunat L, Funk R (2003) Corneal endothelial cytotoxicity of riboflavin/UVA treatment in vitro. Ophthalmic Res 2003; 35:324-8

Wollensak G, Spoerl E, Reber F, Seiler T (2004) Keratocyte cytotoxicity of riboflavin/UVA-treatment in vitro. Eye 18:718-22 